NUREG/CR-

ORNL/TM-2000/340

\title{
LAPUR5.2 Verification and User's Manual
}

Manuscript Completed: November 2000

Date Published:

Prepared by:

Alberto Escrivá," José March-Leuba

Oak Ridge National Laboratory

Managed by UT-Battelle, LLC

P.O. Box 2008

Knoxville, TN 37831-6004

* Polytechnic University of Valencia

46022 Valencia, Spain

T. L. Huang, NRC Project Manager

\section{Prepared for}

Reactor Systems Branch

Office of Nuclear Reactor Regulation

U.S. Nuclear Regulatory Commission

Washington DC 20555

NRC Job Code J2840 


\section{ABSTRACT}

This report documents a series of programming upgrades to increase the available number of thermal-hydraulic regions (i.e., channels) and other parameters in LAPUR. LAPUR, a computer program in FORTRAN, is a mathematical description of the core of a boiling water reactor. Its two linked modules, LAPURX and LAPURW, respectively solve the steady state governing equations for the coolant and fuel and the dynamic equations for the coolant, fuel, and neutron field in the frequency domain. General implementation descriptions are followed by a detailed description of input and output parameters of LAPURX and LAPURW. Sample inputs are included and stability benchmarks are noted. The original version of LAPUR was limited to seven channels; the current version, LAPUR 5.2, has been verified with up to 200 channels, each of which can have its own axial and radial power shape. Other significant parameter upgrade is the calculation of the transfer functions for up to 100 frequencies. All code dimensions are now parameterized and can be increased if necessary. 


DISCLAIMER
This report was prepared as an account of work sponsored by
an agency of the United States government. Neither the United
States Government nor any agency thereof, nor any of their
employees, makes any warranty, express or implied, or
assumes any legal liability or responsibility for the accuracy,
completeness, or usefulness of any information, apparatus,
product, or process disclosed, or represents that its use would
not infringe privately owned rights. Reference herein to any
specific commercial product, process, or service by trade name,
trademark, manufacturer, or otherwise, does not necessarily
constitute or imply its endorsement, recommendation, or
favoring by the United States Government or any agency
thereof. The views and opinions of authors expressed herein
do not necessarily state or reflect those of the United States
Government or any agency thereof.




\section{CONTENTS}

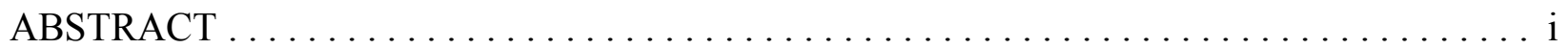

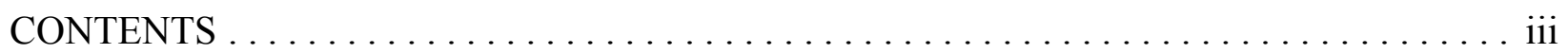

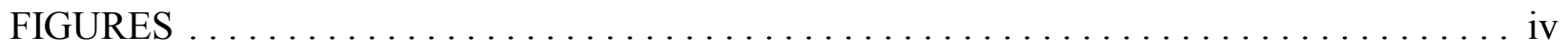

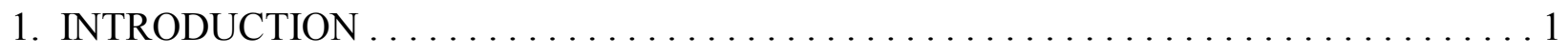

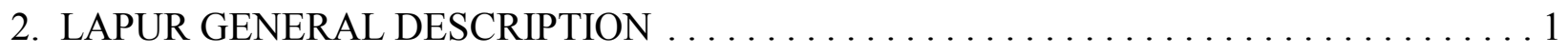

2.1 GENERAL DESCRIPTION OF THE INPUT AND OUTPUT $\ldots \ldots \ldots \ldots \ldots 2$

2.2 SUCCINCT DESCRIPTION OF THE PROGRAM $\ldots \ldots \ldots \ldots \ldots \ldots \ldots \ldots$

2.2.1 LAPURX, the Steady State Module $\ldots \ldots \ldots \ldots \ldots \ldots \ldots \ldots \ldots$

2.2.2 LAPURW, the Dynamics Module $\ldots \ldots \ldots \ldots \ldots \ldots \ldots \ldots \ldots \ldots$

2.2.3 Intermediate Storage Devices $\ldots \ldots \ldots \ldots \ldots \ldots \ldots \ldots \ldots \ldots$

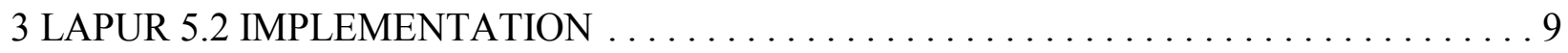

3.1 DIFFERENCES BETWEEN LAPUR 5.2 AND LAPUR $5.1 \ldots \ldots \ldots \ldots \ldots \ldots 9$

3.2 LAPUR 5.2 INPUT AND OUTPUT FILES $\ldots \ldots \ldots \ldots \ldots \ldots \ldots \ldots \ldots \ldots \ldots$

3.3 OPERATING SYSTEM REQUIREMENTS $\ldots \ldots \ldots \ldots \ldots \ldots \ldots \ldots \ldots \ldots$

3.4 INSTALLING AND EXECUTING LAPUR5 $\ldots \ldots \ldots \ldots \ldots \ldots \ldots \ldots \ldots 11$

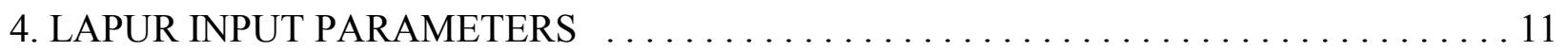

4.1 LAPUR Dimension Limits . . . . . . . . . . . . . . . . . . . . . . . . . . . 11

4.2 ALPHABETICAL DESCRIPTION OF THE SUBROUTINES OF LAPURX $\ldots 13$

4.2 PREPARATION OF INPUT FOR LAPURX $\ldots \ldots \ldots \ldots \ldots \ldots \ldots \ldots \ldots \ldots \ldots$

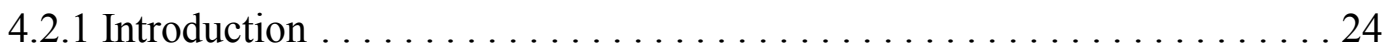

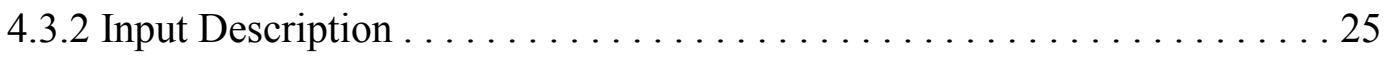

4.4 OUTPUT DESCRIPTION OF LAPURX .................... 34

4.5 ALPHABETICAL DESCRIPTION OF THE SUBROUTINES OF LAPURW . . . . 40

4.6 PREPARATION OF INPUT FOR LAPURW $\ldots \ldots \ldots \ldots \ldots \ldots \ldots \ldots \ldots \ldots$

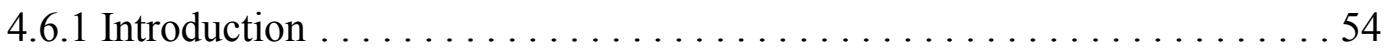

4.6.2 Input Description ............................. 55

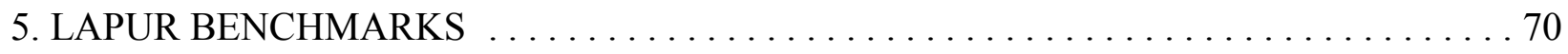

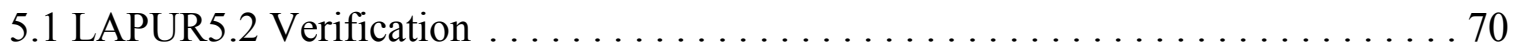

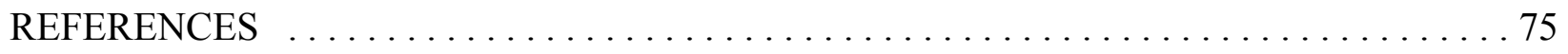

APPENDIX A SAMPLE LAPURX AND LAPURW INPUTS FOR A SINGLE-CHANNEL

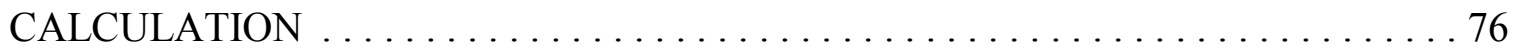


APPENDIX C SAMPLE LAPURX AND LAPURW INPUTS FOR A 200-CHANNEL

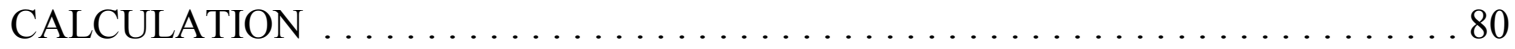

APPENDIX D SAMPLE CSV OUTPUT FILES FOR A 200-CHANNEL CALCULATION .91

APPENDIX E MISCELLANEOUS ERRORS FOUND IN VERSION $5.1 \ldots \ldots \ldots \ldots \ldots 102$

\section{FIGURES}

Figure 1. Closed loop transfer function calculated with 100 frequency point (solid line) shows results similar to those calculated with the old 25 point limit (circles) . . . . . . . 72

Figure 2. Channel powers and flows from 200-channel LAPUR 5.2 calculations at $30 \%, 50 \%$, and $70 \%$ core flow, respectively, show consistent results. . . . . . . . . . . 72

Figure 3. Closed-loop transfer function with a constant radial power profile shows consistent results for either 1 channel (circles) or 200 channels (solid line) . . . . . . . . . . . 73

Figure 4. Closed-loop transfer function calculated with different number of channels shows good convergence and demonstrates good behavior of the 200-channel case with a radial power profile. 


\section{INTRODUCTION}

This report documents a series of programming upgrades to increase the available number of thermalhydraulic regions (i.e., channels) and other parameters in the LAPUR code. This report also contains an updated User Manual for the new code version, LAPUR 5.2.

LAPUR, a computer program in FORTRAN, is a mathematical description of the core of a boiling water reactor. Its two linked modules, LAPURX and LAPURW, respectively solve the steady state governing equations for the coolant and fuel and the dynamic equations for the coolant, fuel, and neutron field in the frequency domain. General implementation descriptions are followed by a detailed description of input and output parameters of LAPURX and LAPURW. Sample inputs and outputs are included and stability benchmarks are noted.

The original version of LAPUR was limited to seven channels; the current version, LAPUR 5.2, has been verified with up to 200 channels, each of which can have its own axial power shape. Other significant parameter upgrade is the calculation of the transfer functions for up to 100 frequencies. The motivation behind this upgrade is to facilitate the input preparation by eliminating the need for region collapsing. In addition, this upgrade makes possible detailed modeling of mixed-fuel cores with more than two fuel types.

It must be noted that the LAPUR 5.2 upgrade has not affected the functionality of LAPUR. The same correlations and modeling assumptions are maintained, so this upgrade does not invalidate previous LAPUR benchmarks. The only verification effort has been to guarantee that the solutions with the new parameter limits reproduce the old results, so that the new LAPUR version is computationally equivalent to the old version.

\section{LAPUR GENERAL DESCRIPTION}

The computer program LAPUR, a version coded in the FORTRAN language of the mathematical description of a boiling water reactor (BWR), is presented in this section. This program consists of two autonomous modules, LAPURX and LAPURW, which are linked by means of an intermediate storing device.

The first module, LAPURX, solves the coolant and the fuel steady state governing equations as described in Sect. 3.2.1 of Reference 1. Maps of core steady state parameters are generated by LAPURX and stored into two data files for subsequent use by the dynamics module LAPURW.

The second module, LAPURW, solves the dynamic equations for the coolant, fuel, and neutron field in the frequency domain according to the formulations developed in Sect. 3 of Reference 1.

\subsection{GENERAL DESCRIPTION OF THE INPUT AND OUTPUT}


General input requirements to run a problem are as outlined:

For steady state calculation (LAPURX), system operating status:

1. State parameters: reactor pressure, thermal power generated, core flow rate, and coolant temperature at the inlet plenum.

2. Power map: Vertical power shape of representative channels and either steam exit quality or amount of power generated in each channel.

3. Fraction of power deposited into the coolant by neutron moderation and $\gamma$-ray absorption.

For steady state calculation (LAPURX), system design parameters:

1. Mechanical: channel box and fuel pin dimensions.

2. Physical: hydraulic diameters, friction multipliers, orifice flow coefficients, fuel and clad densities, and gap thermal conductance.

For steady state calculation (LAPURX), user options:

1. Error criteria for the iterative calculations.

2. Adjustable parameters for two-phase correlations.

3. Number of nodes desired in the boiling part of a channel.

4. Output options.

For dynamic calculation (LAPURW), systems parameters:

1. Recirculation loop pressure to flow rate gain and time constant.

For dynamic calculation (LAPURW), neutronic parameters:

1. Effective neutron lifetime table.

2. Steady state core reactivity table.

3. Delayed neutron fractions and their time constants.

4. Doppler reactivity coefficient. 
5. Table of density reactivity coefficients.

For dynamic calculation (LAPURW), output options:

1. Frequencies of interest for the dynamic analysis.

2. Edit and plotting options.

3. Stability calculation options.

Note that each subcore must be assigned a set of neutronic parameters.

Steady state calculation LAPURX generates a map of the thermohydraulic parameters in the core, that is, of the following:

1. Channel flow-rate, pressure drops, and exit quality (or power) for each channel.

2. Nodal coolant density, void fraction, enthalpy, quality, velocities, and friction components at each node along each channel.

3. Set of coefficients for the dynamics calculation.

The dynamic calculation determines:

1. For the fuel, the response of the heat flux to the coolant and of the average temperature to driving perturbations of power generation, coolant temperature, and coolant flow rate at each node in every channel.

2. For the coolant flow in a channel box:

- The response of the coolant parameters at every node to driving perturbations of power generation at each subcore level, coolant flow rate, and coolant inlet temperature.

- The open-loop transfer function (T.F.) for the channel hydrodynamics, its natural frequency, and decay ratio.

- The reactivity feedback induced in each node by the driving perturbations. (This is accomplished by properly weighting the coolant density and fuel temperature perturbations with reactivity coefficients.)

3. For each nuclear subcore: 
- $\quad$ Feedback reactivity transfer functions for driving perturbations in power at each subcore, inlet temperature, and core flow rate.

- $\quad$ Open-loop transfer function matrix; total core natural frequency and decay ratio.

- $\quad$ Closed-loop transfer function matrix of reactivity to power.

4. Nyquist and magnitude-phase plots for all open-loop transfer functions; Bode plots for closed-loop transfer functions.

\subsection{SUCCINCT DESCRIPTION OF THE PROGRAM}

\subsubsection{LAPURX, the Steady State Module}

This module follows the procedure described in Sect 3.2.1 of Reference 1. Table 1 shows a structural description of the LAPURX subroutine-calling sequence. Descriptions of the subroutines, input, and output of this program module are presented in Sects. 4.1, 4.2, and 4.3 of this report.

\subsubsection{LAPURW, the Dynamics Module}

This program is the coded version of the dynamic equations in the frequency domain of Sect. 3 of ref. 1 and its corresponding appendices.

A structural listing of the subroutine-calling sequence is shown in Table 2. Descriptions of the subroutine, input, and output are presented in Sects. 4.4, 4.5, and 4.6 of this report. 


\section{Table 1. LAPURX structural listing}

MAIN:INPUT: $\quad$ INP1

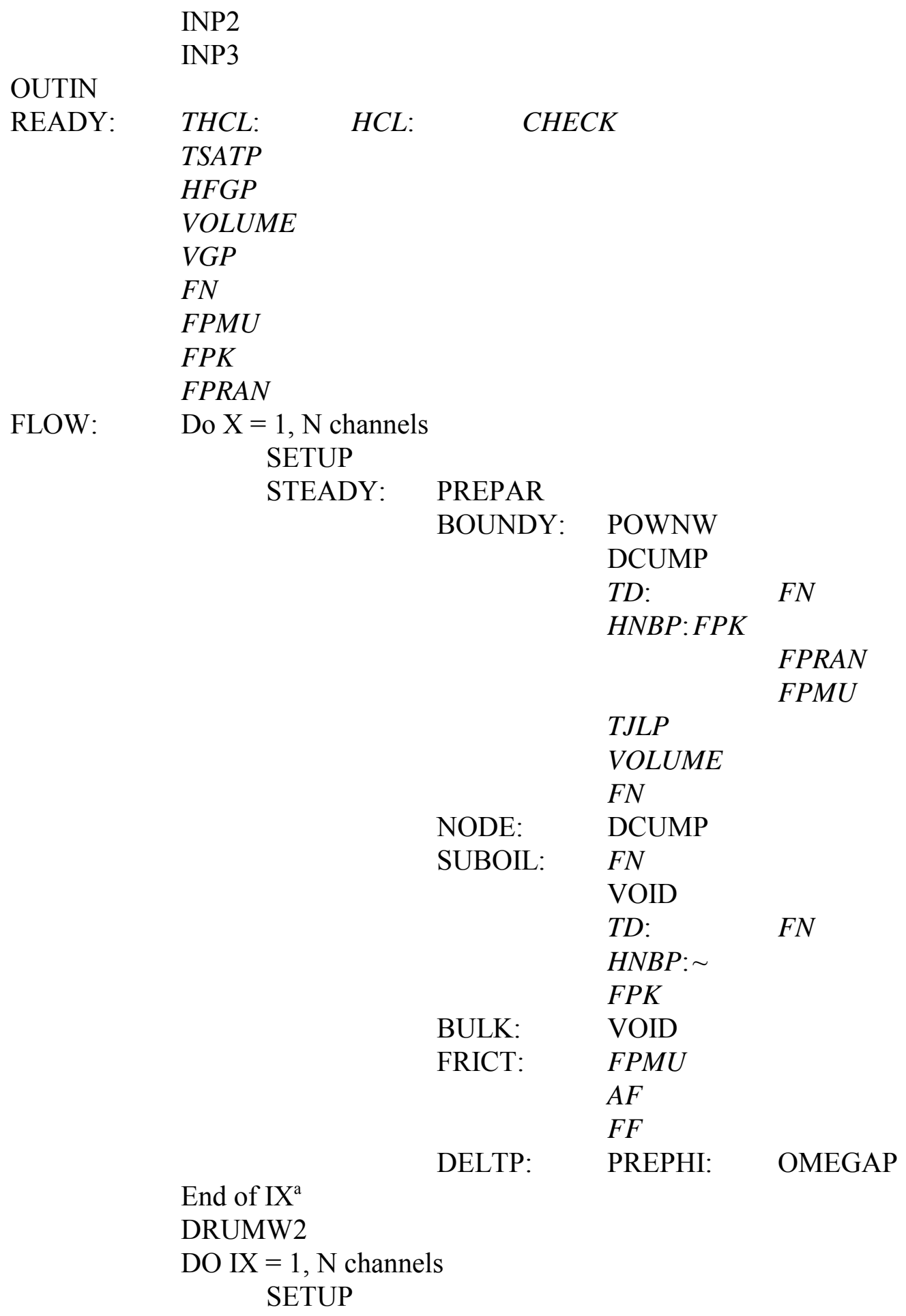




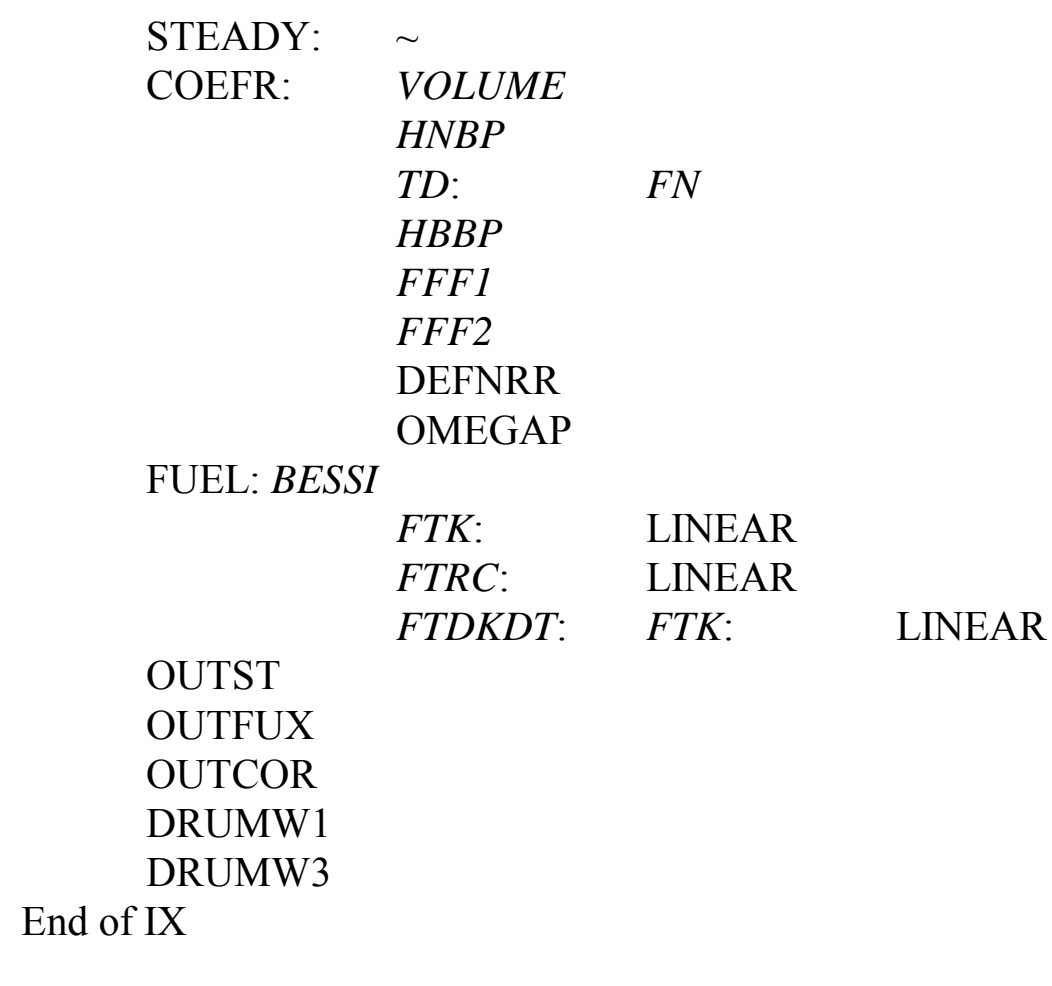

END

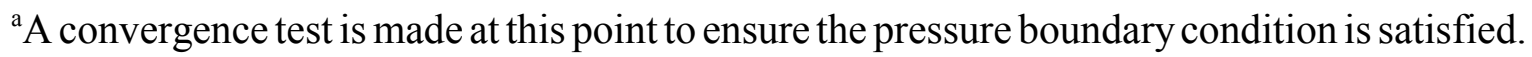
To avoid repetition, the symbol $\sim$ substitutes a subroutine structure already described in the table. 
Table 2. LAPURW structural listing

MAIN:INPUTW: $\quad$ INPW1

INPW2

INPW3

INPW4

INPW5

INPW6

INXS2G

INCROD

OUTINW

DRUMR2

TRANS: $\quad$ WEIGHT: $\quad$ Do IX $=1, \mathrm{~N}$ channels

DRUMR1

NODOS

COUPXS: COND

End of IX

Do IW=1, $\mathrm{N}$ frequencies

Do IX $=1, \mathrm{~N}$ channels

DRUMR1

NODOS

NODREA

REACFA: $\quad C O E F$

JOSELE: COND

DIF: COND

FUEL: BESSI

FTK: $\quad$ LINEAR

FTRC: $\quad$ LINEAR

FTDKDT: FTK:

LINEAR

OUTFUX

DRUMW3

DRUMR3

FUELW

COEFIW

FREQ

End of IX

RECIRC

ONECOR

End of IW

RESPON: OUTFUW: PRINTA: ANGLE

ANGLE

WDSKPR: PRINTA

WDSKGH 


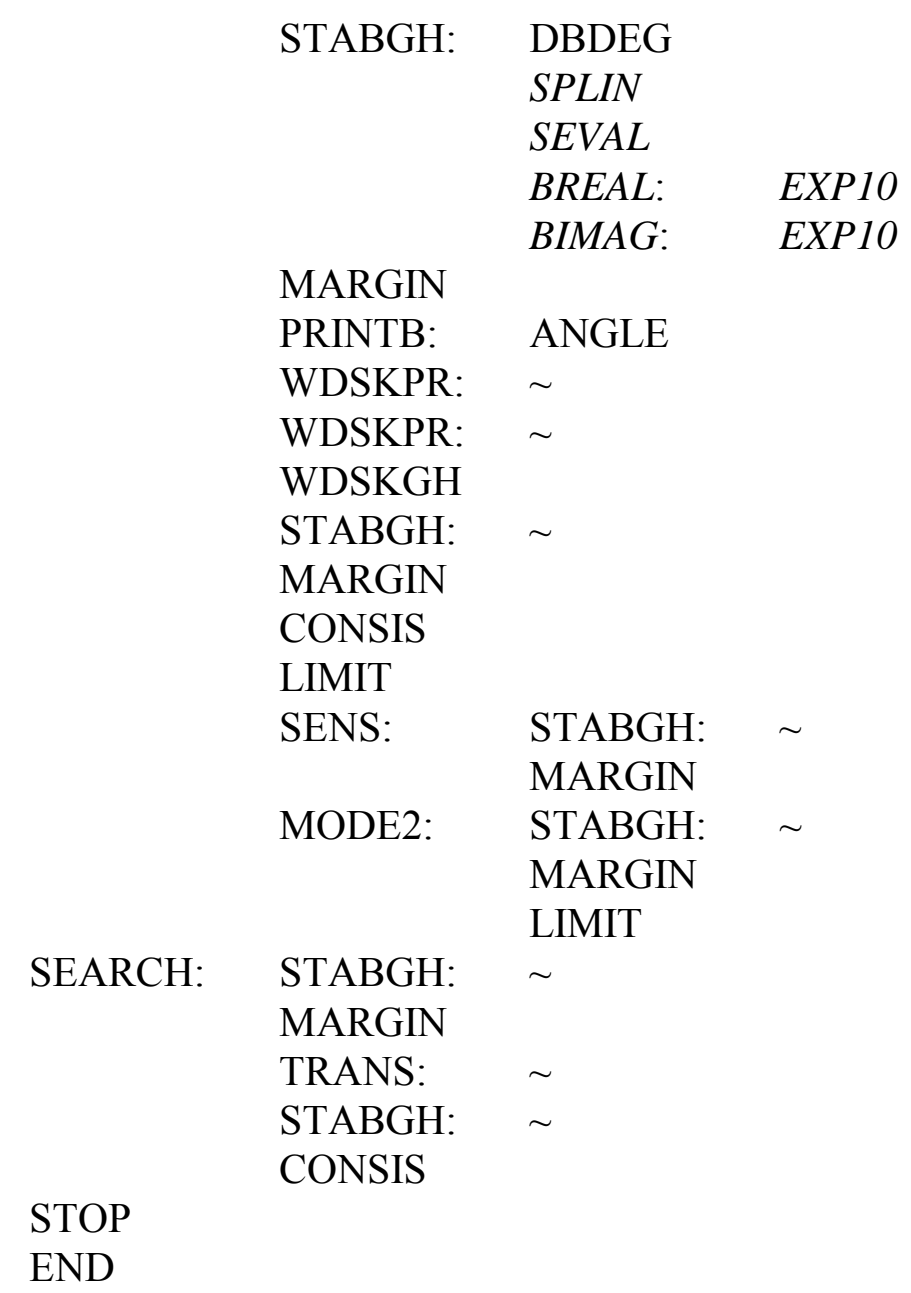

Note: To avoid repetition, the symbol $\sim$ substitutes a subroutine structure already described in the table.

\subsubsection{Intermediate Storage Devices}

Intermediate storage of data is used for two different purposes: (1) to provide a link between the steady state and the dynamics calculation, and (2) to allow the orderly printing of the output T.F.s as a function of frequency while avoiding the need for excessive computer core memory space.

For the first purpose, the storage device can be tape, disk, or drum. The files are addressed as logical units 1 and 2. Their input/output operations are unformatted and sequential.

For the second purpose, a direct access on-line disk or drum is required. Three files are created and assigned to logical units 10,11, and 12. Data are transferred to and from the on-line device unformatted in 8-byte segments per direct access operation. 


\section{LAPUR 5.2 IMPLEMENTATION}

\subsection{DIFFERENCES BETWEEN LAPUR 5.2 AND LAPUR 5.1}

LAPUR 5.2 is the current implementation of the LAPUR model described in Reference 1 . The major improvements with respect to LAPUR 5.1 are:

1. The maximum number of thermal-hydraulic regions has been parameterized. The default value has a maximum number of 200 channels. Note: LAPUR calculations with up to 200 channels have been verified against results from the old LAPUR 5.1 with no significant loss of precision. Calculations with more than 200 channels are typically not necessary due to symmetry considerations, but are possible; however, those calculations have not been verified here.

2. The maximum number of axial power shapes has been parameterized so that each thermalhydraulic region can have its own axial and radial power shape. In the default compilation, the maximum number of axial power shape regions is 200 .

3. The maximum number of bundle and fuel rod types has been parameterized. In the default compilation, the maximum number of bundle types is 10 . This allows to model mixed cores with up to 10 different fuel types.

4. The maximum number of frequencies has been parameterized. The default value is 100 frequencies. This upgrade allows for better definition of the transfer functions and a more robust evaluation of the decay ratio. In the old version, it was often required to perform two LAPURW calculations, one to identify the frequency of oscillation using a coarse frequency mesh, and a second calculation with a fine mesh around the oscillation frequency. With 100 frequencies, a single calculation works for most cases.

5. All relevant dimensions of internal LAPUR variables have been parameterized, so they can be modified in the future. File PARAM.FI contains the definitions for all these parameters. Note: these parameters have been left at their original values, and value changes have not been tested thoroughly; it is the responsibility of the user to verify that any future changes to these parameters don't result in significant loss of precision.

6. A well known behavior of LAPUR was that it would report very-high channel decay ratios if the channel was very stable. This had to be compensated by hand by the user by checking the phase and gain margins. This behavior has been corrected by improving the decay-ratio estimation algorithm. The problem was related to an internal "spline fit" that LAPUR performs on the calculated transfer functions. For a very stable channel, the phase may cross the zero-degree level; since LAPUR maintains the phases negative, the phase jumps from -5 deg to -355 deg. The spline fit under those conditions cannot reproduce the discontinuity accurately and as a result a very-high decay ratio is reported. This behavior has been 
corrected in LAPUR5.2, which should calculate and report accurately low-channel-decay-ratio conditions.

7. The calculation of the Average Saturated Boiling Boundary has been added at the end of the LAPURX execution. This calculation is performed for output purposes only and does not affect the LAPURW input files; thus it does not affect the calculated decay ratios.

8. Two new output files are generated by LAPUR. These files have an ASCII "Comma Separated Value" format and contain a summary the most relevant output information. The file names are LAPURX.CSV and LAPURW.CSV and can be opened with most spreadsheet programs for further manipulation of the LAPUR output data. LAPURX.CSV contains the relative power and flow, the pressure drop, exit quality, an the saturated boiling boundary of each channel. LAPURW.CSV contains the decay ratio and frequency for each channel and for the core, as well as the open-loop and closed-loop transfer functions as function of frequency.

9. Miscellaneous programming errors have been corrected. During the detailed code review the authors found and corrected three programming errors. These errors were evaluated and did not affect the LAPUR results with fixed dimensions, but they resulted in loss of precision when more than the original seven channels were used. The errors were corrected and are documented in Appendix E.

10. The screen-input routines have been removed. Batch is the only available mode for LAPUR 5.2. The executable files have been renamed LAPURX.EXE and LAPURW.EXE.

\subsection{LAPUR 5.2 INPUT AND OUTPUT FILES}

The current implementation of LAPUR 5.2 expects the input data described in Sect. 4 of this report in two files named LAPURX.DAT and LAPURW.DAT. It generates the main (verbose) output to two files named LAPURX.OUT and LAPURW.OUT. A summary of the most relevant information is generated in ASCII Comma Separeted Values (CSV) format in files LAPURX.CSV and LAPURW.CSV. LAPUR 5.2 also generates intermediate storage files that can be deleted after successful completion of a run. These files are named LAPUR.D1, LAPUR.D2, LAPUR.D3, LAPURW.T1, and LAPURW.T2.

\subsection{OPERATING SYSTEM REQUIREMENTS}

LAPUR5 does not require any special operating system. The current version is compiled as a Windows Console Application using Microsoft FORTRAN PowerStation.

\subsection{INSTALLING AND EXECUTING LAPUR5}


LAPUR5 is composed of two executable files: LAPURX.EXE, and LAPURW.EXE. LAPURX performs steady state and initialization calculations. LAPURW computes the frequency domain or dynamic part of the calculations.

To install LAPUR 5.2, simply copy the executable files to any directory.

To run LAPUR 5.2, follow these steps:

1. Generate input files for the steady state (LAPURX) and dynamic (LAPURW) modules.

2. Rename these input files to LAPURX.DAT and LAPURW.DAT.

3. Execute LAPURX.EXE

4. Execute LAPURW.EXE

5. Rename the output files LAPURX.OUT, LAPURX.CSV, LAPURW.OUT, and LAPURW.CSV so that future runs will not overwrite them.

\section{LAPUR INPUT PARAMETERS}

\subsection{LAPUR Dimension Limits}

All arrays in LAPUR 5.2 are dimensioned using parameters instead of hard constants. These parameters are defined in file PARAM.FI, which is included in both LAPURX and LAPURW during the compilation step. These parameters are summarized in Table 3, and they can be changed and the program recompiled to generate a version with larger dimension limits; however, any changes would have to be verified to guarantee that programming errors do not affect the results. 
Table 3. Dimension Limits for LAPUR Arrays

\begin{tabular}{|c|c|c|}
\hline PARAMETER (NPSMAX =200) & ! Max \# of power shapes & $(>=6)$ \\
\hline PARAMETER $($ NPSNMAX $=50)$ & ! Max \# of nodes of power shapes & $(50)$ \\
\hline PARAMETER $($ NCHMAX $=200)$ & ! Max \# of TH channels & $(>=7)$ \\
\hline PARAMETER $($ NFBMAX = 10) & ! Max \# of channel types & $(>=5)$ \\
\hline PARAMETER (NFRMAX = 10) & ! Max \# of fuel rod types & $(>=5)$ \\
\hline PARAMETER (NFMMAX = 10) & ! Max \# of friction multipliers & $(>=10)$ \\
\hline PARAMETER $($ NFMNMAX $=90)$ & ! Max \# of axial intervals fri-mul & $(90)$ \\
\hline PARAMETER $($ NCIMAX $=10)$ & ! Max \# of channel inlet types & $(>=10)$ \\
\hline PARAMETER $($ NCINMAX $=10)$ & ! Max \# of pipes in series chan-in & $(10)$ \\
\hline PARAMETER (NCEMAX = 10) & ! Max \# of channel exit types & $(>=10)$ \\
\hline PARAMETER $($ NCENMAX $=10)$ & ! Max \# of pipes in series chan-ex & $(10)$ \\
\hline PARAMETER (NAPMAX = 10) & ! Max \# of axial points edit rod & $(>=10)$ \\
\hline PARAMETER $($ NOBMAX = 90) & ! Max \# of axial nodes boiling & $(>=90)$ \\
\hline PARAMETER (NOTMAX =140) & ! Max \# of axial nodes total & $(>=140)$ \\
\hline PARAMETER (NNBMAX = 50) & ! Max \# of axial nodes nonboiling & $(>=50)$ \\
\hline PARAMETER (NNJMAX = 1) & ! Max \# of horizontal subcores & $(>=1)$ \\
\hline PARAMETER (NNKMAX = 1) & ! Max \# of vertical subcores & $(>=1)$ \\
\hline PARAMETER $($ NNDMAX $=40)$ & ! Max \# of sets of delay-n characterist & st $\quad(=1)$ \\
\hline PARAMETER (NROMAX = 40) & ! Max \# of initial reactivities & $(=1)$ \\
\hline PARAMETER (NNLMAX = 40) & ! Max \# of neutron lifetime in subcore & $(=1)$ \\
\hline PARAMETER (NNCMAX =200) & ! Max \# of neutron coupling coefficie & $(=1)$ \\
\hline PARAMETER (NDGMAX = 6) & ! Max \# of delayed $n$ energy groups & $(>=6)$ \\
\hline PARAMETER (NBTMAX = 3) & ! Max \# of fuel bundle types (4f-b\&1r & r) $\quad(>=3)$ \\
\hline PARAMETER (NFTMAX = 8) & ! Max \# of different fuel types & $(>=8)$ \\
\hline PARAMETER $(\mathrm{NXSEC}=7)$ & ! \# of Xsect D1,D2,Sa1(inc scatt),Sa2 & 2,Sf1,Sf2,S1-2 (= 7) \\
\hline PARAMETER (NECMAX = 3) & ! Max \# of order power expansion coe & $\operatorname{eff}(>=3)$ \\
\hline PARAMETER (NAFMAX =6) & ! Max \# of axial fuel intervales & $(>=6)$ \\
\hline PARAMETER $($ NACMAX $=11)$ & ! Max \# of axial control bundles inter. & r. $\quad(>=11)$ \\
\hline PARAMETER (NDRMAX =7) & ! Max \# of tables of dens. react. coeff & fs (ID 18) $(>=7)$ \\
\hline PARAMETER $($ NDRNMAX $=10)$ & ! Max \# of values table react. coeffs & $(>=10)$ \\
\hline PARAMETER (NFPMAX = 100) & ! Max \# of frequency points & $(>=25)$ \\
\hline PARAMETER (NSRMAX = 20) & ! Max \# of subcritical reactivity o-pha & a $\quad(>=20)$ \\
\hline PARAMETER (NFUMAX = 10) & ! Max \# of fuel radial nodes & $(>10)$ \\
\hline
\end{tabular}




\subsection{ALPHABETICAL DESCRIPTION OF THE SUBROUTINES OF LAPURX}

Notes on the format used in these descriptions:

(i) "Input" indicates the means by which the subroutine receives the parameters on which it operates. The parameters may come from an outside source defined by a logical unit, from the calling program through shared COMMON areas, or as arguments.

(ii) "Output" indicates the means by which the parameters calculated or modified by the subroutine are disposed of. These can be transferred to the calling subroutine, a COMMON area, or an outside device.

\section{Subroutine BOUNDY}

Called from: STEADY.

Input: $\quad$ (i) Argument: IX $\equiv$ channel type.

(ii) COMMONS: DATA, INPT, REDY, REDY2, SETP, SETP2, PRPR, PRPR2.

Performs: (i) If $\operatorname{IOP}(3) \neq \dot{2}$, where the dot indicates "multiple," the position of the boiling boundary $Z_{n b}$ is read as input; hence, the enthalpy and temperature at the boiling boundary are calculated accordingly.

(ii) If IOP(3) $=\dot{2}$, the Jens-Lottes correlation [Eq. (3.2.4)]* is used to determine the temperature of inception of subcooled boiling. Subsequently, the boiling boundary position and physical parameters for the nonboiling part of the flow in the channel are calculated.

Output: $\quad$ COMMONS: TBOUND, BNDY.

(*Citations of equations, appendices, and paragraphs throughout Sect. 3 refer to Reference 1 unless otherwise specified.)

Subroutine BULK

Called from: STEADY.

Input: (i) Argument: IX.

(ii) COMMONS: TVOID, INPT, REDY, BNDY, NOHD, BOIL, BOIL2, BALK.

Performs: Calculation of the distributions of liquid and steam mass flow rates, void fraction, steam quality, and other parameters of interest at each node along the bulk boiling region. It also determines the position at which boiling would begin if subcooled boiling did not occur and the fraction of channel power deposited in its nonboiling length.

Output: $\quad$ COMMONS: BOIL, BOIL2, BALK.

\section{Subroutine COEFR}

Called from: FLOW.

Input: $\quad$ (i) Argument: IX. 
(ii) COMMONS: DATA, INPT, REDY2, REDY, SETP2, SETP, PRPR2, BNDY, NOHD, NOHD2, BOIL, BOIL2, FRCT2, FRCT, PRP12, OMGP2, OMGP.

(iii) Output of the subroutine: OMEGAP.

Performs: $\quad$ Calculation of those coefficients in the set of dynamic equations in App. B10 and B11, which are frequency independent. Since some of the D coefficients of the subcooled boiling region in App. B10 are frequency dependent, a set of coefficients B, which contain their frequency-independent part, is generated here.

Output: $\quad$ COMMONS: TCOEFR, CEFR, CEFR2, CEFR3.

\section{Subroutine DCUMP}

Called from: BOUNDY, NODE

Input: $\quad$ Arguments I, ZM

Performs:

Output: $\quad$ DELPC

\section{Subroutine DEFNRR}

Called from: COEFR.

Input: $\quad$ Arguments: NR, DZ, DZR.

Performs: It defines the integration mesh for the coolant equations in the nonheated boiling sections of the channel. This is a provision to account for the possibility of having a series of different pipes connected at the exit of the heated channel. The length of the mesh is taken as DZ, the mesh length in the heated boiling section. The length of a nonheated section is stored in DZR(I), and the maximum number of nodes allowed in any of these sections is NR $\leq 10$, that is, the value $\mathrm{NRR}(\mathrm{I}) \leq 10$ where $\mathrm{I}$ is the nonheated section index.

Output: $\quad$ Argument: NRR $\equiv$ number of nodes in the nonheated boiling section under consideration.

\section{Subroutine DELTP}

Called from: STEADY.

Input: $\quad$ COMMONS: DATA, INPT, REDY, SETP, SETP2, PRPR2, BNDY, NOHD, NOHD2, BOIL, BOIL2, FRCT, PRP12, OMGP, OMEGP2.

Performs: Calculation of the flow pressure losses at the inlet and outlet orifices and at every node along the length of the channel. It uses the subroutine PREPHI for those nodes in boiling sections of the channel.

Output: $\quad$ COMMON: DELTP.

\section{Subroutine DRUMW1}

Called from: FLOW.

Activated by: $\operatorname{IOP}(1)<2$.

Input: $\quad$ (i) Argument: IX.

(ii) COMMONS: SETP2, SETP, PRPR2, PRPR, BNDY, NOHD, NOHD2, BOIL, BOIL2, BALK, FRCT2, FRCT, DLTP, PRPI2, PRPI, OMGP2, OMGP, CEFR, 


\section{CEFR3, CEFR2, REACOE.}

Performs: $\quad$ Saving out-of-core the steady state thermohydraulic parameters of the coolant for each node along the length of channel IX. The map thus created will be used to define the initial conditions for subsequent dynamics calculations.

Output: Logical unit 1: Sequential unformatted writing of the content of the COMMON statements listed above.

\section{Subroutine DRUMW2}

Called from: FLOW.

Activated by: $\operatorname{IOP}(1)<2$.

Input: $\quad$ COMMONS: IIOP1, DATA, INPT, INPT2, REDY2, REDY, ADD1.

Performs: $\quad$ Saving out-of-core of the input data and the system parameters determined by the subroutine READY.

Output: $\quad$ Logical unit 2: Sequential writing of the content of the COMMON statements listed above.

\section{Subroutine DRUMW3}

Called from: FLOW.

Activated by: $\operatorname{IOP}(1)<2$.

Input: $\quad$ (i) Argument: IX.

(ii) COMMONS: ADIN, FUL, FULIX.

Performs: $\quad$ Saving out-of-core of the thermal parameters of the fuel rods within a channel for subsequent use in the dynamics calculations.

Output: $\quad$ Logical unit 1: Sequential unformatted writing of the COMMON statements listed above.

\section{Subroutine FLOW}

\section{Called from: MAIN.}

Input: $\quad$ (i) Argument: NPAGE.

(ii) COMMONS: DATA, INPT, REDY, REDY2, IIOP1, PREBC, ADD1.

Performs: (i) Determination of the flow rate distribution among the fuel channels subject to uniform inlet and outlet pressure boundary conditions. To this effect an iterative procedure is followed. First, the thermohydraulic conservation equations are solved along the length of a channel by means of the subroutines SETUP(IX) and STEADY(IX). The mass flow rate, exit steam quality, and total pressure drop along the channel are retained prior to repeating the process with another channel. Once the pressure drops for all channels are known, they are compared to see if they are equal. If they are not equal, a new flow rate is estimated for each channel and a new iteration is started.

The results of the first iteration are used to determine the partial derivative of the total pressure drop with respect to the mass flow rate for each of the channels. These partial derivatives are used to determine the tentative pressure drop to which all the channels 
will converge and the corresponding flow rates. After the second iteration, a parabolic interpolation scheme is used to estimate the new flow rates, using the results of the two previous iterations. The maximum number of iterations provided for is 20 .

(ii) Generation of the parameters needed as initial conditions for the subsequent dynamic calculations. To this effect, once that pressure drop convergence has been achieved, the subroutines SETUP(IX) and STEADY(IX) are called again to repeat the calculations of the last iteration. The subroutines COEFR(IX) and FUEL(IX) are called this time. Prior to starting with another channel, all parameters generated for the channel are transferred to a disk by means of the subroutines DRUMW1(IX) and DRUMW3(IX) and printed, if desired, by calling the subroutines OUTST(IX), OUTCOR (IX) and OUTFUX(IX).

Output: $\quad$ (i) COMMON: TFLOW.

(ii) Logical unit 1: The output of the subroutines DRUMW1(IX), DRUMW3(IX).

(iii) Logical unit 2: The output of the subroutine DRUMW2.

(iv) Logical unit 6: Under the heading: ***FLOW***, the flow characteristics of each channel type and the tentative pressure drop for the next iteration at every iteration step.

\section{Subroutine FRICT}

Called from: STEADY.

Input: $\quad$ COMMONS: INPT, REDY, SETP, SETP2, PRPR, BNDY.

Performs: Calculation of the Reynolds number for each of the flow regions and the corresponding Moody friction factor $\mathrm{f}$ and coefficient $\mathrm{a}_{2}$. It uses the function subroutines FF, AF, and FPMU.

Output: $\quad$ COMMONS: FRCT, FRCT2.

\section{Subroutine FUEL}

Called from: FLOW.

Input: $\quad$ (i) Argument: IX.

(ii) COMMONS: DATA, INPT, SETP, SETP2, PRPR, BNDY, NOHD, CEFR, CEFR3, ADIN, ADD1, IIOP1.

Performs: $\quad$ (i) Calculation of the temperature distribution across the fuel element at every node as described in the fuel steady state calculation (paragraph 3.2.2.1).

(ii) Calculation of the parameters $\alpha, \beta$, and $\gamma$ for the dynamics analysis as described in Eq. (3.2.42).

(iii) Saving into common FEL1 the characteristics of up to 10 vertical nodes as specified by NFPRT at input time.

Output: $\quad$ (i) COMMONS: TFUEL1, FUL, FEL1, FULIX.

(ii) Logical unit 6: Error message 3.

\section{Subroutine INPUT}

Called from: MAIN.

Input: $\quad$ Logical unit 5. 
Performs: $\quad$ (i) Reading of the data which specify the steady state thermohydraulic calculations to be performed. The subroutines INP1, INP2, and INP3 are used to input some of the arrays.

(ii) Consistency check of some of the input data.

Output: $\quad$ (i) COMMONS: INPT, INPT2, DATA, REDY, REDY2, ADD1, ADIN, JJJ, PREBC, TINPUT, ICH, COFC.

(ii) Logical unit 6: Error message 1.

\section{Subroutine INPI}

Called from: INPUT

Input: $\quad \mathrm{NO}, \mathrm{NNN}$

Performs: $\quad$ Reads an array of integers of length NO in the standard format 8I10 for the first line

Output: $\quad$ NNN

\section{Subroutine INP2}

Called from: INPUT

Input: $\quad$ NO, NNN, AAA, ID

Performs: $\quad$ Reads a two-dimesional array of floating point variables in the standard format

Output: $\quad$ AAA(ID, *)

\section{Subroutine INP3}

Called from: INPUT

Input: $\quad$ NO, AAA

Performs: $\quad$ Reads an array of floating point variables in the standard format I10,7E10.5 for the first line and 10X,7E10.5 for the continuation lines

Output: $\quad$ AAA $(*)$

\section{Subroutine LINEAR}

Called from: FTK, FTRC, TSATP, VGP, HFGP.

Input: $\quad$ Arguments: X, XF, YF.

Performs: Linear interpolation within the table XF, YF to determine the value of $\mathrm{Y}$ that corresponds to that of $\mathrm{X}$.

Output: $\quad$ Argument: Y.

\section{Subroutine NODE}

Called from: STEADY.

Activated by: BOUNGO $\neq 0$.

Input: $\quad$ (i) Argument: IX.

(ii) COMMONS: DATA, INPT, REDY, SETP, PLRPR, PRPR2, BNDY,

Performs: $\quad$ (i) Definition of a new mesh along the channel so that there are $\mathrm{N}$ nodes in the boiling length of the channel.

(ii) Transformation of the nodal parameters to the new coordinate system. The 
parameters affected by the transformation are: nodal boundary ordinates $\mathrm{ZCOM}(\mathrm{J})$, normalized cumulative power generation $\operatorname{CCOM}(\mathrm{J})$, homogenized enthalpy $\mathrm{HAV}(\mathrm{J})$, mixed steam quality XMIX(J), and friction multipliers $\operatorname{EKFL(J).~}$

Output. (i) COMMONS: NOHD, NOHD2.

(ii) Logical unit 6: Error message 4.

Subroutine OMEGAP

Called from: COEFR and PREPHI.

Input: $\quad$ Arguments: J, GP, H, INO.

COMMONS: DATA, INPT, REDY, SETP, PRPR2, BOIL2.

Performs: $\quad$ Calculation of the Jones flow correction factor $\Omega$ for the Martinelli-Nelson two-phase friction multiplier and its derivatives. $\mathrm{J}$ is the node index number, GP is the mass flow rate in $\mathrm{g} / \mathrm{s}, \mathrm{H}$ is the relative subcooling of the liquid phase, and INO is a flag to indicate whether node $\mathrm{J}$ is in a heated section or not.

Output: $\quad$ COMMONS: OMGP, OMGP2.

\section{Subroutine OUTCOR}

Called from: FLOW

Input: $\quad$ IX, NPAGE

Performs: $\quad$ Outputs the steady state core conditions to the OUT file.

Output

\section{Subroutine OUTFUX}

Called from: FLOW.

Input: $\quad$ (i) Arguments: IX, NPAGE, NFU.

(ii) COMMONS: DATA, ADDIN, FEL1.

Performs: $\quad$ Listing of the steady state thermal parameters of the fuel in each channel at selected vertical nodes for all the radial nodes in the fuel.

Output: $\quad$ (i) Argument: NPAGE.

(ii) Logical unit 6: Under the heading $* * * \operatorname{FUEL}(\mathrm{IX}=)^{* * *}$ the calculated fuel parameters are printed for each of the selected NFN0 vertical nodes and the 10 radial nodes.

\section{Subroutine OUTIN}

Called from: MAIN.

Activated by: INPUGO $>1$.

Input: $\quad$ COMMONS; DATA, INPT, INPT2, REDY, ADD1, ADIN, PREBC, COFC, JJJ.

Performs: $\quad$ Printout of the input data.

Output: Logical unit 6: Check print of the data read by the subroutine INPUT.

\section{Subroutine OUTST}

Called from: FLOW.

Activated by: $\operatorname{IOP}(4) \neq 0$.

Input: $\quad$ (i) Arguments: IX, MMMM, NPAGE. 
(ii) COMMONS: DATA, INPT, REDY, SETP, SETP2, PRPR, PRPR2, BNDY, NOHD, NOHD2, BOIL, BOIL2, BALK, FRCT, FRCT2, DELTP, OMGP, OMEGP2.

Performs: (i) The calculation of the partial derivatives: $\partial \beta / \partial \mathrm{Z}$ and $\partial \beta / \partial \mathrm{X}$ for each node for printing purposes only.

(ii) Printing of the thermohydraulic nodal parameters as determined by the subroutines READY and STEADY for each of the channels.

Output: $\quad$ (i) Arguments: NPAGE.

(ii) Logical unit 6: Under the heading: **STEADY***ITERATION MMMM: tables of the thermohydraulic parameters for each node and channel.

\section{Subroutine POWNW}

Called from: BOUNDY

Input: none

Performs:

Output $\quad$ ZF, F (in common /POWNW1/)

\section{Subroutine PREPAR}

Called from: STEADY.

Input: $\quad$ (i) Argument: IX.

(ii) COMMONS: DATA, REDY, STEP, SETP2.

Performs: $\quad$ (i) For a total of NP +1 nodes, the calculation of the normalized cumulative power distribution CIN(I) at the nodal boundaries along the channel IX. The nodal mesh Z(I) is the one defined when reading in the power distribution in subroutine INPUT. The entrance to the first node is represented by the index $\mathrm{I}=1$.

(ii) Calculation of the inlet mass velocity $\mathrm{w}_{\mathrm{o}}$ in $\mathrm{g} / \mathrm{s}$, the base reference inlet linear velocity $u_{o}$ in $\mathrm{cm} / \mathrm{s}$, and the average heat flux through the heating surfaces in the channel $\mathrm{q}_{\text {ave }} \mathrm{cal} / \mathrm{cm}^{2} \mathrm{~s}$.

Output: $\quad$ COMMONS: PRPR, PRPR2.

\section{Subroutine PREPHI}

Called from: DELTP

Input: $\quad$ COMMONS: INPT, REDY, SETP, SETP2, BOIL, BOIL2.

Performs: Calculation of the Martinelli-Nelson two-phase friction multiplier $\phi^{2}$ and its derivative by means of the set of coefficients COEFF in BLOCK DATA as described in App. B5.

Output: $\quad$ COMMONS: PRPI, PRPI2.

\section{Subroutine READY}

Called from: MAIN.

Input: $\quad$ (i) Argument: NPAGE.

(ii) COMMONS: DATA, INPT.

Performs: $\quad$ (i) Determination of the physical characteristics of the coolant water at the operating conditions in metric engineering units. This is accomplished by means of the function 
subroutines: THCL, TSATP, HFGP, VOLUME, VGP, FN, FPMU, FPK, and FPRAN. (ii) Calculation of the factors $\mathrm{k}_{\mathrm{s}}$ and $\mathrm{r}$ for the slip correlation, according to Eq. (B2.2) in App. B2.

(iii) Calculation of the coefficients $\mathrm{a}_{\mathrm{i}}$ for the Martinelli-Nelson two-phase friction multiplier $\phi^{2}$ according to Eq. (B5.2) in App. B5.

(iv) Estimation of the initial distributions of coolant flow rates and power generation or exit quality among the channels in the core for the iterative procedure described in Sect. 3.2 of ref. 1.

Output: $\quad$ (i) Argument: PAGE.

(ii) COMMONS: TREADY, REDY, REDY2.

(iii) Logical unit 6: (a) error message 2; (b) under the heading ***READY***, the fundamental thermohydraulic characteristics of the reactor core.

\section{Subroutine SETUP}

Called from: FLOW.

Input: $\quad$ (i) Argument: IX.

(ii) COMMONS: INPT, INPT2, JJJ, REDY.

Performs: $\quad$ (i) The selection of the parameters specific to channel type IX from the arrays in the subroutines INPUT and READY.

(ii) Calculation of the power fraction or exit quality corresponding to the new estimate of the channel flow rate during the iterative procedure.

Output: $\quad$ COMMONS: SETP, SETP2.

\section{Subroutine STEADY}

Called from: FLOW.

Input: $\quad$ (i) Argument: IX.

(ii) COMMONS: INPT, BNDY, BOIL, BOIL2, BALK, TBOUND, TNODE, TSUBOI, TBULK.

Performs: $\quad$ (i) Initialization to zero of the content of the COMMONS BOIL, BOIL2 and BALK.

(ii) Manages the solution of the thermohydraulic equations of the coolant flow by calling the subroutines PREPAR, BOUNDY, NODE, SUBOIL, BULK, FRICT, and DELTP in succession.

Output: $\quad$ COMMONS: BNDY, BOIL, BOIL2, BALK, TSTEAD.

\section{Subroutine SUBOIL}

Called from: STEADY

Input: $\quad$ (i) Argument: IX.

(ii) COMMONS: DATA, INPT, REDY, REDY2, SETP, SETP2, PRPR, PRPR2, BNDY, NOHD, NOHD2, ADD1.

Performs: $\quad$ Calculation of the liquid and steam mass flow rates, liquid enthalpy, void fraction, and other parameters of interest at each node along the subcooled boiling region of the channel. To this effect the continuity and energy equations are solved as described in Sect. 3.2 of ref 1 . The basis for the iterative procedure followed is that of ref. 4, p. 31 . 
The function subroutines FN, FPK, TD, and HNBP and the subroutine VOID are used.

Output: $\quad$ (i) COMMONS: BOIL, BOIL2.

(ii) Logical unit 6: Error message 5.

\section{Subroutine VOID}

Called from: SUBOIL and BULK.

Input: $\quad$ (i) Arguments: IX, M, X02, H02.

(ii) COMMONS: DATA, INPT, REDY, SETP, BOIL2, ADD1.

Performs: Calculation of the void fraction as a function of steam quality and relative subcooling of the liquid phase as described in Sect. 3.2 of ref. 1.

Output: $\quad$ (i) Argument: B02.

(ii) COMMON: TVOID.

(iii) Logical unit 6: Error message 6.

\section{Function Subroutine AF}

Argument: $\quad \mathrm{f} \equiv$ the smooth Moody friction factor.

Output: $\quad \mathrm{a}_{2} \equiv$ the exponent of the Reynolds number in the general expression for the Moody friction factor as described in Eq. (B7.4a).

BLOCK DATA

Performs: Initialization of the variables in the COMMON statements DATA and FNCT prior to execution of the first statement in the MAIN program.

The content of this data block is:

$\mathrm{SG}=\mathrm{g} \equiv$ the gravitational acceleration in $\mathrm{cm} / \mathrm{s}$, $\mathrm{SBP} 0, \mathrm{SBP} 1=\mathrm{c}_{\mathrm{i}}$ and $\mathrm{d}_{\mathrm{i}}$ respectively $\equiv$ table of coefficients for the Jones two-phase flow friction multiplier,

$\mathrm{BBB}=\mathrm{b}_{\mathrm{ij}} \equiv$ table of fitting coefficients of the Martinelli-Nelson friction factor $\phi^{2}$, as described in App. B5.

A tabulation, based on the ASME steam tables, of the saturation temperature, the specific volume of saturated steam, and the enthalpy of evaporation of water vs pressure (from 0.2 to 3206.2 psia) is implemented by means of: ARG-ARG2 as pressure in psia, FCT1-FCTll as $\mathrm{T}_{\text {sat }}$ in ${ }^{\circ} \mathrm{F}, \mathrm{FCT} 2-\mathrm{FCT} 22$ as $\mathrm{v}_{\mathrm{s}}$ in $\mathrm{ft}^{3} / \mathrm{lb}$, and FCT3-FCT33 as $\mathrm{h}_{\mathrm{fo}}$ in Btu/lb.

\section{Function Subroutine BESSI}

Arguments: $\quad \mathrm{N} \equiv$ order of the modified Bessel function, $\mathrm{X} \equiv$ argument.

Output: $\quad$ The value of $\mathrm{I}_{\mathrm{N}}(\mathrm{X})$, the modified Bessel function of order $\mathrm{N}$, for the argument $\mathrm{X}$. The algorithm used is valid for $N<3000$ and $X<87$. In the program, the subroutine FUEL uses the $\mathrm{N}=0$, that is, $\mathrm{I}_{0}(\mathrm{X})$, function to represent the radial distribution of the power generation within the fuel pellets.

\section{Function Subroutine CHECK}


Arguments: $\quad \mathrm{P} \equiv$ pressure in $\mathrm{kg} / \mathrm{cm}^{2}$,

$\mathrm{T} \equiv$ temperature in ${ }^{\circ} \mathrm{C}$,

$\mathrm{N}$ and $\mathrm{M} \equiv$ indices.

Output: $\quad$ It fixes the lower and upper bounds for $\mathrm{P}$ and $\mathrm{T}$ so that if the input value is out of bounds, the boundary value is returned to the calling program. The index $\mathrm{N}$ determines which of the two variables is being checked; that is, $\mathrm{N}=1$ specifies pressure, while $\mathrm{N}=2$ specifies temperature. The bounds are

$$
\begin{array}{ll}
M=1: & 0.06 \leq \mathrm{P} \leq 600.0 ;-1 \leq \mathrm{T} \leq 505.7 \\
\mathrm{M}=2: & 0.06 \leq \mathrm{P} \leq 250.0 ;-1 \leq \mathrm{T} \leq 505.7 \\
\mathrm{M}=3: & 0.06 \leq \mathrm{P} \leq 600.0 ;-1 \leq \mathrm{T} \leq 800.0
\end{array}
$$

\section{Function Subroutine FF}

Argument: $\quad \mathrm{R}_{\mathrm{e}} \equiv$ the Reynolds number.

Output: $\quad$ The smooth Moody friction factor f corresponding to the value of the argument. It follows the description in App. B7. A maximum of 50 iterations is programmed for the solution of the transcendental Eq. (B7.3); if convergence is not achieved, that is, $\mathrm{f}_{50}-\mathrm{f}_{49}>10^{-5}$ then the relation,

$$
\mathrm{f}=0.213 \mathrm{R}_{\mathrm{e}}^{-0.214}
$$

is used.

Function Subroutine FFF1 $\left(A_{-}, B_{\_}\right)$

Internal function called from: COEFR

Function Subroutine FFF2 $\left(A \_, B \_\right)$

Internal function called from: COEFR

Function Subroutine FN $(P, T)$

Arguments: $\quad \mathrm{P} \equiv$ pressure in $\mathrm{kg} / \mathrm{cm}^{2}$, $\mathrm{T} \equiv$ temperature in ${ }^{\circ} \mathrm{C}$.

Output: $\quad$ Liquid saturation enthalpy in cal $/ \mathrm{g}$.

Function Subroutine $\operatorname{FPK}(P, T)$

Internal function called from: HNBP, READY, SUBOIL

Function Subroutine $\operatorname{FPMU}(P, T)$

Arguments: $\quad \mathrm{P} \equiv$ pressure in $\mathrm{kg} / \mathrm{cm}^{2}$,

$\mathrm{T} \equiv$ temperature in ${ }^{\circ} \mathrm{C}$.

Output: $\quad$ Liquid dynamic viscosity in $\mathrm{g} / \mathrm{cm}^{2} \mathrm{~s}$.

Function Subroutine FPRAN $(P, T)$

Arguments: $\quad \mathrm{P} \equiv$ pressure in $\mathrm{kg} / \mathrm{cm}^{2}$, 


$$
\mathrm{T} \equiv \text { temperature in }{ }^{\circ} \mathrm{C} \text {. }
$$

Output: $\quad$ Prandtl number for water, as a function of pressure and temperature. The correlations used are those of the code STABLE (ref. 5, pp. 73-74).

\section{Function Subroutine FTDKDT}

Argument: $\quad \mathrm{T} \equiv$ temperature in ${ }^{\circ} \mathrm{C}$.

Output: The temperature derivative of the heat conductivity of the $\mathrm{UO}_{2}$ fuel pellet. It is based on the correlation used in the subroutine FTK.

Function Subroutine FTK(T)

Internal function called from: FTDKDT, FUEL

Function Subroutine FTRC(RHOF_T)

Internal function called from: FUEL

Function Subroutine $\operatorname{HBBP}(P, Q)$

Internal function called from: COEFR

Function Subroutine HCL(PD, TD)

Internal function called from: THCL

\section{Function Subroutine HFGP(P)}

Argument: $\quad \mathrm{P} \equiv$ pressure in atm.

Output: Evaporation enthalpy in cal/g of water, as a function of system pressure $\mathrm{P}$. The subroutine LINEAR is used to interpolate from the tables defined in BLOCK DATA prior to the application of the system of units transformation factors.

Function Subroutine $\mathrm{HNBP}(P, T, G, D)$

Arguments: $\quad \mathrm{P} \equiv$ pressure $\mathrm{kg} / \mathrm{cm}^{2}$

$\mathrm{T} \equiv$ temperature ${ }^{\circ} \mathrm{C}$,

$\mathrm{G} \equiv$ flow rate $\mathrm{g} / \mathrm{s}$,

$\mathrm{D} \equiv$ hydraulic diameter $\mathrm{cm}$.

Output: The convective heat transfer coefficient between the coolant and the fuel clad, in $\mathrm{cal} / \mathrm{cm}^{2}{ }^{\circ} \mathrm{C}$.

Function Subroutine TD $(P, H)$

Arguments: $\quad \mathrm{P} \equiv$ pressure in atm,

$\mathrm{H} \equiv$ enthalpy in cal/g.

Output: $\quad$ The liquid temperature in ${ }^{\circ} \mathrm{C}$ as a function of pressure and liquid enthalpy. An iterative procedure is used based on the function subroutine FN (P,T).

Function Subroutine TJLP(P,QZ,H,TSAT)

Arguments: $\quad \mathrm{P} \equiv$ pressure in $\mathrm{kg} / \mathrm{cm}^{2}$,

$\mathrm{QZ} \equiv$ surface heat flux cal $/ \mathrm{cm}^{2} \mathrm{~s}$, 
$\mathrm{H} \equiv$ convective heat transfer coefficient $\mathrm{cal} / \mathrm{cm}^{2}{ }^{\circ} \mathrm{C}$, TSAT $\equiv$ saturation temperature ${ }^{\circ} \mathrm{C}$.

Output: $\quad$ The temperature of inception of subcooled boiling in ${ }^{\circ} \mathrm{C}$. The Jens-Tottes correlation in Eq. (3.2.4) is used.

Function Subroutine THCL(H,P)

Internal function called from: READY

Function Subroutine TSATP $(P)$

Argument: $\quad \mathrm{P} \equiv$ pressure in atm.

Output: $\quad$ Saturation temperature in ${ }^{\circ} \mathrm{C}$.

Function Subroutine VGP(P)

Argument: $\quad \mathrm{P} \equiv$ pressure in atm.

Output: $\quad$ Specific volume of saturated steam in $\mathrm{g} / \mathrm{cm}^{3}$.

Function Subroutine VOLUME(P,T)

Arguments: $\quad \mathrm{P} \equiv$ pressure in $\mathrm{kg} / \mathrm{cm}^{2}$,

$\mathrm{T} \equiv$ temperature in ${ }^{\circ} \mathrm{C}$.

Output: $\quad$ Specific volume of liquid water in $\mathrm{cm}^{3} / \mathrm{g}$.

\subsection{PREPARATION OF INPUT FOR LAPURX}

\subsubsection{Introduction}

Data are read in by the subroutine INPUT. The input deck consists of a title card, data set cards, and a last card. The title card can contain up to 72 characters. These characters will be printed on each page of output to allow for easy identification of the case.

Each data set is preceded by an ID card that identifies the set. Thus, the sets need not be read in a specific sequence, although sets 1 and 2 have to be read before sets 7 or larger; set 3 before sets 4 and 5 ; and sets 35, 36, and 37 as well as the groups $(38,39,40,41,42,43,44)$ and $(45,46,47,48,49$, $50,51,52)$ must be read in sequence. All ID cards carry their number in format (I4). Most of the time the data cards use an (I10) format for integers and an (E10.3) format for the real values. All numbers are right justified. The input routine will accept commas to separate fields as long as each filed is less than 10 characters long. Note, however, that most continuation cards start with a " $10 \mathrm{X}$ " format, so continuation card data must start in column 11 even if commas are used to separate the fields.

The last card is equivalent to an ID number equal to zero; thus a 0 in column 4 will terminate the input. 
Once the input process is finished, the program will be executed.

When the calculations are finished, a new title card is sought by the subroutine INPUT. If a new title is found, a new case will be run.

For consecutive runs, only those data sets that change from one run to the next need be reentered.

Execution stops when the end-of-data card is found.

\subsubsection{Input Description}

\subsubsection{First Card}

Title ... columns 1 through 72 .

\subsubsection{Data Cards}

Each data set is preceded by a card containing only the ID number of the corresponding data set in format (I4).

Description of the data sets:

\begin{tabular}{|c|l|l|l|}
\hline $\begin{array}{c}\text { Data set } \\
\text { ID No. }\end{array}$ & \multicolumn{1}{|c|}{ FORTRAN symbols } & Format & Comment \\
\hline 1 & P,T0,POWT,WT,CWBYP,CPROMP,CPRBYP,UNITS & $8 \mathrm{E} 10.3$ & if UNITS=0 \\
\cline { 2 - 5 } & PPSI,ENTBTU,POWT,WLBSHR,CWBYP,CPROMP,CPRBYP,UNITS & $8 \mathrm{E} 10.3$ & if UNITS=1 \\
\hline 2 & NXE,N,ICOFC(IOP(J),J=1,7) & 1015 & $\begin{array}{l}\text { NXE } \leq \\
\text { NCHMAX } \\
\text { N } \leq \\
\text { NOBMAX }\end{array}$ \\
\hline
\end{tabular}

P,PPSI P System pressure $\mathrm{P} \quad\left(\mathrm{kg} / \mathrm{cm}^{2}\right)$, PPSI (psia).

TO $\quad \mathrm{T}_{0} \quad$ Core inlet water temperature $\left({ }^{\circ} \mathrm{C}\right)$.

ENTBTU $\mathrm{H} \quad$ Core inlet water enthalpy (Btu/lb).

POWT Pth Core thermal power (MWth).

WT,WLBSHRW Total flow rate (active core + bypass)

WT $(\mathrm{kg} / \mathrm{s}) ;$ WLBSHR $(\mathrm{lb} / \mathrm{h})$.

CWBYP Fraction of total flow through bypass.

CPROMP $\quad \gamma_{\mathrm{pr}} \quad$ Fraction of thermal energy given to water through moderation of neutron and $\gamma$-ray attenuation. 
CPRBYP

UNITS

Same as CPROMP but in bypass region.

Option for units to be used with the following input variables:

\begin{tabular}{|l|l|l|}
\hline \multicolumn{1}{|c|}{ Units } & \multicolumn{1}{c|}{0} & \multicolumn{1}{c|}{1} \\
\hline System pressure & $\mathrm{kg} / \mathrm{cm}^{2}$ & $\mathrm{psia}$ \\
\hline Inlet water condition & ${ }^{\circ} \mathrm{C}$ & $\mathrm{Btu} / \mathrm{lb}$ \\
\hline Core total flow & $\mathrm{kg} / \mathrm{s}$ & $\mathrm{lb} / \mathrm{h}$ \\
\hline Channel mass velocity & $\mathrm{g} / \mathrm{cm}^{2} \mathrm{~s}$ & $10^{6} \mathrm{lb} / \mathrm{ft}^{2} \mathrm{~h}$ \\
\hline
\end{tabular}

NXE

$\mathrm{N}$

IOP(I)

$\operatorname{IOP}(2)$

$\operatorname{IOP}(3)$

Number of regions within which the thermohydraulic behavior of the channels is uniform ( $\equiv$ thermal region: same exit quality, same hydraulic diameter, same flow rate, and same power shape).

Number of axial nodes desired in the boiling region of the channels.

Option for the calculation of the flow distribution among channels in the steady state and for the calculation of transfer functions.

\begin{tabular}{|l|l|l|l|l|}
\hline IOP(1) & 0 & 1 & 2 & 3 \\
\hline flow distribution & 0 & $\mathrm{X}$ & 0 & $\mathrm{X}$ \\
\hline transfer function & 0 & 0 & $\mathrm{X}$ & $\mathrm{X}$ \\
\hline
\end{tabular}

Input option for GPOW(IX) and FPOW(IX) (see IDs 8 and 9, respectively).

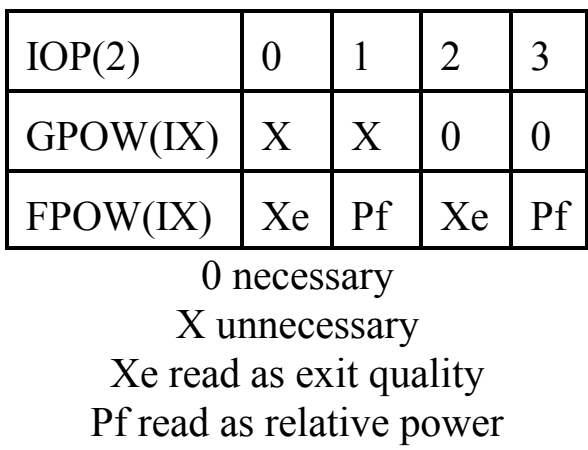

Option to specify ZNBM, EKX, and R by input (see IDs 12 and 6, respectively). 


\begin{tabular}{|c|c|c|c|c|}
\hline $\operatorname{IOP}(3)$ & 0 & 1 & 2 & 3 \\
\hline ZNBM & X & 0 & $X$ & 0 \\
\hline EKS and $\mathrm{R}$ & $\mathrm{X}$ & $\mathrm{X}$ & 0 & 0 \\
\hline
\end{tabular}

$\operatorname{IOP}(4) \quad$ If $=0$, it will print the steady state results. If $\neq 0$, it will not do it.

IOP(5) Edit option for the results of the subroutine FUEL1. If $=0$, yes. If $=1$, no.

$\mathrm{IOP}(6)$ Input option for NFNO and NFPRT(I) (see ID 54). If $=0$, edit FUEL1 at default node numbers. If $\neq 0$, data set 54 is required.

$\operatorname{IOP}(7)$

Output option for the results of COEFR. If $=0$, yes. If $\neq 0$, no. 


\begin{tabular}{|c|l|l|l|}
\hline 3 & NPD,(NPP(I),I=1,NPD) & $8 \mathrm{I} 10$ & $\begin{array}{l}\text { NPD } \leq \\
\text { NPSMAX }\end{array}$ \\
\hline 4 & $(($ DELZM(IP,I),I=1,NPPP(IP)),IP=1,NPD) & $\begin{array}{l}10 \mathrm{X}, 7 \mathrm{E} 10.3, \\
(10 \mathrm{X}, 7 \mathrm{E} 10.3)\end{array}$ & \\
\hline 5 & $((\mathrm{POWM}(\mathrm{IP}, \mathrm{I}), \mathrm{I}=1, \mathrm{NPPP}(\mathrm{IP})), \mathrm{IP}=1, \mathrm{NPD})$ & $\begin{array}{l}10 \mathrm{X} \text { 7E10.3, } \\
(10 \mathrm{X}, 7 \mathrm{E} 10.3)\end{array}$ & \\
\hline
\end{tabular}

NPD

NPPP(IP)

Number of regions within which the axial power distributions are uniform (power shape regions).

Number of axial nodes for the specification of the relative nodal power in the IP-th power shape region.

$\operatorname{DELZM}(\mathrm{IP}, \mathrm{I}) \quad \Delta \mathrm{z}_{\mathrm{i}}$ Length of the I-th node in region IP $(\mathrm{cm}) \mathrm{I}=1$ :bottom of the core.

POWM(IP,I) $\quad \mathrm{f}(\mathrm{z})$ Relative nodal power of the I-th node in region IP.

\begin{tabular}{|l|l|l|l|}
\hline 6 & EKS,R,SA0,SA1,SA2,SA3,SA4 & $7 \mathrm{E} 10.3$ & $\begin{array}{l}\text { See IOP(3) } \\
@ \text { ID 1 }\end{array}$ \\
\hline
\end{tabular}

EKS $\quad \mathrm{k}_{\mathrm{s}} \quad$ Constant for Bankoff's slip correlation.

$\mathrm{R} \quad \mathrm{r} \quad$ Constant to modify Bankoff's slip correlation; App. B2.

SA0, SA1, $\quad \mathrm{S}_{\mathrm{a} 0}$ Coefficients for the calculation of the power distribution within a fuel $\mathrm{SA} 2, \mathrm{SA} 3, \sim$ rod.

SA4 $\quad \mathrm{S}_{\mathrm{a} 4}$

\begin{tabular}{|l|l|l|l|}
\hline 7 & NXE,(NPOW(IX),IX=1,NXE) & $\begin{array}{l}8 \mathrm{I} 10, \\
(10 X, 7 \mathrm{I} 10)\end{array}$ & $\begin{array}{l}\text { NXE } \leq \\
\text { NCHMAX }\end{array}$ \\
\hline
\end{tabular}

NPOW(IX) Nuclear region number to which the IX-th thermal region belongs.

\begin{tabular}{|c|l|l|l|}
\hline 8 & NXE,(GPOW(IX),IX=I,NXE) & $\begin{array}{l}\text { I10,7E10.3, } \\
(10 X, 7 \mathrm{E} 10.3)\end{array}$ & $\begin{array}{l}\text { See IOP(2), } \\
\text { ID 1 }\end{array}$ \\
\hline
\end{tabular}

POW(IX) $\quad G_{\mathrm{p}} \quad$ Channel mass flow rate.

$\left(\mathrm{g} / \mathrm{cm}^{2}\right) / \mathrm{s} \quad$ if UNITS $=0$.

$\left(\mathrm{Mlb} / \mathrm{ft}^{2} \mathrm{~h}\right)$ if $\mathrm{UNITS}=1$.

Unnecessary when $\operatorname{IOP}(2)=0$ or 1 . 


\begin{tabular}{|l|l|l|l|}
\hline 9 & NXE,(FPOW(IX),IX=I,NXE) & $\begin{array}{l}\text { I10,7E10.3, } \\
(10 X, 7 \mathrm{E} 10.3)\end{array}$ & $\begin{array}{l}\text { See IOP(2), } \\
\text { ID 1 }\end{array}$ \\
\hline
\end{tabular}

FPOW(IX) $\quad$ If $\operatorname{IOP}(2)=1$ or $3:$

$=\mathrm{f}_{\mathrm{ix}}$, relative power generated in region IX.

If $\operatorname{IOP}(2)=0$ or 2 :

$=\mathrm{Xe}_{\mathrm{ix}}$, exit quality for region IX.

EKCPM(IX) $\quad \mathrm{k}_{\hat{\mathrm{c}}} \quad$ Contraction coefficient at the inlet of the channels. This coefficient is normalized by assuming a velocity with a nominal flow area of $10 \mathrm{in}^{2}$, not the actual velocity in the nozzle.

\begin{tabular}{|l|l|l|l|}
\hline 11 & NXE,(EKEPM(IX),IX=1,NXE) & $\begin{array}{l}\text { I10,7E10.3, } \\
(10 X, 7 \mathrm{E} 10.3)\end{array}$ & \\
\hline
\end{tabular}

EKEPM(IX) $\quad \mathrm{k}_{\dot{\mathrm{e}}} \quad$ Contraction coefficient at the exit of the channels. If the flow is expanded, it has a negative value. The velocity is calculated assuming a $10 \mathrm{in}^{2}$ flow area.

\begin{tabular}{|l|l|l|l|}
12 & NXE,(ZNBM(IX),IX=1,NXE) & $\begin{array}{l}\text { I10,7E10.3, } \\
(10 X, 7 \mathrm{E} 10.3)\end{array}$ & See IOP(3) \\
\hline
\end{tabular}

ZNBM(IX) $\quad Z_{\mathrm{nb}} \quad$ Position of the boiling boundary from the bottom of the channel (cm).

13 NXE,(ZELP(IX),IX=1,NXE)
I10,7E10.3, (10X,7E10.3)

ZELP(IX) $\quad Z_{\mathrm{LP}}$ Height of the channel inlet measured from the point at which pressure is uniform $(\mathrm{cm})$. 


\begin{tabular}{|c|l|l|l|}
\hline 15 & NXE,(NROD(IX),IX=1,NXE) & $\begin{array}{l}8 \mathrm{I} 10, \\
(10 \mathrm{X}, 7 \mathrm{I} 10)\end{array}$ & \\
\hline
\end{tabular}

NROD(IX) Number of fuel rods in a channel from region IX.

\begin{tabular}{|c|c|c|c|}
\hline 16 & NXE,(NDIM(IX),IX=1,NXE) & $\begin{array}{l}8 \mathrm{I} 10, \\
(10 \mathrm{X}, 7 \mathrm{I} 10)\end{array}$ & \\
\hline 17 & NTD,(ELM(ITD),ITD=1,NTD) & $\begin{array}{l}\text { I10,7E10.3, } \\
(10 \mathrm{X}, 7 \mathrm{E} 10.3)\end{array}$ & $\begin{array}{l}\text { NTD } \leq \\
\text { NFBMAX }\end{array}$ \\
\hline 18 & NTD,(WHTM(ITD),ITD=1,NTD) & $\begin{array}{l}\text { I10,7EI0.3, } \\
(10 \mathrm{X}, 7 \mathrm{E} 10.3)\end{array}$ & \\
\hline 19 & NTD,(A0M(ITD),ITD=1,NTD) & $\begin{array}{l}\mathrm{I} 10,7 \mathrm{E} 10.3, \\
(10 \mathrm{X}, 7 \mathrm{E} 10.3)\end{array}$ & \\
\hline 20 & NTD,(ACELM(ITD),ITD=1,NTD) & $\begin{array}{l}\text { I10,7E10.3, } \\
(10 \mathrm{X}, 7 \mathrm{E} 10.3)\end{array}$ & \\
\hline 21 & NTD,(DEM(ITD),ITD=1,NTD) & $\begin{array}{l}\text { I10,7E10.3, } \\
(10 \mathrm{X}, 7 \mathrm{E} 10.3)\end{array}$ & \\
\hline 22 & NTD,(BETOMM(ITD),ITD=1,NTD) & $\begin{array}{l}\text { I10,7E10.3, } \\
(10 \mathrm{X}, 7 \mathrm{E} 10.3)\end{array}$ & \\
\hline 23 & NTD,(BETGMM(ITD),ITD=1,NTD) & $\begin{array}{l}\text { I10,7E10.3, } \\
(10 \mathrm{X}, 7 \mathrm{E} 10.3)\end{array}$ & \\
\hline 24 & NTD,(FPM(ITD),ITD=1,NTD) & $\begin{array}{l}\text { I10,7E10.3, } \\
(10 \mathrm{X}, 7 \mathrm{E} 10.3)\end{array}$ & \\
\hline 25 & NTD, $($ CLAMPM(ITD),ITD=I,NTD $)$ & $\begin{array}{l}\text { I10,7E10.3, } \\
(10 \mathrm{X}, 7 \mathrm{E} 10.3)\end{array}$ & \\
\hline
\end{tabular}

NDIM(IX) Channel type of the IX-th thermal region.

NTD Number of channel types.

ELM(ITD) L Height of the ITD-th type channel $(\mathrm{cm})$.

WHTM(ITD) $\quad \mathrm{W}_{\mathrm{ht}}$ Heat transfer area per unit axial length of the channel $(\mathrm{cm})$.

A0M(ITD) $\quad \mathrm{A}_{0} \quad$ Channel flow area $\left(\mathrm{cm}^{2}\right)$.

ACELM(ITD) $\quad A_{\text {cell }} \quad$ The same as A0M(ITD) $\left(\mathrm{cm}^{2}\right)$.

This value is used for the calculation of the relative water density in the reactivity feedback model. If the density reactivity coefficient is defined for the density of active coolant.

$\mathrm{A}_{0}=\mathrm{A}_{\text {cell }}$.

DEM(ITD) $\quad \mathrm{D}_{\mathrm{e}} \quad$ Hydraulic diameter $(\mathrm{cm})$.

BETOMM(ITD) $\beta_{\Omega} \quad$ Parameter for the calculation of $\Omega$ in the subcooled boiling region, App. 
B6.

BETGMM(ITD) $\beta_{\gamma} \quad$ Parameter for the calculation of $\gamma$ in the subcooled boiling region, App. B2.

FPM(ITD) $\quad \mathrm{f}_{\mathrm{p}} \quad$ Adjustable parameter to correlate the calculated and measured void fraction distribution in the subcooled boiling region. It is inversely related to the fraction of energy invested in voids in the S.B. region, App. B3.

CLAMPM $\quad c^{\prime} \quad$ Adjustable parameter for the same purpose as $\mathrm{f}_{\mathrm{p}}$. This one is directly related to the mean lifetime of the voids in the S.B. region, App. B4.

\begin{tabular}{|c|c|c|c|}
\hline 26 & NXE,(NFUEL(IX),IX=1,NXE) & $\begin{array}{l}8 \mathrm{I} 10, \\
(10 \mathrm{X}, 7 \mathrm{I} 10)\end{array}$ & \\
\hline 27 & NTFU,(RHOFM(IFU),IFU=I,NTFU) & $\begin{array}{l}\text { I10,7E10.3, } \\
(10 \mathrm{X}, 7 \mathrm{E} 10.3)\end{array}$ & $\begin{array}{l}\text { NTFU } \leq \\
\text { NFRMAX }\end{array}$ \\
\hline 28 & NTFU,(TFM(IFU),IFU=1,NTFU) & $\begin{array}{l}\text { I10,7EI0.3, } \\
(10 \mathrm{X}, 7 \mathrm{E} 10.3)\end{array}$ & \\
\hline 29 & NTFU,(RHOCCM(IFU),IFU=1,NTFU) & $\begin{array}{l}\text { I10,7E10.3, } \\
(10 \mathrm{X}, 7 \mathrm{E} 10.3)\end{array}$ & \\
\hline 30 & NTFU,(EKCLM(IFU),IFU=1,NTFU) & $\begin{array}{l}\text { I10,7E10.3, } \\
(10 \mathrm{X}, 7 \mathrm{E} 10.3)\end{array}$ & \\
\hline 31 & NTFU,(TCM(IFU),IFU=1,NTFU) & $\begin{array}{l}\text { I10,7E10.3, } \\
(10 \mathrm{X}, 7 \mathrm{E} 10.3)\end{array}$ & \\
\hline 32 & NTFU,(HGAPM(IFU),IFU=1,NTFU) & $\begin{array}{l}\text { I10,7E10.3, } \\
(10 \mathrm{X}, 7 \mathrm{E} 10.3)\end{array}$ & \\
\hline 33 & NTFU,(TGAPM(IFU),IFU=1,NTFU) & $\begin{array}{l}\text { I10,7E10.3, } \\
(10 \mathrm{X}, 7 \mathrm{E} 10.3)\end{array}$ & \\
\hline
\end{tabular}

NFUEL(IX)

NTFU RHOFM(IFU) $\quad \rho_{\text {fu }}$ TFM(IFU) $\quad \mathrm{T}_{\mathrm{f}}$ RHOCCM(IFU) $\operatorname{EKCIM(IFU)~} \quad \mathrm{k}_{\mathrm{c}}$ TCM(IFU) $t_{c}$ HGAPM(IFU) $\mathrm{h}_{\text {gap }}$ Gap heat transfer coefficient $\left(\mathrm{cal} / \mathrm{cm}^{2} \mathrm{~s}{ }^{\circ} \mathrm{C}\right)$.

TGAPM(IFU) $\mathrm{t}_{\text {gap }} \quad$ Gap width (cm).
Fuel rod type of the IX-th thermal region.

Number of fuel rod types.

Density of the fuel in the IFU-th type of fuel rod $\left(\mathrm{g} / \mathrm{cm}^{3}\right)$.

Fuel pellet diameter $(\mathrm{cm})$.

Cladding heat capacity $\left(\mathrm{cal} / \mathrm{cm}^{3}{ }^{\circ} \mathrm{C}\right)$.

Cladding thermal conductivity $\left(\mathrm{cal} / \mathrm{cm} \mathrm{s}^{\circ} \mathrm{C}\right)$.

Cladding thickness $(\mathrm{cm})$. 


\begin{tabular}{|c|l|l|l|}
\hline 35 & NTFR,(NFM(IFR),IFR=1,NTFR) & $\begin{array}{l}8 \mathrm{I} 10, \\
(10 X, 7110)\end{array}$ & $\begin{array}{l}\text { NTFR } \leq \\
\text { NFMMAX }\end{array}$ \\
\hline 36 & $(($ DZFM(IFR,I),I=1,NFM(IFR)),IFR=1,NTFR) & $\begin{array}{l}10 \mathrm{X}, 7 \mathrm{E} 10.3, \\
(10 \mathrm{X}, 7 \mathrm{E} 10.3)\end{array}$ & \\
\hline 37 & $(($ EKFM(IFR,I),I=1,NFM(IFR)),IFR=1,NTFR) & $\begin{array}{l}10 \mathrm{X}, 7 \mathrm{E} 10.3, \\
(10 \mathrm{X}, 7 \mathrm{E} 10.3)\end{array}$ & \\
\hline
\end{tabular}

NFRC(IX)

NTFR

NFM(IFR)

$\operatorname{DZFM}($ IFR,I)

EKFM(IFR,I) $\quad \mathrm{k}_{\mathrm{f}} \quad$ Friction multiplier for the I-th axial interval.

\begin{tabular}{|c|l|l|l|}
\hline 38 & NXE,(NIN(IX),IX=1,NXE) & $\begin{array}{l}8 \mathrm{I} 10, \\
(10 \mathrm{X}, 7 \mathrm{I} 10)\end{array}$ & \\
\hline 39 & NTIN,(NCM(IIN),IIN=1,NTIN) & $\begin{array}{l}8 \mathrm{I} 10, \\
(10 \mathrm{X}, 7 \mathrm{I} 10)\end{array}$ & $\begin{array}{l}\text { NTIN } \leq \\
\text { NCIMAX }\end{array}$ \\
\hline 40 & $((\mathrm{DZINM}(\mathrm{IIN}, \mathrm{I}), \mathrm{I}=1, \mathrm{NCM}(\mathrm{IIN})), \mathrm{IIN}=1, \mathrm{NTIN})$ & $\begin{array}{l}10 \mathrm{X}, 7 \mathrm{E} 10.3, \\
(10 \mathrm{X}, 7 \mathrm{E} 10.3)\end{array}$ & \\
\hline 41 & $((\mathrm{AINM}(\mathrm{IIN}, \mathrm{I}), \mathrm{I}=1, \mathrm{NCM}(\mathrm{IIN})), \mathrm{IIN}=1, \mathrm{NTIN})$ & $\begin{array}{l}10 \mathrm{X}, 7 \mathrm{E} 10.3, \\
(10 \mathrm{X}, 7 \mathrm{E} 10.3)\end{array}$ & \\
\hline 42 & $((\mathrm{DEINM}(\mathrm{IIN}, \mathrm{I}), \mathrm{I}=1, \mathrm{NCM}(\mathrm{IIN}), \mathrm{IIN}=1, \mathrm{NTIN})$ & $\begin{array}{l}10 \mathrm{X}, 7 \mathrm{E} 10.3, \\
(10 \mathrm{X}, 7 \mathrm{E} 10.3)\end{array}$ & \\
\hline 43 & $((\mathrm{EKCINM}(\mathrm{IIN}, \mathrm{I}), \mathrm{I}=1, \mathrm{NCM}(\mathrm{IIN})), \mathrm{IIN}=1, \mathrm{NTIN})$ & $\begin{array}{l}10 \mathrm{X}, 7 \mathrm{E} 10.3, \\
(10 \mathrm{X}, 7 \mathrm{E} 10.3)\end{array}$ & \\
\hline 44 & $((\mathrm{EKFINM}(\mathrm{IIN}, \mathrm{I}), \mathrm{I}=1, \mathrm{NCM}(\mathrm{IIN})), \mathrm{IIN}=1, \mathrm{NTIN})$ & $\begin{array}{l}10 \mathrm{X}, 7 \mathrm{E} 10.3, \\
(10 \mathrm{X}, 7 \mathrm{E} 10.3)\end{array}$ & \\
\hline
\end{tabular}

NIN(IX) Channel inlet piping type of the IX-th thermal region.

NTIN

$\operatorname{NCM}(\mathrm{IIN})$

DZINM(IIN,I) $\Delta z_{\text {in }} \quad$ Length of the I-th inlet pipe $(\mathrm{cm}) \mathrm{I}=1 \equiv$ the
$\operatorname{AINM}(\mathrm{IIN}, \mathrm{I}) \quad \mathrm{A}_{\text {in }} \quad$ Flow area of the I-th inlet pipe $\left(\mathrm{cm}^{2}\right)$.

$\operatorname{DEINM}(\mathrm{IIN}, \mathrm{I}) \mathrm{D}_{\text {ein }}$ Hydraulic diameter of the I-th inlet pipe (cm).

EKCINM(IIN,I) $\quad \mathrm{K}_{\text {cin }}^{\prime} \quad$ Contraction coefficient at the boundary between the (I+1)-th and the I-th pipes.

EKFINM(IIN,I) $\mathrm{k}_{\text {fin }} \quad$ Friction multiplier for the I-th pipe. 


\begin{tabular}{|c|c|c|c|}
\hline 45 & NXE,(NEX(IX),IX=1,NXE) & $\begin{array}{l}8 \mathrm{I} 10, \\
(10 \mathrm{X}, 7 \mathrm{I} 10)\end{array}$ & \\
\hline 46 & NTEX,(NEXM(IEX),IEX=1,NTEX) & $\begin{array}{l}8 \mathrm{I} 10, \\
(10 \mathrm{X}, 7 \mathrm{I} 10)\end{array}$ & $\begin{array}{l}\text { NTEX } \leq \\
\text { NCEMAX }\end{array}$ \\
\hline 47 & $((\mathrm{DZEXM}(\mathrm{IEX}, \mathrm{I}), \mathrm{I}=1, \mathrm{NEXM}(\mathrm{IEX})), \mathrm{IEX}=1, \mathrm{NTEX})$ & $\begin{array}{l}\text { 10X,7E10.3, } \\
(10 \mathrm{X}, 7 \mathrm{E} 10.3)\end{array}$ & \\
\hline 48 & $((\operatorname{AEXM}(\operatorname{IEX}, \mathrm{I}), \mathrm{I}=1, \mathrm{NEXM}(\mathrm{IEX})), \mathrm{IEX}=1, \mathrm{NTEX})$ & $\begin{array}{l}\text { 10X,7E10.3, } \\
(10 \mathrm{X}, 7 \mathrm{E} 10.3)\end{array}$ & \\
\hline 49 & $((\operatorname{DEEXM}(\mathrm{IEX}, \mathrm{I}), \mathrm{I}=1, \mathrm{NEXM}(\mathrm{IEX})), \mathrm{IEX}=1, \mathrm{NTEX})$ & $\begin{array}{l}\text { 10X,7E10.3, } \\
(10 \mathrm{X}, 7 \mathrm{E} 10.3)\end{array}$ & \\
\hline 50 & $((\operatorname{EKEXM}(\mathrm{IEX}, \mathrm{I}), \mathrm{I}=1, \mathrm{NEXM}(\mathrm{IEX})), \mathrm{IEX}=1, \mathrm{NTEX})$ & $\begin{array}{l}\text { 10X,7E10.3, } \\
(10 \mathrm{X}, 7 \mathrm{E} 10.3)\end{array}$ & \\
\hline 51 & $((\operatorname{EKFEXM}(\mathrm{IEX}, \mathrm{I}), \mathrm{I}=1, \mathrm{NEXM}(\mathrm{IEX})), \mathrm{IEX}=1, \mathrm{NTEX})$ & $\begin{array}{l}\text { 10X,7E10.3, } \\
(10 \mathrm{X}, 7 \mathrm{E} 10.3)\end{array}$ & \\
\hline 53 & $(($ THETEM(IEX,I),I=1,NEXM(IEX)),IEX=1,NTEX) & $\begin{array}{l}\text { 10X,7E10.3, } \\
(10 \mathrm{X}, 7 \mathrm{E} 10.3)\end{array}$ & \\
\hline
\end{tabular}

NEX(IX) Exit piping type of the IX-th thermal region.

NTEX Number of exit piping types.

NEXM(IEX) Number of pipes in series in the IEX-th type of piping.

$\operatorname{DZEXM}(\operatorname{IEX}, \mathrm{I}) \quad \mathrm{z}_{\mathrm{ex}} \quad$ Length of the I-th exit pipe $(\mathrm{cm}) \mathrm{I}=1$ : the nearest pipe to the exit of the channel.

$\operatorname{AEXM(IEX,I)~} \quad \mathrm{A}_{\text {ex }}$ Flow area of the I-th exit pipe $\left(\mathrm{cm}^{2}\right)$.

$\operatorname{DEEXM(IEX,I)~} \quad \mathrm{D}_{\mathrm{ex}}$ Hydraulic diameter of the I-th exit pipe $(\mathrm{cm})$.

$\operatorname{EKEXM(IEX,I)~} \mathrm{k}_{\mathrm{ex}} \quad$ Contraction coefficient at the boundary between the (I-1)-th and the I-th pipes.

$\operatorname{EKFEXM(IEX,I)~} \mathrm{k}_{\mathrm{fex}} \quad$ Friction multiplier for the I-th pipe.

THETEM(IEX,I) $\theta_{\text {ex }} \quad$ Angle of the I-th pipe tilt from vertical.

53

(EPSINP(I),I=1,8)

$8 \mathrm{E} 10.3$

EPSINP(I) $\quad \varepsilon_{\mathrm{i}} \quad$ Convergence criteria for the iterative calculations.

*Calculation of the flow distribution among the channels:

$\operatorname{EPSINP}(1)(0.01) \quad$ pressure drop relative error $\leq \varepsilon_{1}$.

$\operatorname{EPSINP}(2)(0.01) \quad$ total flow relative error $\leq \varepsilon_{2}$.

$\operatorname{EPSINP}(3)(0.01) \quad$ mass velocity relative error $\leq \varepsilon_{3}$.

*Calculation of the flow quality in the subcooled boiling region: 
$\operatorname{EPSINP}(4)(0.00002)$ flow quality error $\leq \varepsilon_{4}$.

*Calculation of void fraction:

$\operatorname{EPSINP}(5)(0.001)$ void fraction relative error $\leq \varepsilon_{5}$.

*Calculation of boundary between the subcooled and the bulk boiling regions:

$\operatorname{EPSINP}(6)\left(10^{-9}\right) \quad$ normalized degree of subcooling error $\leq \varepsilon_{6}$.

*Calculation of the steady state temperature distribution within a fuel rod:

$\operatorname{EPSINP}(7)(0.01) \quad$ fuel temperature relative error $\leq \varepsilon_{7}$.

$\operatorname{EPSINP}(8)(0.05) \quad$ fuel heat transfer energy balance relative error $\leq \varepsilon_{8}$.

\begin{tabular}{|l|l|l|l|}
\hline 54 & NFNO,(NFPRT(I),I=1,NFNO) & $\begin{array}{l}8 \mathrm{I} 10, \\
(10 X, 7 \mathrm{I} 10)\end{array}$ & $\begin{array}{l}\text { See IOP(6) } \\
\text { NFNO } \leq \\
\text { NAPMAX }\end{array}$ \\
\hline
\end{tabular}

NFNO Number of axial points to edit the transient response of the fuel rods. NFPRT(I) Axial node number to edit the transient response of the fuel rods.
57
ZN, SN
$10 \mathrm{X}, 2 \mathrm{E} 10.3$

ZN

Parameter to vary the axial power shape peak location.

SN

Parameter to vary the axial power shape peaking factor.

If ID 57 is input, the axial power shape is calculated as

$$
\mathrm{P}(\mathrm{Z})=\left[\sin \pi\left(\frac{\mathrm{Z}}{\mathrm{H}}\right)^{1 / \mathrm{ZN}}\right]^{\mathrm{SN}}
$$

\subsection{OUTPUT DESCRIPTION OF LAPURX}

First, the date of the day is printed, followed by a listing generated by OUTIN of the input parameters using the input mnemonics are described in App. C2 of Reference 1.

Next, a list of those system parameters directly calculated from the input parameters is printed by READY.

What follows next depends on the selected options in card 2. Provided that they have not been bypassed by the options, the subroutines produce output in the following sequence: 


\section{a. During the Iterations*}

${ }^{*}$ Calculation controlled by IOP(1).

Let $\mathrm{M}$ be the number of iterations required to find the steady state flow distribution. Then,

$\mathrm{FLOW}_{\mathrm{m}}$

prints its output $M$ - 1 times, once for each iteration (i.e., for all $m=1$ to $M-1$ ).

\section{b. When the Steady State Is Found}

\section{STEADY $_{\mathrm{M}}(\mathrm{IX})^{\dagger} \quad$ FUELX (IX) $\left.^{*} \quad \mathrm{COEFR}^{\dagger} \mathrm{IX}\right)^{* *}$}

Print their output NXE times, once for each channel, that is, for all IX $=1$ to NXE, followed by the output of $\mathrm{FLOW}_{\mathrm{M}}$. The subindex $\mathrm{M}$ indicates the values corresponding to the converged last flow iteration.

Output controlled by IOP(4).

Output controlled by IOP(5).

${ }^{* *}$ Output controlled by IOP(7).

\section{Description of the Output Generated by These Subroutines}

\section{- OUTIN}

Prints the INPUT parameters using the same mnemonics found in the input instructions.

\section{- READY}

The parameters printed are:

\begin{tabular}{|c|c|c|}
\hline Mnemonics & Math \& Units & Description \\
\hline IX-INITIAL & $\Phi_{\text {ix }}$ & \\
\hline POWER RATIO & $\overline{\sum_{\mathrm{ix}} \mathrm{NCH}_{\mathrm{ix}} \Phi_{\mathrm{ix}}}$ & $\begin{array}{l}\text { pertaining to region IX, it will remain constant unless the exit } \\
\text { quality is the variable fixed by NOPT(5). }\end{array}$ \\
\hline $\mathrm{T} 0=\mathrm{TIN}$ & $\left({ }^{\circ} \mathrm{C}\right)$ & Water inlet temperature. \\
\hline TSAT & $\left({ }^{\circ} \mathrm{C}\right)$ & Water saturation temperature. \\
\hline $\mathrm{HO}$ & $(\mathrm{cal} / \mathrm{g})$ & Enthalpy of inlet water. \\
\hline HF & $1 / \mathrm{g})$ & thalpy of water at TSAT. \\
\hline HFG & $(\mathrm{cal} / \mathrm{g})$ & Enthalpy of evaporation of water. \\
\hline RHOLIN & $\left(\mathrm{g} / \mathrm{cm}^{3}\right)$ & nsity of inlet water. \\
\hline RHOL & $\left(\mathrm{g} / \mathrm{cm}^{3}\right)$ & nsity of water at TSAT. \\
\hline
\end{tabular}




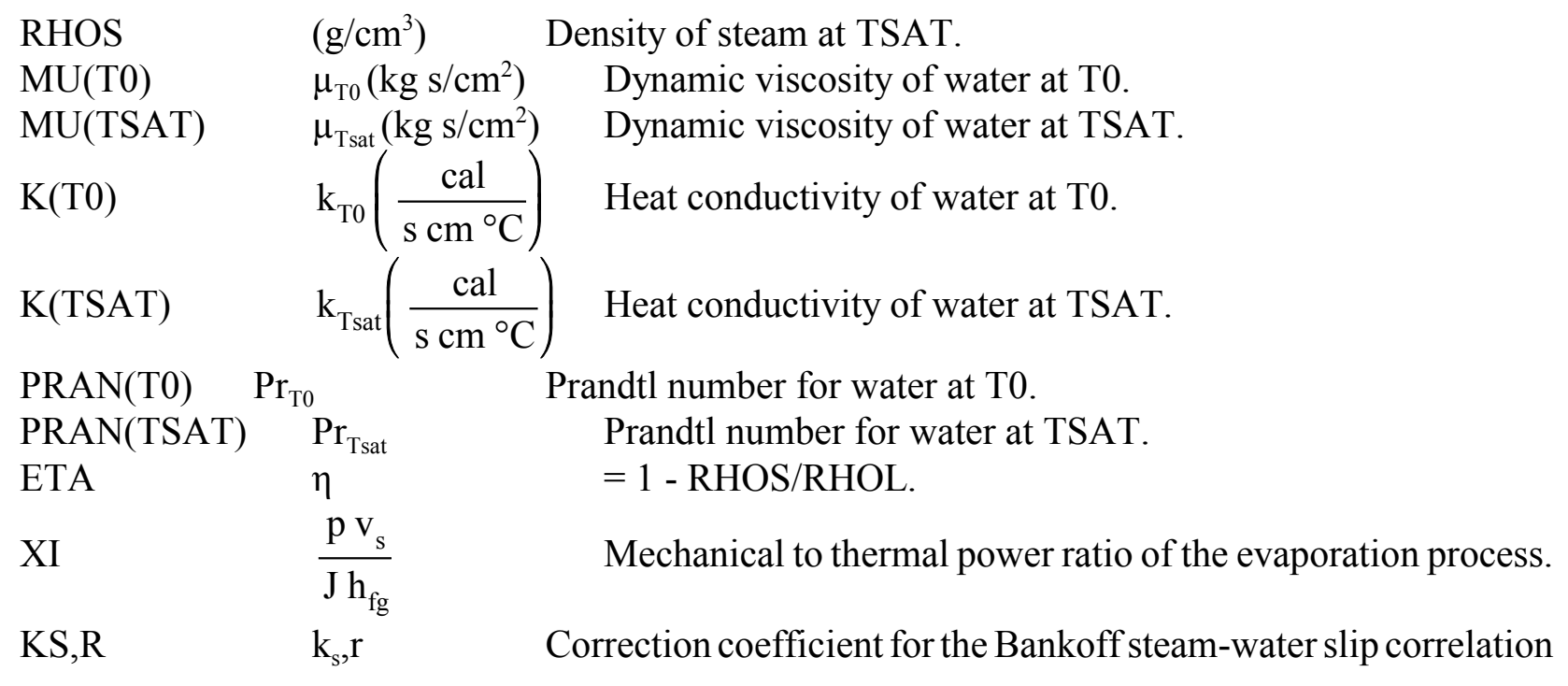

\section{- STEADY(IX)}

The output of this subroutine is performed by OUTST. Note: those variables whose headings in the printout are self-explanatory are not included in this description.

Under the heading "Subcooled and Bulk Boiling Regions":

\begin{tabular}{|c|c|c|}
\hline & $\mathrm{i}$ & Node number \\
\hline Z & $\mathrm{z}(\mathrm{cm})$ & Vertical position of the lower node boundary. \\
\hline$D \beta / D Z$ & $\frac{\partial \beta}{\partial z}\left(\mathrm{~cm}^{-1}\right)$ & Void fraction gradient. \\
\hline$D \beta / D X$ & & Slope of void fraction vs quality. \\
\hline DPAC & $\left(\mathrm{kg} / \mathrm{cm}^{2}\right)$ & Pressure drop from inlet due to acceleration. \\
\hline PDH & $\left(\mathrm{kg} / \mathrm{cm}^{2}\right)$ & Pressure drop from inlet due to gravitation. \\
\hline & $\left(\mathrm{kg} / \mathrm{cm}^{2}\right)$ & Pressure drop from inlet due to friction. \\
\hline
\end{tabular}

Under the heading "Subcooled Boiling Region":

$\begin{array}{lll}\text { Subcool enthalpy } \frac{\mathrm{h}_{\mathrm{f}}-\mathrm{h}_{\mathrm{i}}}{\mathrm{h}_{\mathrm{fg}}} & \text { Enthalpy difference to saturation, relative to } \mathrm{h}_{\mathrm{fg}} . \\ \text { FS01 } & \mathrm{F}_{\mathrm{s}_{01}} & \begin{array}{l}\text { Fraction of energy invested in voids at the entrance of the } \\ \text { node. See App. B3 }\end{array} \\ \text { FS02 } & \mathrm{F}_{\mathrm{s}_{02}} & \begin{array}{l}\text { Fraction of energy invested in voids at the exit of the node. } \\ \text { FPH1 }\end{array} \\ \mathrm{F}(\phi) & \begin{array}{l}\text { Heat flux dependent factor for the calculation of the bubble } \\ \text { lifetime in the SBR. See App. B4. }\end{array}\end{array}$


In the next page:

NNB

NSB

NBB

QAV

WO

UO

KFNB

LAMO

TAUK

C17

TZNB

ZNB

ZB

ZBB

IZNB

IZB

IZBB

HZNB

DELTAH

RHOZNB

RHOLB

CPSB

CPSAT

CPAVG

OMEGA

DOMDY0

H02LAST $\mathrm{q}_{\mathrm{av}}\left(\mathrm{cal} / \mathrm{cm}^{2} \mathrm{~s}\right)$

$\omega_{\mathrm{o}}(\mathrm{g} / \mathrm{s})$

$\mathrm{u}_{\mathrm{o}}(\mathrm{cm} / \mathrm{s})$

$\mathrm{k}_{\mathrm{fnb}}$

$\lambda_{\mathrm{o}}\left(\mathrm{s}^{-1}\right)$

$\tau_{\mathrm{k}}(\mathrm{s})$

$\mathrm{T}_{\mathrm{z} 1}\left({ }^{\circ} \mathrm{C}\right)$

$\mathrm{z}_{\mathrm{nb}}=\mathrm{z}_{1}(\mathrm{~cm})$

$\mathrm{z}_{\mathrm{b}}=\mathrm{z}_{2}(\mathrm{~cm})$

$\mathrm{z}_{\mathrm{bb}}(\mathrm{cm})$

$\mathrm{E}_{\mathrm{i}_{\mathrm{z} \mathrm{nb}}}$

$\mathrm{E}_{\mathrm{i}_{\mathrm{b}}}$

$\mathrm{E}_{\mathrm{i}_{\mathrm{zb}}}$

$\mathrm{h}_{\mathrm{z}_{\mathrm{nb}}}(\mathrm{cal} / \mathrm{g})$

$\Delta \mathrm{h}(\mathrm{cal} / \mathrm{g})$

$\rho_{\mathrm{z}_{\mathrm{nb}}}\left(\mathrm{g} / \mathrm{cm}^{3}\right)$

$\rho\left(\mathrm{g} / \mathrm{cm}^{3}\right)$

$\mathrm{c}_{\mathrm{p}_{\mathrm{sb}}}\left(\mathrm{cal} / \mathrm{g}^{\circ} \mathrm{C}\right)$

$\mathrm{c}_{\mathrm{p}_{\mathrm{sat}}}\left(\mathrm{cal} / \mathrm{g}^{\circ} \mathrm{C}\right) \mathrm{Sp}$

$\mathrm{c}_{\mathrm{p}_{\text {avg }}}\left(\mathrm{cal} / \mathrm{g}{ }^{\circ} \mathrm{C}\right)$

$\Omega$

$\left(\frac{\partial \Omega}{\partial y}\right)_{o}$

$\mathrm{H}_{02}$
Number of nodes in the nonboiling region (NBR).

Number of nodes in the subcooled boiling region (SBR).

Number of nodes in the bulk boiling region (BBR).

Average heat flux rate in the channel.

Total mass flow rate through the channel.

Volumetric flow rate per unit area (fluid velocity) in the channel at saturated liquid density equivalent mass.

Crude friction factor multiplier for the NBR.

Parameter for the calculation of the mean lifetime of the bubbles in the subcooled boiling region.

Node transient time corresponding to the stream density equivalent mass fluid velocity.

Bulk boiling boundary subcooling to void transformation factor.

Temperature of the water at the subcooled boiling boundary (SBB).

Position of the SBB.

Position of the boiling boundary if subcooled boiling did not occur.

Position of the bulk boiling boundary (BBB).

Fraction of power deposited in the coolant in the NBR.

Fraction of bundle power invested in heating the water to saturation temperature.

Fraction of power deposited in the coolant below the BBB.

Enthalpy of the water at the SBB.

Enthalpy increment in the NBR.

Density of water at the SBB.

Average density of water below the BBB.

Specific heat of water at the average temperature of the NBR.

Specific heat of water at saturation temperature.

Average specific heat of water in the NBR.

Jones correction factor to the Martinelli-Nelson two-phase friction multiplier. See App. B6.

Slope of the Jones factor vs flow rate relation.

Degree of subcooling, relative to $\mathrm{h}_{\mathrm{fg}}$, at the exit of the last subcooled boiling node. 


$\begin{array}{ll}\text { FNB } & \mathrm{f}_{\mathrm{nb}} \\ \text { FSB } & \mathrm{f}_{\mathrm{sb}} \\ \text { FBB } & \mathrm{f}_{\mathrm{bb}} \\ \text { A2NB } & \mathrm{a}_{2_{\mathrm{nb}}} \\ \text { A2SB } & \mathrm{a}_{2_{\mathrm{sb}}} \\ \text { A2BB } & \mathrm{a}_{2_{\mathrm{bb}}} \\ \text { RE(T0) } & \mathrm{Re}_{\mathrm{T}_{0}} \\ \text { RE(TSAT) } & \mathrm{Re}_{\mathrm{T}_{\mathrm{sat}}} \\ \text { EKFL } & \mathrm{k}_{\mathrm{f}}\end{array}$

Moody single-phase friction coefficient in the NBR.

Moody single-phase friction coefficient in the SBR.

Moody single-phase friction coefficient in the BBR. Reynolds number exponent for the nonboiling region.

Reynolds number exponent for the SBR.

Reynolds number exponent for the BBR.

Reynolds number for the fluid at temperature $\mathrm{T} 0$.

Reynolds number for the fluid at temperature TSAT.

Surface friction factor multiplier for those nodes in the boiling region.

In the next output page, the results of the solution of the momentum equation are printed in self-explanatory fashion.

\section{- FLOW}

$\mathrm{M}$

QPL

WTP

IX

$\mathrm{NCH}$

POWFR

$\begin{array}{lr}\text { QG } & \left(\mathrm{g} / \mathrm{cm}^{2} \mathrm{~s}\right) \\ \text { QX } & \\ \text { QP } & \left(\mathrm{kg} / \mathrm{cm}^{2}\right) \\ \text { WN0 } & (\mathrm{g} / \mathrm{s}) \\ \text { POWT } & \end{array}$

- FUEL

$\begin{array}{ll}\text { I } & \mathrm{i} \\ \text { NFU } & \\ \mathrm{P} & (\mathrm{cal} / \mathrm{s} \mathrm{cm}) \\ \text { T } & \left({ }^{\circ} \mathrm{C}\right) \\ \text { K } & \left(\mathrm{cal} / \mathrm{s} \mathrm{cm}^{\circ} \mathrm{C}\right) \\ \text { RHOCF } & \left(\mathrm{cal} / \mathrm{cm}^{3}{ }^{\circ} \mathrm{C}\right) \\ \text { CAP } & \left(\mathrm{cal} / \mathrm{cm}^{\circ} \mathrm{C}\right) \\ \text { RES } & \left(\mathrm{s} \mathrm{cm}^{\circ} \mathrm{C} / \mathrm{cal}\right)\end{array}$

Flow redistribution iteration number.

Average pressure drop in the channels (slope-weighted).

Total core flow rate.

Channel type number.

Number of channels of a type in the core.

Power fraction of the core total that is generated in one channel.

Channel mass flow rate.

Channel exit steam quality.

Channel pressure drop.

Mass flow rate in a channel region.

Nominal power generated in the core.

Vertical node number.

Cross-sectional fuel ring zone number.

Power generated in a ring per unit length.

Fuel temperature at the center of the ring.

Fuel thermal conductivity.

Specific heat of the fuel.

Heat capacity per unit length of fuel.

Thermal resistance. The last ring includes the gap and the inner half of the clad. See Eq. (3.2.17). 


\begin{tabular}{|c|c|c|}
\hline ALP & a) & \\
\hline BET & $\beta\}$ & Parameters for the transient analysis. See Eq. (3.2.42). \\
\hline GAM & $\gamma]$ & \\
\hline PTP & $(\mathrm{cal} / \mathrm{s} \mathrm{cm})$ & $\begin{array}{l}\text { Total power generated in the node that is transmitted to the } \\
\text { coolant by convection. }\end{array}$ \\
\hline TC & $\left({ }^{\circ} \mathrm{C}\right)$ & Temperature at the center of the clad. \\
\hline TG & $\left({ }^{\circ} \mathrm{C}\right)$ & Temperature of the gap. \\
\hline TAV & $\left({ }^{\circ} \mathrm{C}\right)$ & Fuel average temperature. \\
\hline RFUEL & & Average thermal resistance of the fuel. \\
\hline RGAP & & Thermal resistance of the gap. \\
\hline RCLD1 & & Thermal resistance of the inner half of the clad. \\
\hline RCLD2 & & Thermal resistance of the outer half of the clad. \\
\hline EPSW & & $\begin{array}{l}\text { Effect of the film coefficient on the thermal conductance of the } \\
\text { outer half of the clad and water film. See Eq. (3.2.34). }\end{array}$ \\
\hline EPSY & & $\begin{array}{l}\text { Effect of the flow rate on the convective heat transfer } \\
\text { coefficient. See Eq. (3.2.36). }\end{array}$ \\
\hline
\end{tabular}

\section{- COEFR}

The output of this subroutine if performed by OUTCOR:

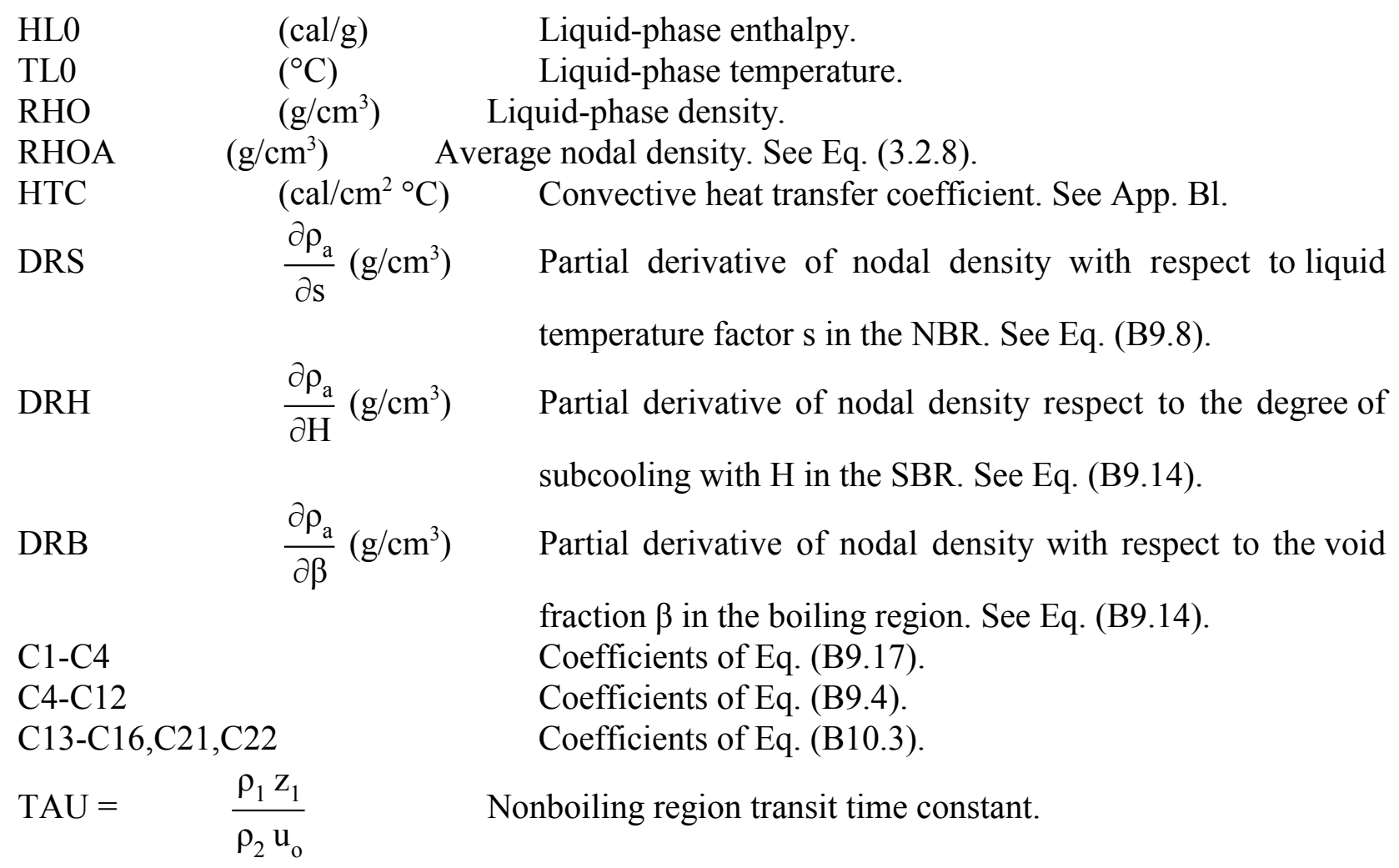



$\mathrm{TAUA}=\quad \frac{\Delta \mathrm{z}_{\mathrm{i}}}{2 \mathrm{u}_{\mathrm{o}}}$
Nodal transit time constant. See Eq. (B9.17).
$\mathrm{TAUL}=\quad \mathrm{C}_{18} \tau_{\mathrm{NBR}}$
Pressure differential between inlet plenum and boiling boundary time constant. See Eq. (B10.2b). Note that $\tau_{\mathrm{NBR}}=$ TAUIP $(\mathrm{DZ}=\mathrm{z})$.

TAUIP

$\mathrm{C} 17$

$\mathrm{C} 18$

$$
\frac{\mathrm{u}_{\mathrm{o}} \Delta \mathrm{z}_{\mathrm{i}}}{\mathrm{g} \mathrm{L}}
$$

Nodal momentum transfer time constant. See Eq. (B10.2a).

Enthalpy to void transfer function at the boiling boundary. See Eq. (B9.22b).

Flow to pressure drop from plenum to the boiling boundary gain coefficient. See Eq. (B10.2b).

\subsection{ALPHABETICAL DESCRIPTION OF THE SUBROUTINES OF LAPURW}

\section{Subroutine ANGLE}

Called from: PRINTA, PRINTB and RESPON.

Input:

$$
\begin{aligned}
& \text { Arguments: } \mathrm{A} \equiv \text { imaginary number, } \\
& \mathrm{B} \equiv \text { real number, } \\
& \mathrm{C} \equiv \text { angle in the range } \pm 90, \\
& \mathrm{IFLG} \equiv \text { quadrant flag, } \\
& \mathrm{ICOUNT} \equiv \text { counter, } \\
& \mathrm{I} \equiv \text { number of vectors to be printed in a row. }
\end{aligned}
$$

Performs: $\quad$ Calculation of the true angle in degrees defined by $\mathrm{A}$ and $\mathrm{B}$. The vectors IFLG, ICOUNT, and I are used to track the displacement of the vector pointer defined by A and $B$ in the plane $(R, I m)$ as the subroutine is called repeatedly. The purpose is to account for crossings of the imaginary axis by the pointer. It adjusts $\mathrm{C}$ by adding $180^{\circ}$ when the pointer moves clockwise, and by subtracting $180^{\circ}$ when it moves counterclockwise.

Output: $\quad$ Argument: $\mathrm{C} \equiv$ corrected angle.

\section{Subroutine COEFIW}

\section{Called from: TRANS.}

Input: $\quad$ (i) Arguments: IX $\equiv$ channel index number,

$$
\mathrm{CSS} \equiv \text { complex driving perturbation. }
$$

(ii) COMMONS: INPT, REDY, SETP, PRPR, BNDY, NOHD, NOHD2, BOIL, BOIL2, CEFR, CEFR2, FEEL.

Performs: Calculation of the frequency-dependent coefficients needed to solve the thermohydrodynamic equations.

Output: $\quad$ COMMON: CEFI. 


\section{Subroutine COND}

Internal routine called from: COUPXS, DIF, JOSELE, PEPE.

\section{Subroutine CONSIS}

Internal routine called from: RESPON, SEARCH

\section{Subroutine COUPXS}

Internal routine called from: WEIGHT

\section{Subroutine DBDEG}

Called from: STABGH.

Input:

$$
\text { Arguments: } \begin{aligned}
& \mathrm{X} \equiv \text { real part vector, } \\
& \mathrm{Y} \equiv \text { imaginary part vector, } \\
& \mathrm{N} \equiv \text { length of the vectors } \mathrm{X}, \text { and } \mathrm{Y} .
\end{aligned}
$$

Performs: Determination of the magnitude in decibels and phase in degrees of the complex number $\mathrm{X}+\mathrm{jY}$.

Output: $\quad$ Arguments: $\quad \mathrm{AMAG} \equiv$ magnitude in decibels,

$$
\mathrm{PH} \equiv \text { phase in degrees. }
$$

\section{Subroutine DIF}

Internal routine called from: JOSELE

\section{Subroutine DRUMRI}

Called from: WEIGHT and TRANS.

Input: $\quad$ IX $\equiv$ channel number index.

Performs: $\quad$ Sequential reading of the coolant steady state parameter map of a channel into the COMMON statements listed below. This subroutine is the read equivalent to DRUMWl in LAPURX.

Output: $\quad$ COMMONS: SETP2, SETP, PRPR2, PRPR, BNDY, NOHD, NOHD2, BOIL, BOIL2, BALK, FRCT2, FRCT, DLTP, PRPI2, PRPI, OMGP2, OMGP, CEFR, CEFR3, CEFR2, REACOE.

\section{Subroutine DRUMR2}

Called from: MAIN.

Input:

Performs: $\quad$ Sequential reading of steady state data into the COMMON areas listed below. This subroutine is the read equivalent to the write subroutine DRUMW2 in LAPURX.

Output: $\quad$ COMMONS: IIOP1, DATA, INPT, INPT2, REDY2, REDY, ADD.

\section{Subroutine DRUMR3}

Called from: TRANS.

Input: $\quad$ IX $\equiv$ channel number index.

Performs: $\quad$ Sequential reading of the fuel steady state parameter map into the COMMON areas listed below. This subroutine is the read equivalent to DRUMW3 in LAPURX. 
Output: $\quad$ COMMONS: ADIN, FUL, FULIX.

Subroutine DRUMW3

Called from: TRANS

Input: $\quad$ (i) Argument: IX.

(ii) COMMONS: ADIN, FUL, FULIX.

Performs: $\quad$ Saving out-of-core of the thermal parameters of the fuel rods within a channel for subsequent use in the dynamics calculations.

Output: $\quad$ Logical unit 1: Sequential unformatted writing of the COMMON statements listed above.

\section{Subroutine FREQ}

Called from: TRANS.

Input: $\quad$ IX $\equiv$ channel type index,

$\mathrm{CSS} \equiv$ complex driving perturbation,

PSIA $\equiv$ reactivity weighting factors array,

DKDRHO $\equiv$ density reactivity coefficients array,

$\mathrm{CDYPB} \equiv$ complex driving flow rate perturbation,

$\mathrm{CDRAMB} \equiv$ complex driving power generation perturbation,

CDTIN $\equiv$ complex driving coolant temperature perturbation,

IW $\equiv$ frequency index number,

$\mathrm{JJJ} \equiv$ flag,

MX $\equiv$ maximum number of channel types,

$\mathrm{MP} \equiv$ maximum number of thermohydraulic nodes,

$\mathrm{MJ} \equiv$ maximum number of subcores in a horizontal plane.

COMMONS: DOPP, REACOE, NODS, INPT, REDY, SETP2, SETP, BNDY, BOIL, BOIL2, CEFR, CEFR2, FEEL, CEFI, ADD1.

Performs: (i) Solves the continuity and energy equations for the coolant at each node along the channel. As indicated in the response of the nodal mass flow rate, liquid temperature and void fraction (hence, density) to the driving perturbations are calculated.

(ii) The nodal density perturbations are multiplied by the reactivity coefficients and weighting factors to yield reactivity contribution of each subcore.

(iii) The momentum equations are subsequently solved to generate the channel pressure transfer functions.

(iv) The response of the average temperature of the fuel is determined by means of Eq. (3.2.43). Subsequently, multiplication by the Doppler reactivity coefficient and weighting factors produces the Doppler reactivity T.F.s.

Output. (i) Argument: CDROA $\equiv$ coolant density response map.

(ii) COMMONS: FRIQ, FEL2.

\section{Subroutine FUEL}

Called from: TRANS

Input: $\quad$ (i) Argument: IX. 
(ii) COMMONS: DATA, INPT, SETP, SETP2, PRPR, BNDY, NOHD, CEFR, CEFR3, ADIN, ADD1, IIOP1.

Performs: (i) Calculation of the temperature distribution across the fuel element at every node as described in the fuel steady state calculation (paragraph 3.2.2.1).

(ii) Calculation of the parameters $\alpha, \beta$, and $\gamma$ for the dynamics analysis as described in Eq. (3.2.42).

(iii) Saving into common FEL1 the characteristics of up to 10 vertical nodes as specified by NFPRT at input time.

Output: $\quad$ (i) COMMONS: TFUEL1, FUL, FEL1, FULIX.

(ii) Logical unit 6: Error message 3.

\section{Subroutine FUELW}

Called from: TRANS.

Input:

(i) Arguments: IX $\equiv$ channel type index number,

$\mathrm{CSS} \equiv$ complex driving perturbation's frequency.

(ii) COMMONS: INPT, BNDY, NOHD, CEFR3, ADIN, ADD1, FUL, FULIX.

Performs: $\quad$ Solution of fuel dynamics equations, as described in paragraph (3.2.23), for three unity driving perturbations of power generation, coolant flow rate, and coolant temperature, one at a time. This subroutine yields the set of fuel transfer functions $a_{q}, b_{q}, c_{q}$ and $a_{T}$, $\mathrm{b}_{\mathrm{T}}, \mathrm{c}_{\mathrm{T}}$ for each node along the channel, as described in paragraph (3.2.3).

Output: $\quad$ COMMONS: FEEL, FEL2.

\section{Subroutine INCROD}

Called from: INPUTW

Input:

Performs: $\quad$ Reading of control-rod data when cross sections are specified

Output:

\section{Subroutine INPUTW}

Called from: MAIN.

Input: $\quad$ Logical unit 5.

Performs: $\quad$ Reading of the data that specify the dynamic calculation to be performed. The subroutines INPW1, INPW2, INPW3, INPW4, INPW5, and INPW6 are called to input some of the data arrays. Three kinds of information are input: (i) reactor constitution in terms of thermohydraulic channel types, composition of the nuclear subcores; (ii) neutronic parameters; and (iii) output options.

Output: (i) COMMONS: TITLEW, INOUT, NNNNN, TESTSU, DOPP, RELOOP, NNEUTR, XNEUTR, NDENRE, DENRE, WINK, NODS, MPLO.

(ii) Logical unit 6: Error message (self-explanatory).

\section{Subroutine INPWI}

\section{Called from: INPUTW}


Input: $\quad$ NO, NNN

Performs: Reads an array of integers of length $\mathrm{NO}$ in the standard format $8 \mathrm{I} 10$ for the first line and $10 \mathrm{X}, 7 \mathrm{I} 10$ for the continuation lines

Output: $\quad$ NNN

Subroutine INPW2

Called from: INPUTW

Input: $\quad$ NO, NNN, AAA, ID

Performs: Reads a two-dimesional array of floating point variables in the standard format 10X,7E10.5. The row index is input in ID.

Output: $\quad$ AAA(ID, *)

\section{Subroutine INPW3}

Called from: INPUTW

Input: $\quad$ NO, AAA

Performs: Reads an array of floating point variables in the standard format I10,7E10.5 for the first line and 10X,7E10.5 for the continuation lines

Output: $\quad \operatorname{AAA}(*)$

Subroutine INPW4

Called from: INPUTW

Input: $\quad$ MA, I1, I2, N1

Performs: $\quad$ Reads a two dimensional integer array in the standard format 10X,7I10.

Output: $\quad$ MA

\section{Subroutine INPW5}

Called from: INPUTW

Input: $\quad$ MA, I1, I2, I3, N1, N2

Performs: $\quad$ Reads a three dimensional integer array in the standard format 10X,7I10.

Output: $\quad$ MA

\section{Subroutine INPW6}

Called from: INPUTW

Input: $\quad$ A, I1, I2

Performs: $\quad$ Reads a two dimensional real array in the standard format 10X,7E10.5

Output:

Subroutine INXS2G

Called from: INPUTW

Input: none

Performs: Reads the cross section data

Output: $\quad A()$, the cross section coefficients

Subroutine JOSELE 
Called from: REACFA

Input: $\quad$ BETAXS_ IFT, ICT, D

Performs: $\quad$ Computes the void reactivity coefficient

Output: $\quad$ D

Subroutine LIMIT

Called from: MODE2, RESPON

Input: $\quad$ GM, H0

Performs: Estimates the limit cycle amplitude and average power increase given an unstable reactor configuration

Output: $\quad$ PMAX, P0, R0, IER

Subroutine LINEAR

Called from: FTK, FTRC

Input: $\quad \mathrm{X}, \mathrm{Y}, \mathrm{XF}, \mathrm{YF}$

Performs: $\quad$ Performe linear interpolation

Output: $\quad$ Y

Subroutine MARGIN

Called from: MODE2, RESPON, SEARCH, SENS

Input: $\quad \mathrm{GH}, \mathrm{W}, \mathrm{NW}$

Performs: This subroutine estimates the phase and gain margins of an open loop transfer function

Output: $\quad$ PM, WPM, GM, WGM

\section{Subroutine MODE2}

Called from: RESPON

Input: $\quad$ NPAGE

Performs: This subroutine estimates and prints the stability of the first subcritical mode as a function of subcritical reactivity

Output: none

\section{Subroutine NODOS}

Called from: WEIGHT and TRANS.

Input:

(i) Arguments:IX $\equiv$ channel index number,

$\mathrm{X} \equiv$ vector containing the quantity to be integrated over the core volumes, $\mathrm{MX} \equiv$ maximum length of the vector $\mathrm{X}$,

$\mathrm{WE} \equiv$ vector with the integrand weighting factors, $\mathrm{MW} \equiv$ maximum length of the vector $\mathrm{WE}$,

$\mathrm{XAVKJ} \equiv$ zeroed 4 by 10 array, $\mathrm{L}, \mathrm{LL}$, and LLL $\equiv$ flags.

(ii) COMMONS: REDY, BNDY, NOHD, NODS, INPT .

Performs: (i) Calculation of the cores boundaries in terms of the thermohydrodynamic node 
index numbers along a channel.

(ii) Calculation of the power generated in each nuclear core.

(iii) Calculation of the integrals

$$
\int_{V_{\mathrm{ix}, \mathrm{k}}} \mathrm{XW} \mathrm{dV} ; \quad \int_{\mathrm{V}_{\mathrm{ix}, \mathrm{k}}} \mathrm{W} \mathrm{dV} ; \quad \int_{\mathrm{V}_{\mathrm{k}, \mathrm{j}}} \mathrm{X} \mathrm{W} \mathrm{dV} ; \quad \int_{\mathrm{V}_{\mathrm{k}, \mathrm{j}}} \mathrm{W} d \mathrm{~d} \text {; }
$$

and the averaging ratio

where

$$
\frac{\int_{V_{k, j}} X W d V}{\int_{V_{k, j}} W d V}
$$

$\mathrm{V}_{\mathrm{ix}, \mathrm{k}} \equiv$ volume of channel ix within the nuclear core level k,

$\mathrm{V}_{\mathrm{k}, \mathrm{j}} \equiv$ volume of the nuclear core of coordinates $\mathrm{k}, \mathrm{j}$.

The effect of the flags is the following:

If $\mathrm{L} \leq 0 \quad \mathrm{~W}(\mathrm{I})=\mathrm{WE}$ for all $\mathrm{I}=1$ to $\mathrm{MX}$;

$\mathrm{L}>0 \quad \mathrm{~W}(\mathrm{I})=\mathrm{WE}(\mathrm{I})$ for all $\mathrm{I}=1$ to $\mathrm{MX}$;

If $\mathrm{LL} \leq 0$ calculate the core's boundaries and power [steps (i) and (ii)];

$\mathrm{LL} \geq 0 \quad$ perform averaging ratio;

$\mathrm{LL}=\mathrm{N} \equiv$ number of nodes in the boiling region of channel, then the $\mathrm{X}$ array needs to be padded with zeroes and shifted;

If $L L L<0$ the vectors $X$ and WE contain center of node values;

LLL $>0$ the vectors $X$ and WE contain node boundary values;

Output: $\quad$ (i) Argument:

$$
\text { XAVKJ }=\frac{\int_{V_{k, j}} X W d V}{\int_{V_{k, j}} W d V}
$$

(ii) COMMONS: NODS.

\section{Subroutine NODREA}

Called from: TRANS

Input: $\quad$ NBN, IX

Performs: $\quad$ Gets the node numbers where there is a boundary of cross section types

Output:

\section{Subroutine ONECOR}

\section{Called from: TRANS.}

Input: $\quad$ (i) Arguments: IW $\equiv$ frequency index,

I011 $\equiv$ pointer index for direct access file 11 ,

$\mathrm{CSS} \equiv$ complex driving perturbation,

NDG $\equiv$ number of delayed-neutron groups,

ELSTR $\equiv$ effective neutron lifetime, 
$\mathrm{BTF} \equiv$ vector of delayed-neutron fractions,

RAMDA $\equiv$ vector of delayed-neutron lifetimes.

(ii) COMMONS: RCLOOP, INPT, TCHAN.

Performs: (i) Calculation of the forward neutronic reactivity to power T.F.s according to the point kinetics model.

(ii) Calculation of the Doppler and density reactivity T.F.s.

Output: (i) Logical unit 11: Content of the COMMONS: TFCHAN and TFREAC.

(ii) COMMONS: NKINET, TFREAC.

\section{Subroutine OUTFUW}

Called from: RESPON.

Input:

(i) Arguments:IX $\equiv$ channel index number, NPAGE $\equiv$ printed page number, $\mathrm{NFU} \equiv$ number of radial nodes in the fuel pin.

(ii) COMMONS: TITLEW, WINP, OUTF.

Performs: Printing of the fuel transfer functions $\mathrm{a}_{\mathrm{q}}, \mathrm{b}_{\mathrm{q}}, \mathrm{c}_{\mathrm{q}}$ and $\mathrm{a}_{\mathrm{T}}, \mathrm{b}_{\mathrm{T}}, \mathrm{c}_{\mathrm{T}}$ at selected elevations, with the help of the subroutine PRINTA.

Output: $\quad$ Logical unit 6: Fuel T.F.s under the headings CAQ, CAT, CBQ, CBT, CCQ, and CCT as a function of frequency.

Subroutine OUTFUX

Called from: TRANS

Input: $\quad$ IX, NPAGE, NFU

Performs: Prints fuel information

Output:

Subroutine OUTINW

Called from: MAIN.

Activated by: INPWGO $>1$.

Input: $\quad$ COMMON: DATA, TITLEW, INOUT, NNNNN, DOPP, RELOOP, NNEUTR, XNEUTR, NDENRE, DENRE, NODS, WINP, MPLO.

Performs: Print out the input data and transformation of the frequency units from those read $(\mathrm{Hz})$ to the working units $(\mathrm{rad} / \mathrm{s})$.

Output: $\quad$ Logical unit 6: Check print of the data read by the subroutine INPUT.

\section{Subroutine PRINTA}

Called from: OUTFUW, WDSKPR.

Input:

$$
\begin{array}{ll}
\text { Arguments: } & \mathrm{IW} \equiv \text { frequency index number, } \\
\mathrm{W} \equiv \text { frequency vector in } \mathrm{rad} / \mathrm{s}, \\
\mathrm{CA} \equiv \text { complex vector, } \\
\mathrm{CB} \equiv \text { complex vector, } \\
\mathrm{IFLG} \equiv \text { quadrant flag, } \\
\mathrm{COUNT} \equiv \text { counter. }
\end{array}
$$


Performs: Calculation of the magnitude and phase in decibels and degrees, respectively, of the elements of the two vectors $\mathrm{CA}$ and $\mathrm{CB}$ prior to printing them as a function of frequency in hertz. Flags IFLG and ICOUNT track the quadrant to which an element of the vector belongs so that the subroutine ANGLE can decide the angle that corresponds to the next element of the vector.

Output: $\quad$ Logical unit 6: Frequency, real part, imaginary part, magnitude (in $\mathrm{dB}$ ), and phase (in $\mathrm{deg}$ ) of the three vectors $\mathrm{W}, \mathrm{CA}$, and CB.

\section{Subroutine PRINTB}

Called from: RESPON

Input:

$$
\begin{array}{ll}
\text { Arguments: } & \text { IW } \equiv \text { frequency index number, } \\
& \mathrm{W} \equiv \text { frequency vector in } \mathrm{rad} / \mathrm{s}, \\
\mathrm{CA} \equiv \text { complex vector, } \\
\mathrm{CB} \equiv \text { complex vector, } \\
\mathrm{CC} \equiv \text { complex vector. }
\end{array}
$$

Produces: Printing of the four vectors $\mathrm{W}, \mathrm{CA}, \mathrm{CB}$, and CB similarly to PRINTA.

Output: $\quad$ Logical unit 6: Magnitude (in $\mathrm{dB}$ ) and phase (in deg) of vectors $\mathrm{CA}, \mathrm{CB}$, and $\mathrm{CC}$ as a function of frequency $\mathrm{W}$ in hertz.

\section{Subroutine REACFA}

Called from: TRANS.

Input: $\quad$ (i) Arguments: $\mathrm{IX} \equiv$ channel type index,

$\mathrm{NBN} \equiv$ total number of thermohydraulic nodes in the channel,

RHOA $=\rho_{\mathrm{a}} \equiv$ map of average nodal coolant density in the channel, RHOL $=\rho_{2} \equiv$ coolant density at saturation temperature.

(ii) COMMONS: NNNNN, NDENRE, DENRE, NODS.

Performs: Determination of the core map of density reactivity coefficients by means of the function COEF and subroutine JOSELE operating on the input data tables.

Output: Argument: DKDRHO (IX, I, IJ) $\equiv$ map of density reactivity coefficients for channel type IX in horizontal nuclear core region IJ.

\section{Subroutine RECIRC}

Called from: TRANS.

Input: $\quad$ (i) Argument: CSS $\equiv$ complex driving perturbation.

(ii) COMMONS: RCLOOP, TFCHAN.

Performs: $\quad$ Calculation of the recirculation loop transfer functions as indicated in Eq. (3.3.22).

Output: $\quad$ COMMONS: RCLOOP

\section{Subroutine RESPON}

Called from: MAIN.

Input: $\quad$ (i) Arguments: NPACE $\equiv$ output printed page number,

$\mathrm{NK} \equiv$ number of cores in the vertical direction,

$\mathrm{NJ} \equiv$ number of cores in the horizontal plane, 
$\mathrm{NFU} \equiv$ number of radial nodes within the fuel pin,

$\mathrm{NXE} \equiv$ number of channel types.

(ii) COMMONS: WINP, ADIN, OUTF, TITLEW, NKINET, MPLO.

(iii) Direct access logical units 10, 11, and 12.

Performs: $\quad$ Management of the output of the program.

(i) It takes the information stored on the on-line direct access disk and prints it in an orderly manner.

(ii) Calls the stability analysis routine STABGH to calculate the natural frequency and decay ratio of the flow channels and the core.

\section{Subroutine SEARCH}

Called from: MAIN

Input: $\quad$ NPAGE

Performs: $\quad$ Searches for the position of the complex pole in the full complex plane by iteration and prints the results.

Output: $\quad$ none

\section{Subroutine SENS}

Called from: RESPON

Input: $\quad$ NPAGE

Performs: This subroutine recomputes the reactivity to power transfer function and estimates and prints the decay ratio for various values of density reactivity coefficient, and recirculation loop parameters

Output: $\quad$ none

\section{Subroutine SPLIN}

Called from: STABGH

Input:

Performs: $\quad$ Spline interpolation

Output:

\section{Subroutine STABGH}

Called from: MODE2, RESPON, SEARCH, SENS.

Input: (i) Arguments: IOPT $\equiv$ flag,

IXGHF $\equiv$ channel type number,

NPAGE $\equiv$ print out page number,

$\mathrm{XGH} \equiv$ open-loop T.F.

(ii) COMMONS: WINP, MPLO.

Performs: The stability analysis of the system represented by the open-loop transfer function $\mathrm{XGH}$. Smith's method is used to infer the decay ratio and natural frequency as described in ref. 6, pp. 120-128. A third order Lagrange interpolation scheme is used to calculate the distance to the $(-1,0)$ point and subsequently to generate smooth plots. IOPT $=1$ indicates that the stability analysis corresponds to that of a channel. IOPT 
$=0$ corresponds to the whole core power stability.

Output: $\quad$ (i) Logical unit 6: Under the heading ***STABGH*** the results of the stability assessment are printed.

(ii) COMMONS: MAGPH, ZXYW, GHDBDG.

\section{Subroutine TRANS}

Called from: MAIN, SEARCH.

Input: $\quad$ (i) Argument: NPAGE $\equiv$ printed output page number.

(ii) COMMONS: NNNNN, DOPP, NNEUTR, NDENRE, DENRE, WINP, RCLOOP, NKINET, NODS, INPT, INPT2, REDY2, REDY, SETP.

(iii) Subroutines: DRUMR1, DRUMR3.

Performs: (i) Definition of direct access files 10,11, and 12, and zeroing of some arrays.

(ii) Management of the frequency domain dynamic calculations.

First, the reactivity weighting factors for each of the cores are calculated by the auxiliary subroutine WEIGHT. Second, a big loop is opened to sequentially solve all the dynamic equations for one particular frequency at a time. After storing the calculated T.F. in the three direct access files, the loop is repeated for a new frequency.

The solution of the dynamic equations for a particular frequency proceeds as follows: (i) The steady state coolant and fuel parameters corresponding to a particular channel are read from the intermediate storage device by means of the subroutines DRUMR1 and DRUMR3.

(ii) Based on the steady state coolant density map and the input reactivity coefficients, the weighted reactivity factor map is generated by subroutine REACFA.

(iii) Based on the steady state fuel parameters, the fuel dynamic equations are solved by means of FUELW for the current channel type and frequency. This yields the fuel transfer functions $\mathrm{a}_{\mathrm{q}, \mathrm{T}} \mathrm{b}_{\mathrm{q}, \mathrm{T}}$, and $\mathrm{c}_{\mathrm{q}, \mathrm{T}}$ described in paragraph (3.2.2).

(iv) Prior to the solution of the coolant dynamic equations, a set of frequency-dependent coefficients based on the steady state calculation is generated by means of the subroutine COEFIW.

(v) The thermohydrodynamic equations of the coolant are solved sequentially at each of the nodes along the channel by means of the subroutine FREQ. This subroutine determines a map of the response of coolant density, density reactivity, Doppler reactivity, and pressure drop to driving perturbations of (1) channel inlet flow rate, (2) inlet coolant temperature, and (3) power generation at any specific point along the channel. To this effect, the solution of the thermohydraulic equation is repeated several times. Unity driving perturbations of inlet flow rate, power generation in the segment of channel length within the boundaries of each nuclear core, and coolant inlet temperature are considered one at a time while the rest of the independent parameters are kept equal to zero. This process yields the set of channel T.F.s in paragraph 3.2.5. Note that steps (i) through (vi) are repeated for each one of the channel types. 
(vi) Taking into consideration the lower plenum flow boundary condition, the flow redistribution impedances in paragraph 3.3.4 are calculated, that is, the particular driving perturbation-to-particular channel flow rate T.F., for each of the following perturbations: total core flow rate, inlet plenum temperature, and power perturbation in any of the nuclear cores.

(vii) The reactivity feedback T.F.s [Eqs. (3.3.11) and (3.3.12)] are next determined for each of the nuclear cores.

(viii) By means of the subroutine RECIRC and based on the input dynamic characteristics, the recirculation loop T.F.s are determined. They provide the link between the three driving perturbations mentioned.

(ix) By means of the subroutine ONECOR the forward neutronic T.F. is determined.

(x) By combining the neutronic and feedback T.F.s the openand closed-loop T.F.s are obtained.

Output: $\quad$ Logical unit 10 direct access: Channels fuel and coolant T.F.s.

Logical unit 11 direct access: Point kinetics T.F.

Logical unit 12 direct access: Multicore T.F.

\section{Subroutine WDSKGH}

Called from: RESPON.

Input: $\quad$ Arguments: $\quad \mathrm{NW} \equiv$ number of frequencies,

$\mathrm{NF} \equiv$ direct access file number,

NOR $\equiv$ position of the pointer,

NRECL $\equiv$ number of records separating the values of a T.F. for two consecutive frequencies.

Performs: $\quad$ Picks from the specified file all of the values pertaining to the T.F. of interest.

Output: $\quad$ Argument: $\mathrm{X} \equiv$ vector with the T.F. of interest.

\section{Subroutine WDSKPR}

Called from: RESPON.

Input:

Arguments: $\quad \mathrm{W} \equiv$ vector of frequencies in $\mathrm{rad} / \mathrm{s}$,

$\mathrm{NW} \equiv$ number of frequencies,

KMOD2 $\equiv$ flag,

$\mathrm{NF} \equiv$ file number,

$\mathrm{NR} \equiv$ pointer position,

NRECF $\equiv$ number of records separating two consecutive frequencies of the same T.F. in the disk file,

NDEL $\equiv$ number of records separating the two T.F.s to be printed on the same line.

Performs: $\quad$ Selectively picks the data stored in the direct access file and prints two T.F.s as a function of frequency by means of PRINTA. Since PRINTA requires two T.F.s when only one T.F. needs to be printed out, KMOD2 $\equiv 0$, and thus the second T.F. is printed as zero.

Output: $\quad$ Through PRINTA the content of the direct access file address by the pointer. 


\section{Subroutine WEIGHT}

\section{Called from: TRANS.}

Input:

(i) Argument: ALPKJ $\equiv$ ratio of total core to individual nuclear core.

Performs: $\quad$ (i) Prior normalization of the input power shapes; the map of power squared nodal weighting factors is determined.

(ii) By means of the subroutine NODOS, the power and power squared quantities corresponding to each nuclear core are calculated.

(iii) The ratio,

$$
\operatorname{ALPKJ}=\alpha_{k, j}=\frac{\int_{V_{T}} \Phi^{2} d V}{\int_{V_{k, j}} \Phi^{2} d V}
$$

where $\mathrm{V}_{\mathrm{T}}$ and $\mathrm{V}_{\mathrm{k}, \mathrm{j}}$ are the total and core "k,j" volumes, respectively, is determined. Note, $\mathrm{k}$ and $\mathrm{j}$ are the vertical and horizontal subcore position indices.

Qutput: (i) Argument: ALPKJ.

(ii) COMMONS: NODS, REACWT.

\section{Function Subroutine BESSI $(N, X)$}

Arguments: $\quad \mathrm{N} \equiv$ order of the modified Bessel function, $\mathrm{X} \equiv$ argument.

Output: $\quad$ The value of $\mathrm{I}_{\mathrm{N}}(\mathrm{X})$, the modified Bessel function of order $\mathrm{N}$, for the argument $\mathrm{X}$. The algorithm used is valid for $\mathrm{N}<3000$ and $\mathrm{X}<87$. In the program, the subroutine FUEL uses the $\mathrm{N}=0$, that is, $\mathrm{I}_{0}(\mathrm{X})$, function to represent the radial distribution of the power generation within the fuel pellets.

\section{Function Subroutine BIMAG}

Arguments: $\quad X \equiv$ magnitude in decibels, $\mathrm{Y} \equiv$ phase in degrees.

Output: $\quad$ Imaginary component of the vector defined by $\mathrm{X}$ and $\mathrm{Y}$.

\section{Function Subroutines BREAL}

Arguments: $\quad \mathrm{X} \equiv$ magnitude in decibels, $\mathrm{Y} \equiv$ phase in degrees.

Output: $\quad$ Real component of the vector defined by $\mathrm{X}$ and $\mathrm{Y}$.

\section{Function Subroutine COEF}

Called from: REACFA.

Input: $\quad$ Arguments: $\quad \mathrm{RA} \equiv$ ordinate;

$\mathrm{NR} \equiv$ number of points in the table, i.e., length of DR and RT;

$\mathrm{DR} \equiv$ vector with the ordinates of the data points;

$\mathrm{RT} \equiv$ vector with the abscissas of the data points.

Performs: $\quad$ Lagrange interpolation of the table defined by the vectors (DR, RT) to generate the 
value that corresponds to the ordinate RA.

Output: $\quad \mathrm{COEF} \equiv$ ordinate corresponding to RA in the table (DR, RT).

Function Subroutine EXP10

Argument: $X \equiv$ a real number.

Output: $\quad$ The value EXP10 $=10^{\mathrm{X}}$.

Function Subroutine FTDKDT(T)

Argument: $\mathrm{T} \equiv$ temperature in ${ }^{\circ} \mathrm{C}$.

Output: $\quad$ The temperature derivative of the heat conductivity of the $\mathrm{UO}_{2}$ fuel pellet. It is based on the correlation used in the subroutine FTK.

Function Subroutine FTK(T)

Internal routine called from: FTDKDT, FUEL

Function FTRC (RHOF_,T)

Internal routine called from: FUEL

Double Precision Function SEVAL(N, $U, X, Y, B, C, D)$

Internal routine called from: STABGH

\subsection{PREPARATION OF INPUT FOR LAPURW}

\subsubsection{Introduction}

Data are read in from logical unit 5 by the subroutine INPUTW. The input deck consists of a title card, data set cards, and a last card. The title card can contain up to 72 characters. These characters will be printed on each page of output for identification convenience.

Each data set is preceded by an ID card that identifies the set. The data sets need not be read in sequence, but the following should be considered: set 1 must be read before any other set except for sets $4,17,21$, and 26 ; the sets within the groups $(5,6,7,8),(9,10),(11,12),(15,16)$, and $(18,19$, $20,21)$ must be read in order.

A 11 ID cards carry their number in format I4. All of the numbers are right justified.

The last card is equivalent to an ID number equal to zero, thus a 0 in column 4 will terminate the input and initialize the execution of the program.

When the run is finished, a new title card is sought by the subroutine INPUTW. If the end-of-data is found in logical unit 5, then the execution stops; otherwise, a new case will be input and run. Note that for consecutive runs, only those data sets that change need to be entered. 
Because the dynamic equations solved by LAPURW are based on linearization about the steady state conditions calculated by LAPURX, the compatibility with the input of LAPURX must be kept in mind when preparing input for LAPURW.

The link to LAPURX consists of sequential unformatted reading from the intermediate storage device into the appropriate COMMON areas. Provisions for the correct files to be accessible through logical units 1 and 2 must be made.

\subsubsection{Input Description}

\subsubsection{First Card}

Title ... columns 1 through 72 .

\subsubsection{Data Cards}

Each data set is preceded by a card containing only the ID in format (I4).

Description of the data sets:

\begin{tabular}{|c|l|l|l|}
\hline $\begin{array}{c}\text { Data set } \\
\text { ID No. }\end{array}$ & FORTRAN symbols & Format & Comment \\
\hline 1 & NX, NJ, NK & 315 & $\begin{array}{l}\text { NX } \leq \\
\text { NCHMAX } \\
\text { NJ }=1 \\
\text { NK }=1\end{array}$ \\
\hline
\end{tabular}

NX Number of regions within which the fuel channels can be assumed thermohydraulically equal. Hence, only NX representative channel types need to be analyzed in detail.

Note that NX has the same value as NXE in the LAPURX steady state run. NJ Number of nuclear subcores in a horizontal plane.

NK Number of nuclear subcores in the vertical direction.

Note that NJ x NK $\equiv$ total number of nuclear subcores in which the reactor core assembly is mathematically partitioned for analysis purposes.

\begin{tabular}{|l|l|l|l|}
\hline 2 & $((\mathrm{NCHXJ}(\mathrm{IX}, \mathrm{IJ}), \mathrm{IX}=1, \mathrm{NX}), \mathrm{IJ}=1, \mathrm{NJ})$ & $10 \mathrm{X}, 7 \mathrm{I} 10$ & \\
\hline
\end{tabular}

$\mathrm{NCHXJ}(\mathrm{IX}, \mathrm{IF})$

Number of channels of type IX present in the horizontal nuclear mesh of index IJ.

Note that $\mathrm{SUM}(\mathrm{NCHXJ}(\mathrm{IX}, \mathrm{IJ})$ for $\mathrm{IJ}=1, \mathrm{NJ})=\mathrm{NCH}(\mathrm{IX})$ in LAPURX. 


\begin{tabular}{|l|l|l|l|}
\hline 3 & $(\mathrm{ZK}(\mathrm{IK}), \mathrm{IK}=1, \mathrm{NK})$ & $10 \mathrm{X}, 4 \mathrm{E} 10.5$ & \\
\hline
\end{tabular}

ZK(IK) (cm) Elevation, from the bottom of the core, of the upper boundary plane of the vertical nuclear mesh of index IK.

\begin{tabular}{|l|l|l|l|}
\hline 4 & TAUPY, GAINPY & $10 \mathrm{X}, 2 \mathrm{E} 10.5$ & \\
\hline
\end{tabular}

TAUPY $\quad\left(\mathrm{s}^{-1}\right) \quad$ Time constant of the pressure to flow recirculation loop T.F.

GAINPY Gain of the T.F. mentioned above.

\begin{tabular}{|c|l|l|l|}
\hline 5 & NNEUT, NDG & $2 \mathrm{I} 5$ & $\begin{array}{l}\text { NNEUT } \leq \\
\text { NNDMAX } \\
\text { NDG } \leq \\
\text { NDGMAX }\end{array}$ \\
\hline 6 & $((\mathrm{IDGKJ}(\mathrm{IK}, \mathrm{IJ}), \mathrm{IK}=1, \mathrm{NK}), \mathrm{IJ}=1, \mathrm{NJ})$ & $10 \mathrm{X}, 7 \mathrm{I} 10$ & \\
\hline 7 & $((\mathrm{BTFR}(\mathrm{IG}, \mathrm{IN}), \mathrm{IG}=1, \mathrm{NDG}), \mathrm{IN}=1, \mathrm{NNEUT})$ & $\begin{array}{l}10 \mathrm{X}, 7 \mathrm{E} 10.5, \\
(10 \mathrm{X}, 7 \mathrm{E} 10.5)\end{array}$ & \\
\hline 8 & $((\mathrm{XIAMD}(\mathrm{IG}, \mathrm{IN}), \mathrm{IG}=1, \mathrm{NDG}), \mathrm{IN}=1, \mathrm{NNEUT})$ & $\begin{array}{l}10 \mathrm{X}, 7 \mathrm{E} 10.5, \\
(10 \mathrm{X}, 7 \mathrm{E} 10.5)\end{array}$ & \\
\hline
\end{tabular}

NNEUT

NDG

$\operatorname{IDGKJ}(\mathrm{IK}, \mathrm{IJ})$

BTFR(IG,IN)

XLAND(IG,IN)
Number of different sets of delayed-neutron characteristics to be input. Number of delayed-neutron energy groups to be read.

Identification index number to locate in the tables the delayed-neutron characteristics of a subcore (IK,IJ) (i.e., IN below).

Table of delayed-neutron decay constants as a function of energy group IG and subcore index IN.

Table of delayed-neutron decay constants as a function of energy group IG and subcore index IN.

\begin{tabular}{|c|l|l|l|}
\hline 9 & $((\mathrm{IRHOKJ}(\mathrm{IK}, \mathrm{IJ}), \mathrm{IK}=1, \mathrm{NK}), \mathrm{IJ}=1, \mathrm{NJ})$ & $10 \mathrm{X}, 7 \mathrm{I10}$ & \\
\hline 10 & NNERO,(RHOO(IR),IR=1,NNERO) & $\begin{array}{l}\text { I10,7E10.5, } \\
(10 \mathrm{X}, 7 \mathrm{E} 10.5)\end{array}$ & $\begin{array}{l}\text { NNERO } \leq \\
\text { NROMAX }\end{array}$ \\
\hline
\end{tabular}

$\operatorname{IRHOKJ}(\mathrm{IK}, \mathrm{IJ})$

Table of index numbers identifying a value of the table RHOO with the initial reactivity of the subcore of indices (IK,IJ). 
NNERO

RHOO
Length of the table RHOO.

Table of initial reactivity values.

\begin{tabular}{|c|l|l|l|}
\hline 11 & $((\mathrm{IELSKJ}(\mathrm{IK}, \mathrm{IJ}), \mathrm{IK}=1, \mathrm{NK}), \mathrm{IJ}=1, \mathrm{NJ})$ & $10 \mathrm{X}, 7 \mathrm{I1} 0$ & \\
\hline 12 & NNELS,(ELST(IE),IE=1,NNELS) & $\begin{array}{l}\text { I10,7E10.5, } \\
(10 \mathrm{X}, 7 \mathrm{E} 10.5)\end{array}$ & $\begin{array}{l}\text { NNELS } \leq \\
\text { NNLMAX }\end{array}$ \\
\hline
\end{tabular}

IELSKJ(IK,IJ) Table of index numbers identifying a value of the table ELST with the neutron lifetime in the subcore of indices (IK,IJ).

NNELS Length of the table ELST.

\begin{tabular}{|c|c|c|}
\hline \multirow[t]{10}{*}{13} & NFT, NCOPOL & $14 \mathrm{I} 5$ \\
\hline & $\begin{array}{l}((((\mathrm{A}(\mathrm{IXST}, \mathrm{IABC}, \mathrm{ICT}, \mathrm{IFT}), \mathrm{IXST}=1,7), \mathrm{IABC}=1, \mathrm{NCOPOL}), \mathrm{ICT}=1, \\
2), \mathrm{IFT}=1, \mathrm{NFT})\end{array}$ & $\begin{array}{l}\text { 10X,7E10.4, } \\
(10 \mathrm{X}, 7 \mathrm{E} 10.4)\end{array}$ \\
\hline & RHOLXS, RHOSXS & 10X,2E 10.4 \\
\hline & NBT & $10 \mathrm{X}, \mathrm{I5}$ \\
\hline & Input for $\mathrm{I}=1, \mathrm{NBT}\{$ & \\
\hline & IBT, NZXS(IBT) & 10X,14I5 \\
\hline & (ZXS(IZXS, IBT), IZXS = 1, NZXS(IBT)) & 10X, 7E10.4 \\
\hline & $\quad(\mathrm{JFT}(\mathrm{IZXS}, \mathrm{IBT}), \mathrm{IZXS}=1, \mathrm{NZXS}(\mathrm{IBT}))$ & 10X, 7E10.4 \\
\hline & Input for $\mathrm{I}=1, \mathrm{NXE}\{$ & \\
\hline & IX,(NCHXBXJ(IBT, IX), IBT = 1, NBT) & 10X, 7E10.4 \\
\hline
\end{tabular}

A

JFT

NBT

NCHXBJ

NCOPOL
Two-group cross-section expansion coefficients. IXST refers to the cross-section type ( 1 - fast diffusion coefficient, 2 - thermal diffusion coefficient, 3 - fast absorption cross section, 4 - thermal absorption cross section, 5 - fast fission cross section, 6 - thermal fission cross section, 7 remonition from fast group $=$ absorption + scattering). IABC refers to the power expansion coefficients. ICT $=1$ is an uncontrolled bundle and ICT $=2$ is a controlled bundle. IFT refers to the fuel type.

Fuel type of axial interval IZXS for bundle type IBT.

Number of bundle types.

Number of channels of type IX that correspond to bundle type IBT.

Order of the cross section expansion in power series of the density. 
NFT

NZXS

RHOLXS

RHOSXS

ZXS
Number of different fuel types.

Number of different axial intervals with constant fuel.

Liquid density at pressure used in calculation of A.

Steam density at pressure used in calculation of A.

Upper height of axial fuel interval IZXS for bundle type IBT.

\begin{tabular}{|c|c|c|}
\hline \multirow[t]{3}{*}{14} & $\begin{array}{l}\text { Input for I }=1, \mathrm{NBT}\{ \\
\text { IBT, NZCR(IBT) } \\
\quad(\mathrm{ZCR}(\mathrm{IZCR}, \mathrm{IBT}), \mathrm{IZCR}=1, \mathrm{NZC})\end{array}$ & $\begin{array}{l}10 \mathrm{X}, 14 \mathrm{I} 5 \\
10 \mathrm{X}, 7 \mathrm{E} 10.4\end{array}$ \\
\hline & NNBC & $10 \mathrm{X}, \mathrm{I} 5$ \\
\hline & $\begin{array}{l}\text { Input for I }=1, \mathrm{NNBC}\{ \\
\qquad \mathrm{IBT}, \mathrm{IX} \\
(\mathrm{XNBC}(\mathrm{IZCR}, \mathrm{IBT}, \mathrm{IX}), \mathrm{IZCR}=1, \mathrm{NZCR}(\mathrm{IBT}))\end{array}$ & $\begin{array}{l}10 \mathrm{X}, 14 \mathrm{I} 5 \\
10 \mathrm{X}, 7 \mathrm{E} 10.4\end{array}$ \\
\hline
\end{tabular}

NNBC

Number of bundle types with nonzero number of controlled bundles. Bundles not input are taken as uncontrolled.

NZCR

XNBC

Number of regions in which the number of bundles controlled can be considered constant.

Number of bundles controlled in axial region IZCR of bundles type IBT and thermohydraulic region (channel) IX.

ZCR

Upper boundary of region IZCR.

Note: ID 14 must be read after ID 13. If IDs 13 and 14 are read, and IDs number 11, 12, LAPUR will compute neutron lifetime. If IDS 18 through 21 are omitted, LAPUR will compute density reactivity coefficients.

\begin{tabular}{|l|l|l|l|}
\hline 15 & $((\mathrm{ICOUPL}(\mathrm{KJ} 1, \mathrm{KJ} 2), \mathrm{KJ} 1=1, \mathrm{NKJ}), \mathrm{KJ} 2=1, \mathrm{NKJ})$ & $10 \mathrm{X}, 7 \mathrm{I} 10$ & $\mathrm{NKJ}=\mathrm{NK} * \mathrm{NJ}$ \\
\hline 16 & NNCOU,(COUPL(IC),IC=1,NNCOU) & $\begin{array}{l}\mathrm{I} 10,7 \mathrm{E} 10.5, \\
(10 \mathrm{X}, 7 \mathrm{E} 10.5)\end{array}$ & $\begin{array}{l}\text { NNCOU } \leq \\
\text { NNCMAX }\end{array}$ \\
\hline
\end{tabular}

ICOUPL $(\mathrm{KJ} 1, \mathrm{KJ} 2) \quad$ Table of index numbers identifying a value of the table COUPL with the coupling coefficients between the subcores defined by $\mathrm{KJ} 1$ and $\mathrm{KJ} 2$, where $\mathrm{KJ} 1=\mathrm{K} 1+(\mathrm{J} 1-1) \mathrm{x} \mathrm{NK}$ for subcore $(\mathrm{K} 1, \mathrm{~J} 1)$.

NNCOU Length of the table COUPL. 


\begin{tabular}{|l|l|l|l|}
\hline 17 & CDOPP & $10 \mathrm{X}, \mathrm{E} 10.5$ & \\
\hline
\end{tabular}

CDOPP $\quad \frac{\partial \mathrm{k}}{\partial \mathrm{T}} \quad\left[\%{ }^{\circ} \mathrm{C}\right]$ Doppler reactivity coefficient of the fuel.

\begin{tabular}{|c|c|c|c|}
\hline 18 & N0COE,(LENG(IN0),IN0=1,N0COE) & $\begin{array}{l}8 \mathrm{I} 10, \\
(10 \mathrm{X}, 7 \mathrm{I} 10)\end{array}$ & $\begin{array}{l}\text { NOCOE } \leq \\
\text { NDRMAX }\end{array}$ \\
\hline 19 & $(((\mathrm{IDNCOE}(\mathrm{IC}, \mathrm{IK}, \mathrm{IJ}), \mathrm{IX}=1, \mathrm{NX}), \mathrm{IK}=1, \mathrm{NK}), \mathrm{IJ}=1, \mathrm{NJ})$ & $\begin{array}{l}\text { 10X,7I10, } \\
(10 \mathrm{X}, 7 \mathrm{I} 10)\end{array}$ & \\
\hline 20 & $((\mathrm{DENSR} 1(\mathrm{I}, \mathrm{J}), \mathrm{J}=1, \mathrm{LENG}(\mathrm{I})), \mathrm{I}=1, \mathrm{~N} 0 \mathrm{COE})$ & $\begin{array}{l}\text { 10X,7E10.5, } \\
(10 \mathrm{X}, 7 \mathrm{E} 10.5)\end{array}$ & $\begin{array}{l}\text { LENG(I) } \leq \\
\text { NDRNMAX }\end{array}$ \\
\hline 21 & $((\operatorname{REACT} 1(\mathrm{I}, \mathrm{J}), \mathrm{J}=1, \mathrm{LENG}(\mathrm{I}), \mathrm{I}=1, \mathrm{~N} 0 \mathrm{COE})$ & $\begin{array}{l}\text { 10X,7E10.5, } \\
(10 \mathrm{X}, 7 \mathrm{E} 10.5)\end{array}$ & $\begin{array}{l}\operatorname{LENG}(\mathrm{I}) \leq \\
\text { NDRNMAX }\end{array}$ \\
\hline
\end{tabular}

NOCOE

LENG(IN0)
Length of the table LENG.

Index table containing the lengths of each of the sets of reactivity tables to be read into DENSR1-REACT1.

DENSR1 $\quad \frac{\rho}{\rho_{\mathrm{f}}}$ Set of tabulated values of relative water density.

REACT1 $\quad \frac{\partial \mathrm{k}}{\partial \rho}\left[\% \mathrm{~g}^{-1} \mathrm{~cm}^{3}\right]$ Set of tabulated density reactivity coefficients.

These two matrices define a set of tables of reactivity coefficients in units of $(\% \Delta \mathrm{K}) / \mathrm{K}$ per $\mathrm{g} / \mathrm{cm}^{3}$ as function of the relative water density. The set that applies for a particular channel and subcore is specified by IDNCOE.

\begin{tabular}{|l|l|l|l|}
\hline 22 & $\mathrm{NW},(\mathrm{W}(\mathrm{IW}), \mathrm{IW}=1, \mathrm{NW})$ & $\begin{array}{l}\mathrm{I10,7E10.5,} \\
(10 X, 7 \mathrm{E} 10.5)\end{array}$ & $\begin{array}{l}\mathrm{NW} \leq \\
\text { NFPMAX }\end{array}$ \\
\hline
\end{tabular}

NW

W

Number of frequency points at which the dynamic response is to be calculated. 
$\operatorname{IOPTW}(\mathrm{M})$

IOPTW(1)

IOPTW(2)

IOPTW(3)

IOPTW(4)

IOPTW(5)

IOPTW(6)

$\operatorname{IOPTW}(7)$

IOPTW(8)

$\operatorname{IOPTW}(9)$

IOPTW(10)

IOPTW(11)

IOPTW(12)

IOPTW(13)

IOPTW(14)

IOPTW(15)

IOPTW(16)

IOPTW(17)

IOPTW(18)

IOPTW(19)

IOPTW(20)

IOPTW(21)

Output options.

If IOPTW $(\mathrm{M})=0$, no output of type $\mathrm{M}$ is produced by the subroutine RESPON.

If IOPTW(M) $=1$ yes, output is produced.

The following outputs can be controlled:

Fuel transfer functions $\mathrm{a}_{\mathrm{q}}, \mathrm{a}_{\mathrm{T}}, \mathrm{b}_{\mathrm{q}}, \mathrm{b}_{\mathrm{T}}, \mathrm{c}_{\mathrm{q}}, \mathrm{c}_{\mathrm{T}}$. See paragraph 3.2.2.

Channel nodal transfer functions $\equiv$ unity power perturbation response along a channel.

Channel transfer functions.

Core flow impedances $\mathrm{z}_{\mathrm{Y}}, \mathrm{z}_{\mathrm{q}}, \mathrm{z}_{\mathrm{T}}$.

Recirculation loop transfer functions.

Core-feedback, point kinetics open-loop, and closed loop T.F.s.

Multicore power perturbation to pressure at the boiling boundary T.F.s of a channel, $\mathrm{CCXK} \equiv \mathrm{C}_{\mathrm{x}, \mathrm{k}}$. See Eq. (3.2.88c) and matrix C at App. B11.

Multicore inlet flow rate to moderator density reactivity contribution to a core T.F.s CEKJ $\equiv \mathrm{E}_{\mathrm{k}}$. See Eqs. (3.3.1a) and matrix E at App. B11.

Multicore inlet temperature to moderator density reactivity T.F.s CHKJ $\equiv h_{k}$. See Eq. (3.3.1c) and vector $\bar{h}$ at App. B11.

Multicore power to core flow T.F.s CZQKJ $\equiv \bar{z}_{\mathrm{q}}$ at Eq. (B12.2).

Multicore power to moderator density reactivity T.F.s, CFKPJK $\equiv \mathrm{f}_{\mathrm{k}, \mathrm{k}}$. See Eq. (3.3.1b) and matrix F at App. B11.

Multicore power to channel flow rate T.F.s CMXJK $\equiv$ matrix M, in Eqs. (3.3.10) and (B12.9).

Multicore power to total moderator reactivity feedback T.F. matrix CQ $\equiv$ $\mathrm{Q}$ in Eqs. (3.3.23a) and (B12.14).

Multicore total flow rate to total moderator reactivity feedback T.F. matrix $\mathrm{CR} \equiv \mathrm{R}$ in Eqs. (3.3.23b) and (B12.16).

Multicore inlet temperature to total moderator reactivity feedback T.F. matrix $\mathrm{CS} \equiv \mathrm{S}$ in Eqs. (3.3.23c) and (B12.18).

Multicore core to core power transfer function matrix $\mathrm{CHQ} \equiv$ matrix $\mathrm{H}$ in Eq. (3.3.17) with Q as in Eq. (B12.14).

Multicore reactor core flow rate to individual core power transfer function $\bar{Z}_{R}$ in Eq. (3.3.20).

Multicore inlet temperature to individual core power transfer function vector $\bar{Z}_{\mathrm{S}}$ in Eq. (3.3.20).

Multicore closed-loop reactivity to power T.F. matrix Z in Eq. (3.3.16).

Sum of the column elements of the feedback T.F. matrix $H$, that is,

$\mathrm{CDENFB}_{\mathrm{ROW}}=\mathrm{SUM}\left[\mathrm{H}_{\text {row,col }}\right]$ for all columns.

Sum of the column elements of the closed-loop T.F. matrix $Z$, that is,

$\mathrm{CLOSEK}_{\mathrm{ROW}}=\mathrm{SUM}\left[\mathrm{Z}_{\text {row,col }}\right]$ for all columns. 
CRFBAC and CLTFPK, the total core reactivity feedback and power response to a unity reactivity vector perturbation.

$\mathrm{CRFBAC}=\mathrm{SUM}\left[\mathrm{CDEFB}_{\mathrm{ROw}}\right]$ for all rows.

$\mathrm{CLTFPK}=\mathrm{SUM}\left[\mathrm{CLOSEK}_{\mathrm{ROW}}\right]$ for all rows.

24

(ISTAB(IX),IX=1,NX+1)
$14 \mathrm{I} 5$,

$(14 \mathrm{I} 5)$

ISTAB(IX)

Stability calculation options: $=0 \equiv$ no; $1 \equiv$ yes.

IX indicates channel type for which the hydrodynamic stability is to be calculated. When IX $=\mathrm{NX}+1$ the total core open-loop t.f. is analyzed if $\operatorname{ISTAB}(\mathrm{NX}+1)=1$.

\begin{tabular}{l|l|l}
25 & $($ IPLOT(IX),IX=1,NX+2) & $\begin{array}{l}14 \mathrm{I} 5 \\
(14 \mathrm{I} 5)\end{array}$ \\
\hline
\end{tabular}

IPLOT(IX) Plotting options: $=0 \equiv$ no; $=1 \equiv$ yes.

IX refers to the open-loop T.F. of channel type IX.

$\mathrm{IX}=\mathrm{NX}+1$ indicates total core open-loop T.F. Magnitude-phase and Nyquist plots are produced for the open loops.

\begin{tabular}{|l|l|l|l|}
\hline 28 & REAMUL & $7 \mathrm{E} 10.5$ & \\
\hline
\end{tabular}

REAMUL

Density reactivity coefficient multiplier. If REAMUL is negative, its absolute value is taken, but a sensitivity calculation is performed on density reactivity coefficient and recirculation loop parameters.

NRHOSC

RHOSC
Number of subcritical reactivities at which out-of-phase mode stability is to be determined.

Array of values of the reactivity of the first subcritical neutronic mode.

Note: If ID 29 is read, LAPUR5 will estimate the stability of the first subcritical neutronic mode with a parallel channel thermohydraulic feedback. If the subcritical reactivity is known, use that value and 
NRHOSC $=1$. NRHOSC $>1$ allows for a sensitivity calculation with little cost.

\begin{tabular}{|l|l|l|l|}
\hline 30 & NSRCH & I10 & \\
\hline
\end{tabular}

NSRCH Number of iterations in the full Laplace domain (with real part of s not equal to 0., i.e., $s=r+j w, r \neq 0$ ). This is done to improve the estimate of the decay ratio. It essentially multiplies the computation time by NSRCH +1 .

\begin{tabular}{|l|l|l|l|}
\hline 31 & WPCNT & E10.4 & \\
\hline
\end{tabular}

WPCNT

Flow rate (percent of nominal).

Note: If ID 31 is read after ID 4 (ID 4 may not be present), LAPUR5 computes a crude estimate of the gain and time constant of the recirculation loop based on the flow rate. This is useful for scoping calculations, but the correct value is recommended for important calculations.

\subsection{OUTPUT DESCRIPTION OF LAPURW}

First, the date is printed, followed by a listing produced by OUTINW of the input parameters with the same mnemonics and self-explanatory headings. What follows next is the output generated by the subroutine NODOS. This subroutine produces the power in MW, average coolant density, and void fraction in each of the nuclear subcores in which the reactor is divided.

Next, the output of the transfer functions generated by the different subroutines is produced in the order described below. The normalization factors for the T.F.s are the following:

For pressure: $\quad \mathrm{RHOL}^{*} \mathrm{~L} * 10^{-3}\left(\mathrm{~kg} / \mathrm{cm}^{2}\right)$, with RHOL in $\left(\mathrm{g} / \mathrm{cm}^{3}\right)$ and $\mathrm{L}$ in $\mathrm{cm}$.

RHOL is the density of water at saturation temperature.

$\mathrm{L}$ is the height of the channel.

For flow: $\quad \mathrm{W} 0$ is the channel mass flow rate at steady state conditions.

WT is the total core flow rate.

For power: $\quad$ POW is the total power of the channel in cal/s.

POWKJ is the total subcore power.

For temperature: $1{ }^{\circ} \mathrm{C}$. 


\section{Description of the Output Generated by the Subroutines}

\section{***FUELW}

The output of this subroutine is performed by OUTFUW, when invoked by RESPON, if IOPTW(1) $=1$. For each channel IX and selected vertical nodes I, the following nodal transfer functions are printed as a function of frequency $\omega$ :

Mnemonics Math \& Units Description

CAQ $\quad \mathrm{a}_{\mathrm{q}} \quad$ Coolant flow rate at the node level-to-heat flux from fuel to coolant T.F.

CAT $a_{\mathrm{T}} \quad$ Coolant flow rate at the node level-to-average fuel pellet temperature T.F. (of interest for Doppler reactivity).

CBQ $\quad b_{q} \quad$ Power generation rate in the fuel-to-heat flux to coolant T.F.

CBT $\quad b_{\mathrm{T}} \quad$ Power generation rate in the fuel-to-average fuel pellet temperature T.F.

CCQ $\quad \mathrm{c}_{\mathrm{q}} \quad$ Liquid-phase coolant temperature at the node level-to-heat flux to coolant T.F.

CCT $\quad c_{\mathrm{T}} \quad$ Liquid-phase coolant temperature-to-average fuel temperature T.F.

Note that $\mathrm{CAQ} \equiv \mathrm{a}_{\mathrm{q}}$ and $\mathrm{CAT} \equiv \mathrm{a}_{\mathrm{T}}$ are equal to $(0 ., 0$.$) at those nodes within the boiling length of$ the channel because of the assumption of independence of the convective heat transfer coefficient.

****FREQ - TRANS

The output of this subroutine is performed from RESPON as follows:

Unity Power Perturbations (when IOPTW $(2)=1)$

Under this heading the frequency response along the length of a channel-to-pressure, power, and inlet temperature unit perturbation is printed.

The following prefixes are used with the variables printed:

M meaning magnitude in absolute units.

$\mathrm{TH}$ meaning phase in degrees.

$\mathrm{R} \quad$ meaning real part.

I meaning imaginary part. 
The variables whose responses are printed for all of the frequencies $\omega(\mathrm{Hz})$ are:

$\begin{array}{lc}\text { DKNB } & (\% \Delta K) \text { Density reactivity response in the NBR. } \\ \text { DKSB } & (\% \Delta K) \text { Density reactivity response in the SBR. } \\ \text { DKBB } & (\% \Delta K) \text { Density reactivity response in the BBR. } \\ \text { DKN } & (\% \Delta K) \text { Density reactivity response in the channel. } \\ \text { Y(NSB+1) } & \text { Flow rate response at the entrance of the BBR. } \\ \text { Y(NBB }+1) & \text { Flow rate response at the exit of the BBR. } \\ \text { Y(NR+1) } & \text { Flow rate response at the exit of the exit. } \\ \text { H(NSB+1) } & \text { Degree of subcooling response at the entrance of the BBR. } \\ \text { Y(1) } & \text { Flow rate response at the entrance of the SBR. } \\ \text { B(NSB+1) } & \text { Void fraction response at the exit of the SBR. } \\ \text { B(NBB+1) } & \text { Void fraction response at the exit of the BBR. } \\ \text { B(NR+1) } & \text { Void fraction response at the exit of the exit pipe. } \\ \text { CDR } & \text { Doppler reactivity response of the channel. } \\ \text { P(NR+1) } & \text { Pressure response at the exit of the exit pipe. } \\ \text { P(NBB+1) } & \text { Pressure response at the exit of the BBR. } \\ \text { P(NSB+1) } & \text { Pressure response at the exit of the SBR. } \\ \text { P(1) } & \text { Pressure response at the exit of the NBR. }\end{array}$

The various TRANSFER FUNCTIONS OF A CHANNEL are printed (if IOPW(3) =1) for all the channels under the underlined heading. Note that the units of reactivity used in this section are the percent of absolute units $\Delta \mathrm{k}$.

CAX

CABX

CBX

CCX

CDX

CDYX

CDQX

CDTX

CEX

CFX

CHX

CLX

CMX

CNX 


$$
\mathrm{N}_{\mathrm{ix}}=\frac{\mathrm{a}_{\mathrm{ix}}}{1 .+\mathrm{a}_{\mathrm{ix}} \times \mathrm{b}_{\mathrm{ix}}} \times\left(\mathrm{z}_{\mathrm{t}}-\mathrm{d}_{\mathrm{ix}}\right)
$$

\section{***STABGH}

This subroutine when invoked by ISTAB(IX) $=1$ will produce the output of the stability analysis of channel IX in a self-explanatory format in accordance with the theory in ref. 7, pp. 29-37. The T.F. object of the stability analysis is $\mathrm{CABX}_{\mathrm{ix}}$.

\section{***Core Flow Impedances}

Output is done by RESPON provided IOPTW $(4)=1$.

CZY $\quad z_{Y} \quad$ Total flow rate to channel inlet pressure T.F.

$$
z_{Y}=\frac{1 .}{\sum_{i x} \frac{a_{i x} \times g_{i x}}{1 .+a_{i x} \times b_{i x}}}
$$

CZQ $\quad \mathrm{z}_{\mathrm{q}} \quad$ Total core power to channel inlet pressure T.F.

$$
\mathrm{z}_{\mathrm{q}}=\mathrm{z}_{\mathrm{Y}} \times \sum_{\mathrm{ix}} \frac{\mathrm{a}_{\mathrm{ix}} \times \mathrm{g}_{\mathrm{ix}} \times \mathrm{c}_{\mathrm{ix}}}{1 .+\mathrm{a}_{\mathrm{ix}} \times \mathrm{b}_{\mathrm{ix}}}
$$

CZT $\quad z_{\mathrm{T}} \quad$ Inlet temperature to channel inlet pressure T.F.

$$
\mathrm{z}_{\mathrm{T}}=\mathrm{z}_{\mathrm{Y}} \times \sum_{\mathrm{ix}} \frac{\mathrm{a}_{\mathrm{ix}} \times \mathrm{g}_{\mathrm{ix}} \times \mathrm{d}_{\mathrm{ix}}}{1 .+\mathrm{a}_{\mathrm{ix}} \times \mathrm{b}_{\mathrm{ix}}}
$$

\section{$* * *$ RECIRC}

Output produced by RESPON provided IOPTW(5) $=1$. Under the heading, RECIRCULATION LOOP T.F.s:

RLPY

Pressure to flow T.F.:

$$
\text { RLPY }=\frac{\delta Y}{\delta \mathrm{n}}=\frac{\text { GAINPY }}{1+\text { TAUPY } \times \mathrm{s}}
$$

CQY

Total core power to core flow T.F.:

$$
\mathrm{CQY}=\frac{\delta \mathrm{Y}}{\delta \mathrm{q}}=\frac{\mathrm{z}_{\mathrm{q}} \times \operatorname{RLPY}}{1-\operatorname{RLPY}\left(\mathrm{z}_{\mathrm{Y}}+\operatorname{RLYT} \times \mathrm{z}_{\mathrm{T}}\right)}
$$


Note that $\mathrm{CLYT}=\frac{\delta \mathrm{T}}{\delta \mathrm{Y}}$ and CQT $=\frac{\delta \mathrm{T}}{\delta \mathrm{q}}=\mathrm{CLYT} \times \mathrm{CQY}$ are not printed since $\frac{\delta \mathrm{T}}{\delta \mathrm{Y}}$ is taken as $(0$, 0$.$) in this program.$

***ONECOR

Output produced by RESPON provided IOPTW $(6)=1$. Under the heading CORE REACTIVITY FEEDBACK T.F.s:

CAR $\quad A_{r} \quad$ Total flow rate to density reactivity T.F.

$$
\mathrm{A}_{\mathrm{r}}=\sum_{\mathrm{ix}} \mathrm{e}_{\mathrm{ix}} \times \mathrm{L}_{\mathrm{ix}}
$$

CAD

$A_{d} \quad$ Total flow rate to Doppler reactivity T.F.

$$
\mathrm{A}_{\mathrm{d}}=\sum_{\mathrm{ix}} \mathrm{d}_{\mathrm{y}_{\mathrm{ix}}} \times \mathrm{L}_{\mathrm{ix}}
$$

CBR

$\mathrm{B}_{\mathrm{r}} \quad$ Total core power to density reactivity T.F.

$$
\mathrm{B}_{\mathrm{r}}=\sum_{\mathrm{ix}} \mathrm{f}_{\mathrm{ix}}+\mathrm{e}_{\mathrm{ix}} \times \mathrm{M}_{\mathrm{ix}}
$$

CBD $\quad \mathrm{B}_{\mathrm{d}} \quad$ Total core power to Doppler reactivity T.F.

$$
\mathrm{B}_{\mathrm{d}}=\sum_{\mathrm{ix}} \mathrm{d}_{\mathrm{t}_{\mathrm{ix}}}+\mathrm{d}_{\mathrm{y}_{\mathrm{ix}}} \times \mathrm{M}_{\mathrm{ix}}
$$

CCR $\quad \mathrm{C}_{\mathrm{r}} \quad$ Inlet temperature to density reactivity T.F.

$$
\mathrm{C}_{\mathrm{r}}=\sum_{\mathrm{ix}} \mathrm{h}_{\mathrm{ix}}+\mathrm{e}_{\mathrm{ix}} \times \mathrm{N}_{\mathrm{ix}}
$$

CCD $\quad \mathrm{C}_{\mathrm{d}} \quad$ Inlet temperature to Doppler reactivity T.F.

$$
\mathrm{C}_{\mathrm{d}}=\sum_{\mathrm{ix}} \mathrm{d}_{\mathrm{t}_{\mathrm{ix}}}+\mathrm{d}_{\mathrm{y}_{\mathrm{ix}}} \times \mathrm{N}_{\mathrm{ix}}
$$

CHAR $\quad \mathrm{H}_{\mathrm{ar}} \quad$ Total core power to density reactivity through flow.

$$
\mathrm{H}_{\mathrm{ar}}=\mathrm{A}_{\mathrm{r}} \times \mathrm{QY}
$$

CHAD $\quad \mathrm{H}_{\mathrm{ad}} \quad$ Total core power to Doppler reactivity T.F. through the perturbation of flow rate.

$$
\mathrm{H}_{\mathrm{ad}}=\mathrm{A}_{\mathrm{d}} \times \mathrm{QY}
$$

CHCR $\quad \mathrm{H}_{\mathrm{cr}} \quad$ Total core power to density reactivity T.F. through the perturbation of inlet temperature.

$$
\mathrm{H}_{\mathrm{cr}}=\mathrm{C}_{\mathrm{r}} \times \mathrm{QT}
$$


CHCD $\quad \mathrm{H}_{\mathrm{cd}} \quad$ Total core power to Doppler reactivity T.F. through the perturbation of inlet temperature.

$$
\mathrm{H}_{\mathrm{cd}}=\mathrm{C}_{\mathrm{d}} \times \mathrm{QT}
$$

CHR $\mathrm{H}_{\mathrm{r}} \quad$ Total core power to total density reactivity T.F. This is the hydrodynamic feedback loop.

$$
\mathrm{H}_{\mathrm{r}}=\mathrm{H}_{\mathrm{ar}}+\mathrm{H}_{\mathrm{cr}}+\mathrm{B}_{\mathrm{r}}
$$

CHD $\quad \mathrm{H}_{\mathrm{d}} \quad$ Total core power to total Doppler reactivity T.F. This is the fuel temperature feedback loop.

$$
\mathrm{H}_{\mathrm{d}}=\mathrm{H}_{\mathrm{ad}}+\mathrm{H}_{\mathrm{cd}}+\mathrm{B}_{\mathrm{d}}
$$

Under the heading NEUTRON KINETICS LOOP:

CG G Total reactivity to total core power T.F. This is the neutron kinetics or forward loop.

$$
\mathrm{G}=\frac{\delta \mathrm{q}}{\delta \mathrm{k}_{\varepsilon}} \quad \text { (point kinetics) }
$$

Under the heading FEEDBACK LOOP:

$\mathrm{CH} \quad \mathrm{H} \quad$ Total core power to total reactivity T.F. This is the overall feedback loop.

$$
\mathrm{H}=\mathrm{H}_{\mathrm{r}}+\mathrm{H}_{\mathrm{d}}
$$

Under the heading OPEN-LOOP RESPONSE:

$\mathrm{CGH} \quad \mathrm{G} \times \mathrm{H} \quad$ Open-loop reactivity T.F. of reactivity.

Under the heading CLOSED-LOOP RESPONSE:

G1GH $\frac{\mathrm{G}}{1+\mathrm{G} \times \mathrm{H}}$ Closed-loop reactivity to power T.F.

\section{***STABGH}

Provided that ISTAB(NXE + 1), the results of the stability analysis of the core open loop T.F. GH are printed by means of RESPON.

***FREQ-TRANS 
Provided that IOPTW(7 to 22$)=1$, the following multicore T.F.s are printed from RESPON:

CCXK $\quad c_{x, k} \quad$ Subcore $k$ power to pressure at the boiling boundary of channel X T.F. Refer to Eq. (3.2.88c) and matrix C at App. B11.

CEKJ $\quad e_{k, j} \quad$ Inlet flow rate into horizontal zone $\mathrm{j}$ to moderator density reactivity feedback of the subcore at level k [i.e., subcore (k,j)]. According to Eq. (3.3.1a) and App. B11,

$$
\mathrm{e}_{\mathrm{k}, \mathrm{j}}=\sum_{\mathrm{x}} \mathrm{e}_{\mathrm{x}, \mathrm{k}, \mathrm{j}} \mathrm{Nch}_{\mathrm{x}, \mathrm{j}}
$$

CHKJ

$\mathrm{h}_{\mathrm{k}, \mathrm{j}} \quad$ Inlet coolant temperature into horizontal zone $\mathrm{j}$ to moderator density reactivity of the subcore at level $\mathrm{k}$ [i.e., subcore $(\mathrm{k}, \mathrm{j})]$. According to Eq. (3.3.1c) and App. B11,

$$
\mathrm{h}_{\mathrm{k}, \mathrm{j}}=\sum_{\mathrm{x}} \mathrm{h}_{\mathrm{x}, \mathrm{k}, \mathrm{j}} \mathrm{Nch}_{\mathrm{x}, \mathrm{j}}
$$

CZQKJ

CFKJK

CMXJK

CQ

$\mathrm{CR}$

CS

CHQ

CHRY R*

CHST $\quad \mathrm{S}^{*}$

CG1MGH

CDENFB $\mathrm{z}_{\mathrm{q}_{\mathrm{k}, \mathrm{j}}}$

$\mathrm{f}_{\mathrm{k}^{1}, \mathrm{j}, \mathrm{k}}$

$M_{x, j_{1}, k, j_{2}}$

Subcore $(k, j)$ power to total reactor core flow T.F. vector $z_{q}$ at Eq. (B12.2).

Subcore $\left(\mathrm{k}^{1}, \mathrm{j}\right)$ power to moderator density reactivity of subcore $(k, j)$ T.F. See Eq. (3.3.1b) and matrix F of App. B.

Subcore $\left(\mathrm{k}, \mathrm{j}_{2}\right)$ power to inlet flow rate to the channel $\mathrm{X}$ placed in zone $\mathrm{j}_{1}$, T.F. See Eq. (3.3.10) and matrix M in App. B12.

Q Matrix of subcore $\left(\mathrm{k}_{1}, \mathrm{j}_{1}\right)$ power to moderator density reactivity of subcore $\left(\mathrm{k}_{2}, \mathrm{j}_{2}\right)$ T.F.s. See Eqs. (3.3.11) and (B15.14).

$\mathrm{R} \quad$ Vector of total core flow rate to moderator density reactivity of subcore $(k, j)$ T.F.s. See Eqs. (3.3.11) and (B12.16).

$\mathrm{S} \quad$ Vector of inlet coolant temperature to moderator density reactivity of subcore (k,j) T.F.s. See Eqs. (3.3.11) and (B12.18).

Feedback matrix of power at subcore $\left(k_{1}, j_{1}\right)$ to reactivity at subcore $\left(\mathrm{k}_{2}, \mathrm{j}_{2}\right)$, including flow redistribution effects. It corresponds to Eq. (3.3.23a).

R* Feedback vector containing the T.F.s of total core inlet flow rate to reactivity at subcore $(\mathrm{k}, \mathrm{j})$. It corresponds to Eq. (3.3.23b).

S* Feedback vector containing the T.F.s of inlet coolant temperature to reactivity at subcore $(\mathrm{k}, \mathrm{j})$. It corresponds to Eq. (3.3.23c).

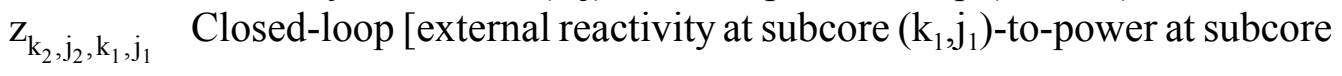
$\left(\mathrm{k}_{2}, \mathrm{j}_{2}\right)$ ] T.F. matrix. It corresponds to Eq. (3.3.16) using $\mathrm{Q}^{*}$ as indicated by Eq. (3.3.23a).

Vector containing the total reactivity effect on each subcore due to a simultaneous unity perturbation of reactivity error in every subcore; that is, 


$$
\operatorname{CDENFB}_{\mathrm{j}, \mathrm{k}}=\sum_{\mathrm{j}^{\prime}} \sum_{\mathrm{k}^{\prime}} \mathrm{Q} *_{\mathrm{j}, \mathrm{k}, \mathrm{j}^{\prime}, \mathrm{k}^{\prime}}
$$

CLOSEK

Vector containing the closed-loop power response of each subcore $(\mathrm{k}, \mathrm{j})$ due to a simultaneous unity perturbation of external reactivity in every subcore; that is,

$$
\operatorname{CLOSEK}_{\mathrm{j}, \mathrm{k}}=\sum_{\mathrm{j}^{\prime}} \sum_{\mathrm{k}^{\prime}} \mathrm{z}_{\mathrm{j}, \mathrm{k}, \mathrm{j}^{\prime}, \mathrm{k}^{\prime}} \operatorname{ALPKJ}_{\mathrm{j}^{\prime}, \mathrm{k}^{\prime}}
$$

CRFBAC

Sum of the point kinetics reactivity feedback T.F.s of each nuclear subcore.

CLTFPK

Sum of the closed-loop T.F.s of each subcore to yield the total reactor core power response to a simultaneous unity perturbation of reactivity in each subcore; that is,

CLTFPK $=\sum_{\mathrm{j}} \sum_{\mathrm{k}}$ CLOSEK $_{\mathrm{j}, \mathrm{k}}$ POWKJ $_{\mathrm{j}, \mathrm{k}} /$ POWT 


\section{LAPUR BENCHMARKS}

The LAPUR code has been validated against a reasonable array of BWR test data. These data include:

1. Peach Bottom tests (see ref. 3).

2. Vermont Yankee stability tests (see ref. 3).

3. Dresden local stability test (see ref. 8).

4. Browns Ferry single-loop stability test (see refs. 9 and 10).

5. Susquehanna-2 stability tests (see refs. 11 and 12).

6. Grand Gulf-1 stability tests (see refs. 11 and 12).

7. Oskarshamn-3 stability tests (see ref. 13).

\subsection{LAPUR5.2 Verification}

As described above, the modifications to version 5.2 of LAPUR do not affect the underlying models of LAPUR 5. The only modifications have been related to the software implementation (e.g., variable dimension for arrays.) Thus, the verification of these modifications has concentrated on wether the LAPUR5.2 with, for example, a larger number of channels reproduce the results of the old LAPUR5 version. Therefore, the claim is that LAPUR5.2 is functionally equivalent to the old code version; the upgrade simply makes it easier to use.

To guarantee this functional equivalence, a large number of calculations have been performed to verify that the software modifications have not introduced new errors. Some of these calculations are summarized in Figures 1 through 4.

Figure 1 demonstrates the ability of calculating transfer functions with up to 100 frequency points in LAPUR5.2. This figure compares the results of a LAPUR5 calculation with 25 frequency points (circles in the figure) against a LAPUR5.2 calculation with 100 points (solid line). As observed in the figure, there is no significant difference between the calculations. The advantage of having 100 frequency points is that a finer mesh can be used around the transfer-function peak, which results in more accurate decay ratio estimation. In addition, the user can select a few frequency points with low and high values to calculate the complete transfer function, as shown in the figure.

Figure 2 illustrates the LPAUR5.2 upgrade of the maximum number of channels to up to 200. With 
this many channels, we may have numerical problems converging the flow distribution among channels. We have tested LAPUR5.2 with a flat radial power distribution, which results with 200 channels with the same power and flow, and with the same pressure drop that LAPUR5 calculates for a one-channel run. Figure 2 shows the channel power and flow calculated by LAPUR5.2 for three 200-channel cases at different core flows. As seen in this figure, the calculated channel powers and flows align as expected following a constant pressure drop line (similar to the natural circulation line). From these and other calculations, we conclude that LAPUR5.2 calculates radial power/flow distributions as accurately as the old LAPUR5 version.

Figures 3 and 4 illustrate the effect on the frequency-domain calculation (LAPURW) of increasing the number of channels. In the case of Figure 3, we compare the closed-loop transfer function using one average channel versus a calculation that uses 200 channels with a flat power profile. As seen in the figure, LAPURW handles up to 200 channels consistently. As expected, the one-averagechannel calculation (circles in Figure 3) results in the same transfer function than the 200-channel calculation (solid line).

Figure 4 shows the effect of a non-uniform radial power distribution. In this figure, we used a symmetric power distribution, so a two-channel calculation implies two channels with the same average power; a four-channel calculation has two power levels, and so on. This is done to compare the results of the two symmetric channels, which should be and were identical. As seen in Figure 4, once we reach the 8-channel calculation (i.,e. 4 different power levels) the results are essentially converged. This example further reinforces the point that the LAPUR5.2 modification does not improve significantly the accuracy of the old LAPUR, which was limited to seven channels. The LAPUR5.2 modification simplifies the generation of the input deck, since essentially we can now model the actual bundles one-to-one (when symmetry is considered.) without need for channel collapsing.

This modification also allows LAPUR5.2 to model complex mixed cores with more than two fuel types with improved accuracy. This was a limitation of the old LAPUR code, which was caused by the old seven-channel limit. 


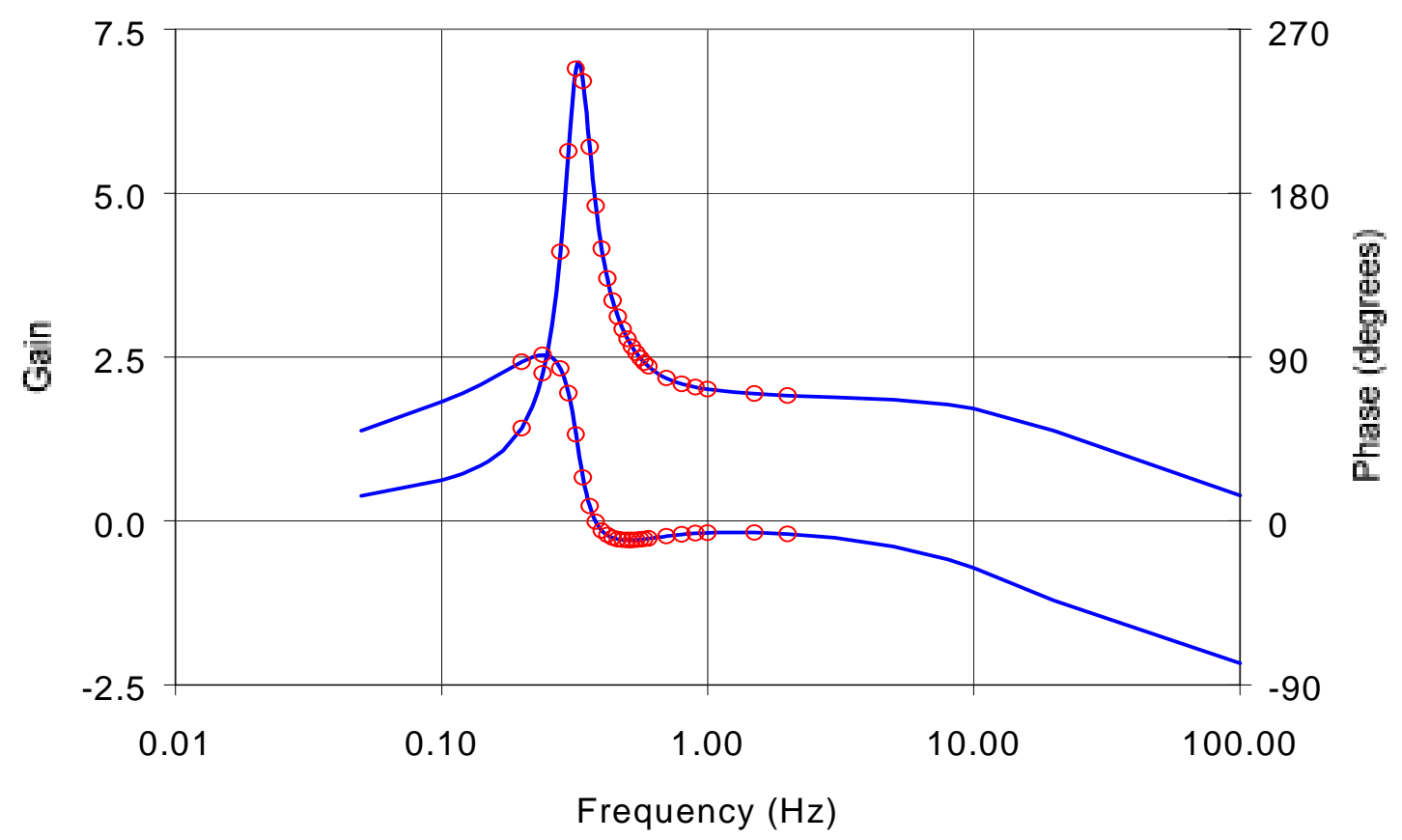

Figure 1. Closed loop transfer function calculated with 100 frequency point (solid line) shows results similar to those calculated with the old 25 point limit (circles)

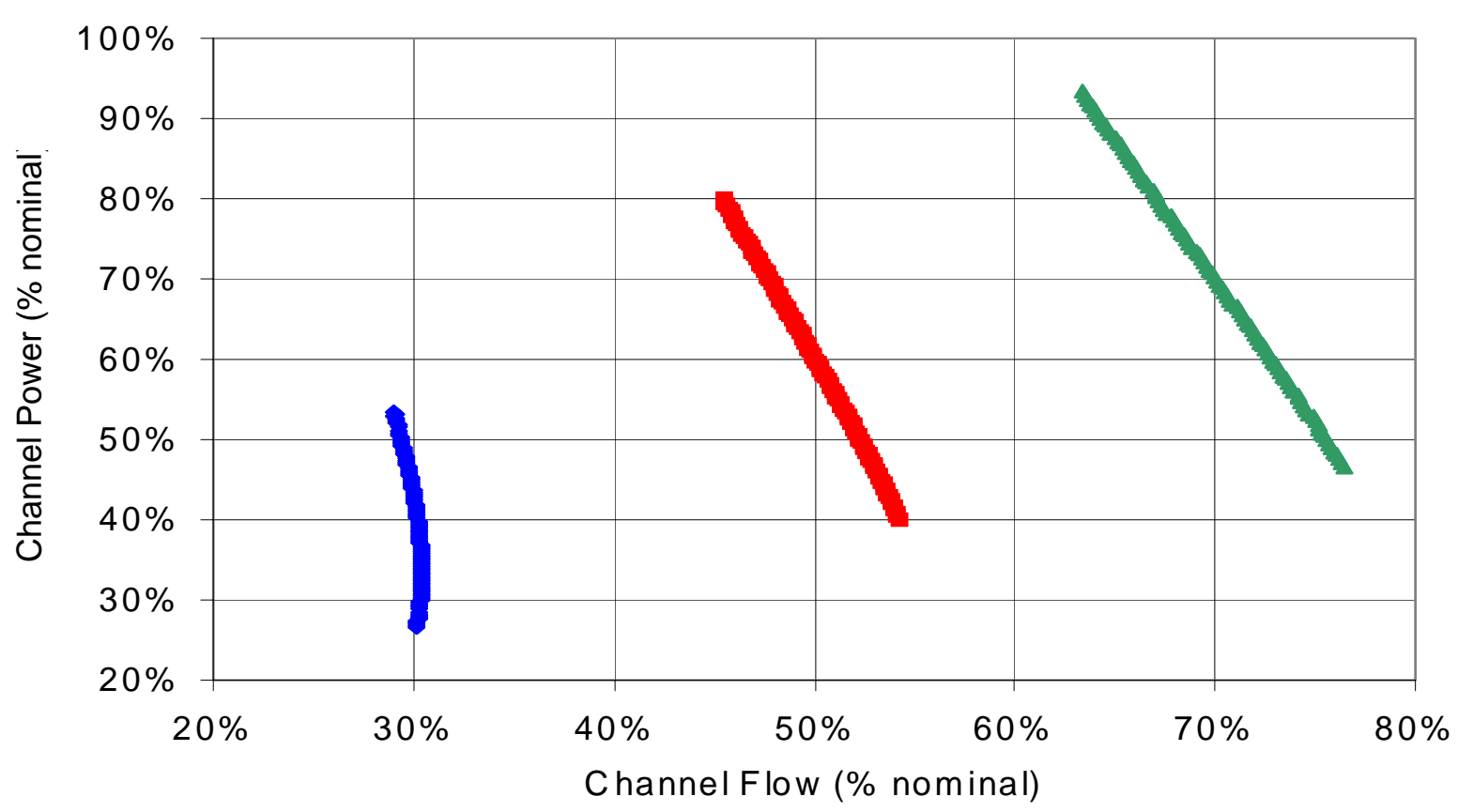

Figure 2. Channel powers and flows from 200-channel LAPUR 5.2 calculations at 30\%, 50\%, and $70 \%$ core flow, respectively, show consistent results. 


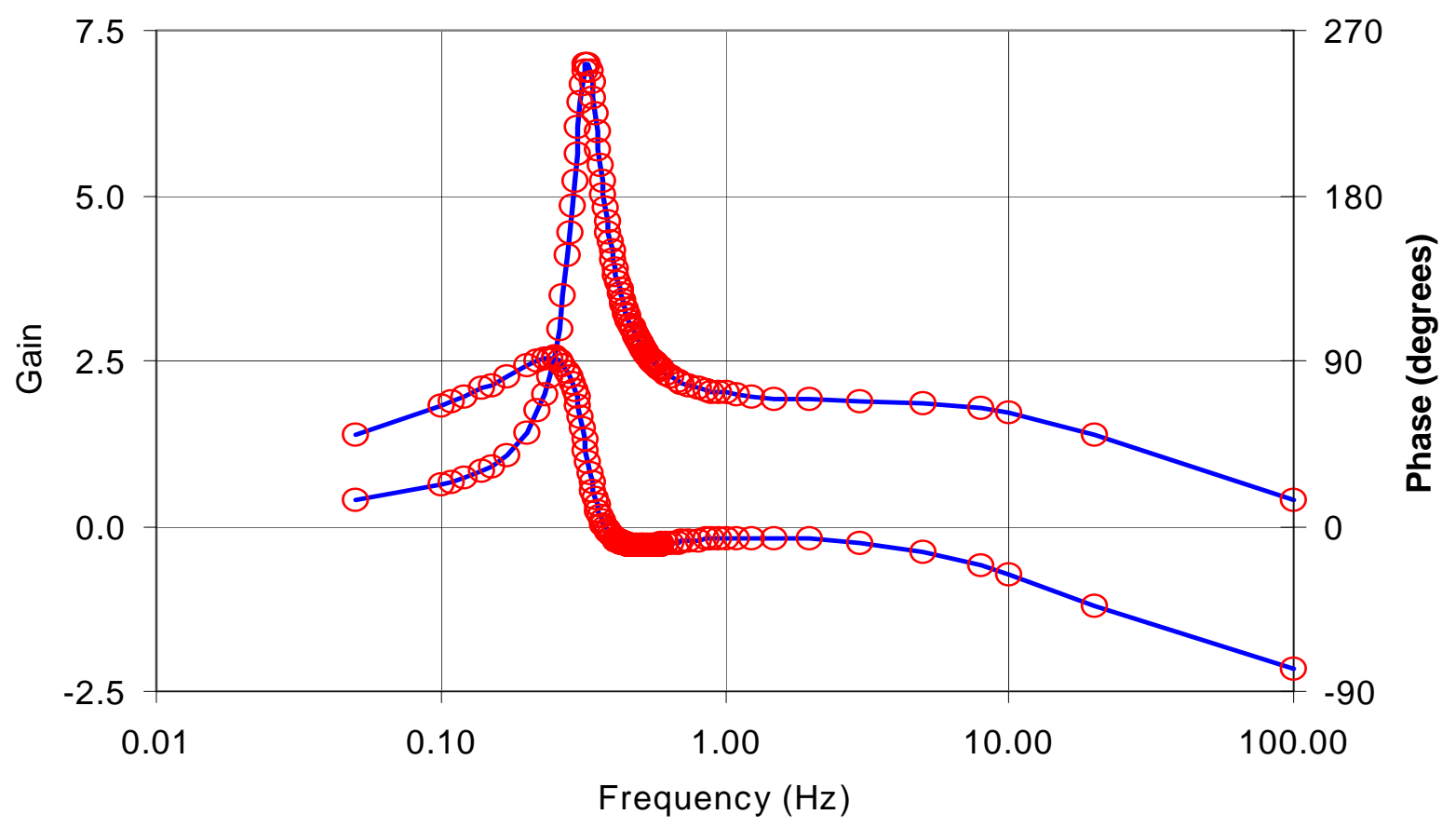

Figure 3. Closed-loop transfer function with a constant radial power profile shows consistent results for either 1 channel (circles) or 200 channels (solid line) 


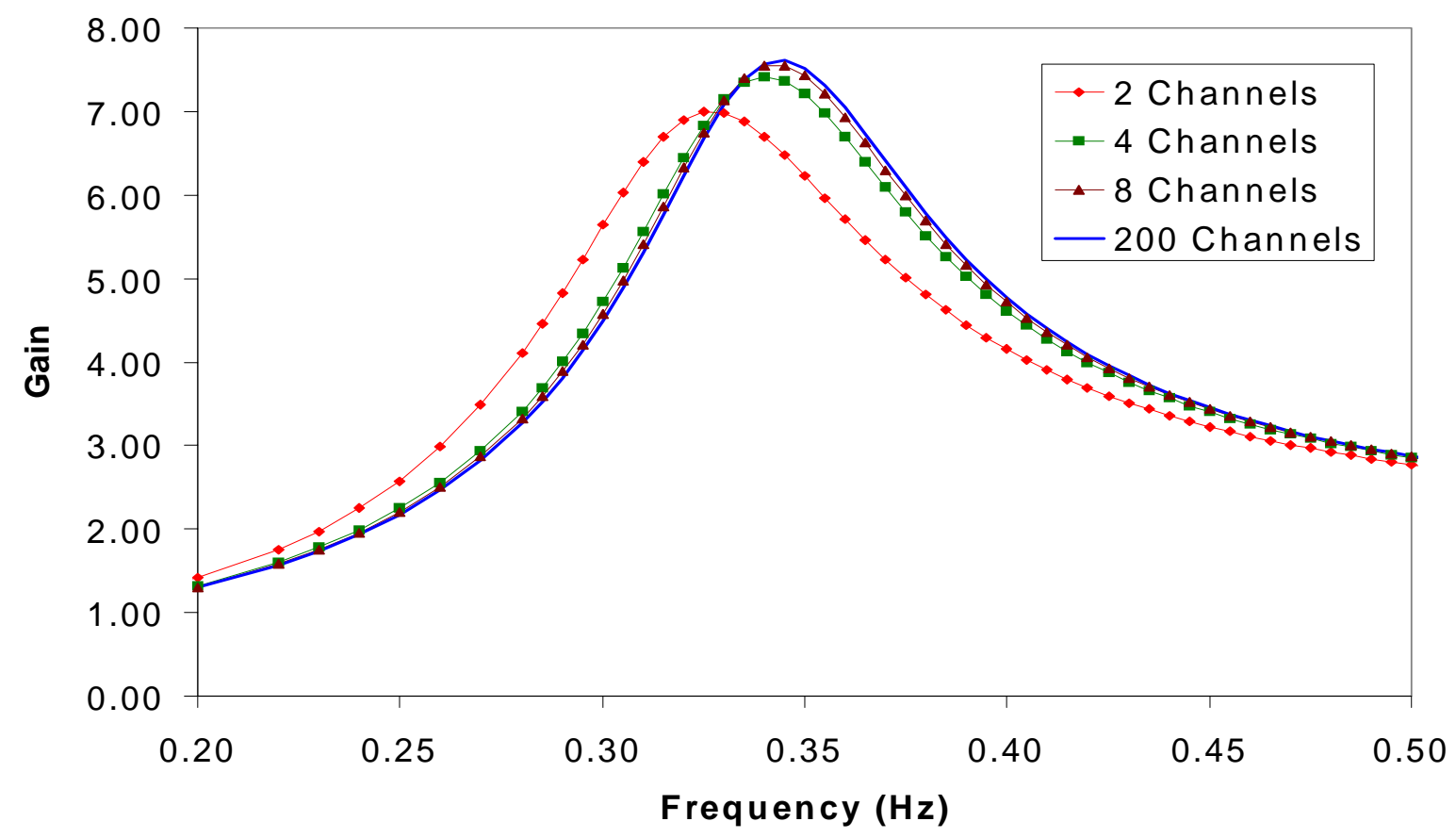

Figure 4. Closed-loop transfer function calculated with different number of channels shows good convergence and demonstrates good behavior of the 200-channel case with a radial power profile. 


\section{REFERENCES}

1. P. J. Otaduy-Bengoa, "Modeling of the Dynamic Behavior of Large Boiling Water Reactor Cores," Ph.D. dissertation, University of Florida, 1979.

2. J. March-Leuba and E. D. Blakeman, "A Study of Out-of-Phase Power Instabilities in Boiling Water Reactor," International Reactor Physics Conference, Jackson Hole, Wyo., September 18-22, 1988.

3. J. March-Leuba and P. J. Otaduy, "A Comparison of BWR Stability Measurements with Calculations Using the Code LAPUR-IV," NUREG/CR2998, ORNL/TM-8546, Oak Ridge National Laboratory, January 1983.

4. A. B. Jones, Hydrodynamic Stability of a Boiling Channel, Part 4, KAPL-3070, 1964.

5. A. B. Jones and D. G. Dight, Hydynamic Stability of a Boiling Channel, Part 2, KAPL-2208, Knolls Atomic Power Laboratory, Schenectady, N.Y., 1962.

6. J. Flinta, The Hydrodynamic Instability of Boiling Channels, AERTL-1014, AB Atomenergi Studsvik, Sweden, 1968.

7. 0. J. M. Smith, Feedback Control Systems, McGraw-Hill, New York, 1958.

8. J. March-Leuba, D. N. Fry, M. E. Buchanan, and C. 0. McNew, Local Stability Tests in Dresden 2, ORNL/TM-9054, Oak Ridge National Laboratory, March 1984.

9. J. March-Leuba, R. T. Wood, P. J. Otaduy, and C. 0. McNew, "Stability Tests at Browns Ferry Unit 1 Under Single-Loop Operating Conditions," Nucl. Techno. 74 38-52 (May 1986).

10. J. March-Leuba, and P. J. Otaduy, "The Importance of Momentum Dynamics is BWR Neutronic Stability: Experimental Evidence," Trans. Am. Nucl. Soc. 50 563-564, November 1985.

11. J. March-Leuba and D. N. Fry, Grand Gulf-1 and Susquehanna-2 Stability Test, ORNL/NRC/LTR-87/01, Oak Ridge National Laboratory, April 1987.

12. J. March-Leuba, Stability Calculations for the Grand Gulf-1 and Susquehanna-2 Boiling Water Reactor, ORNL/NRC/LTR-87/08, Oak Ridge National Laboratory, September 1987. 


\section{APPENDIX A - SAMPLE LAPURX AND LAPURW INPUTS FOR A SINGLE-CHANNEL CALCULATION}

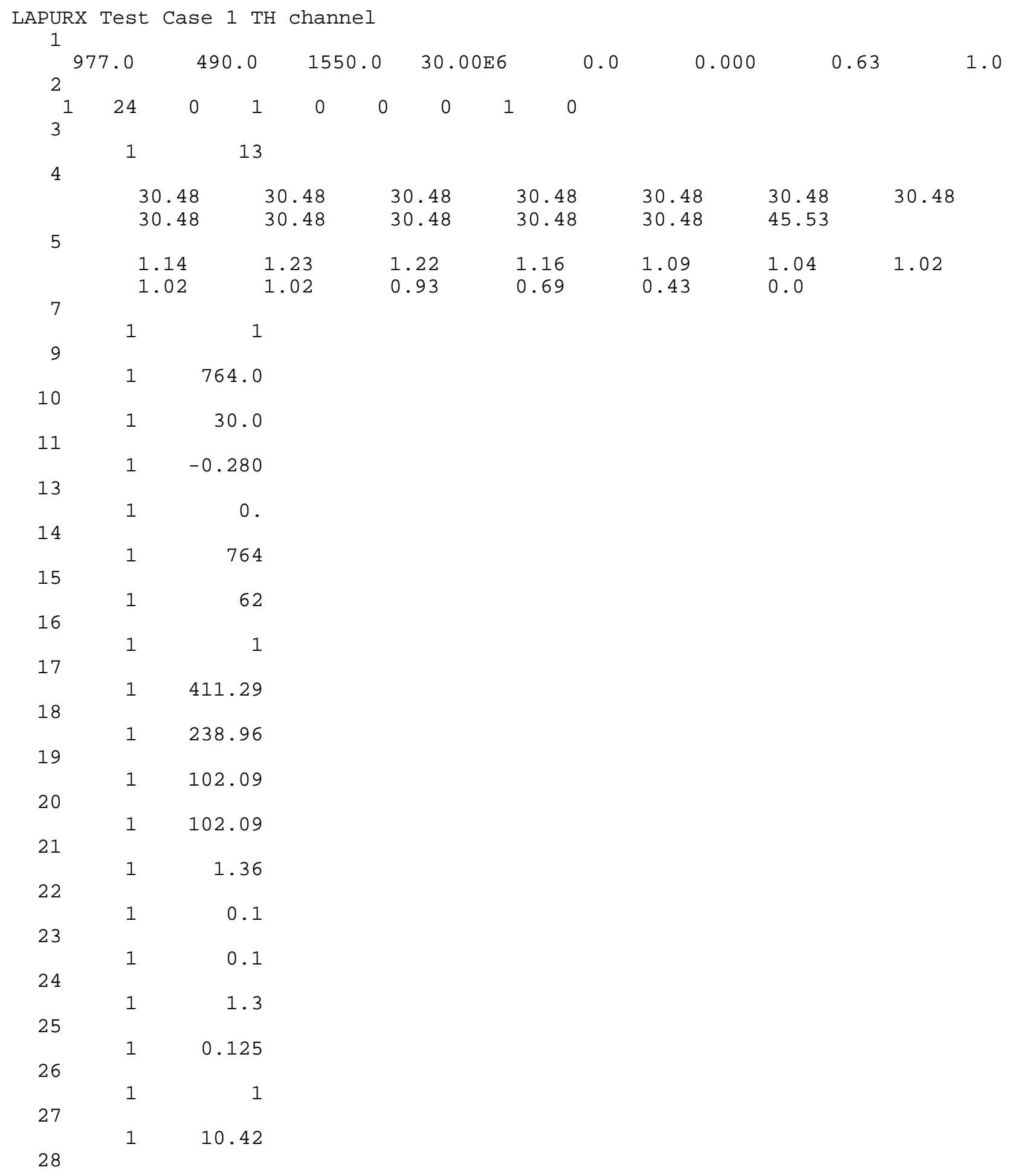




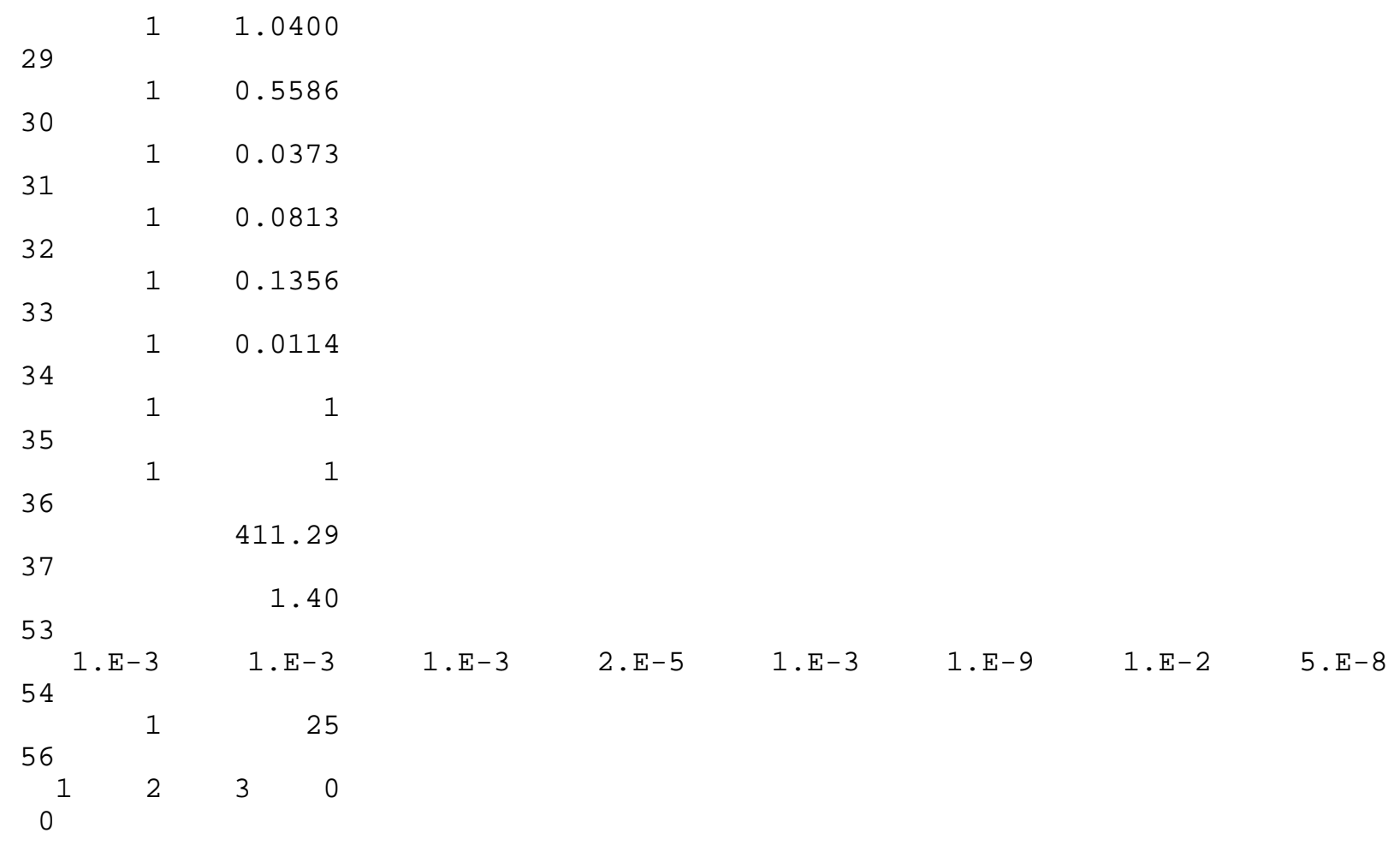




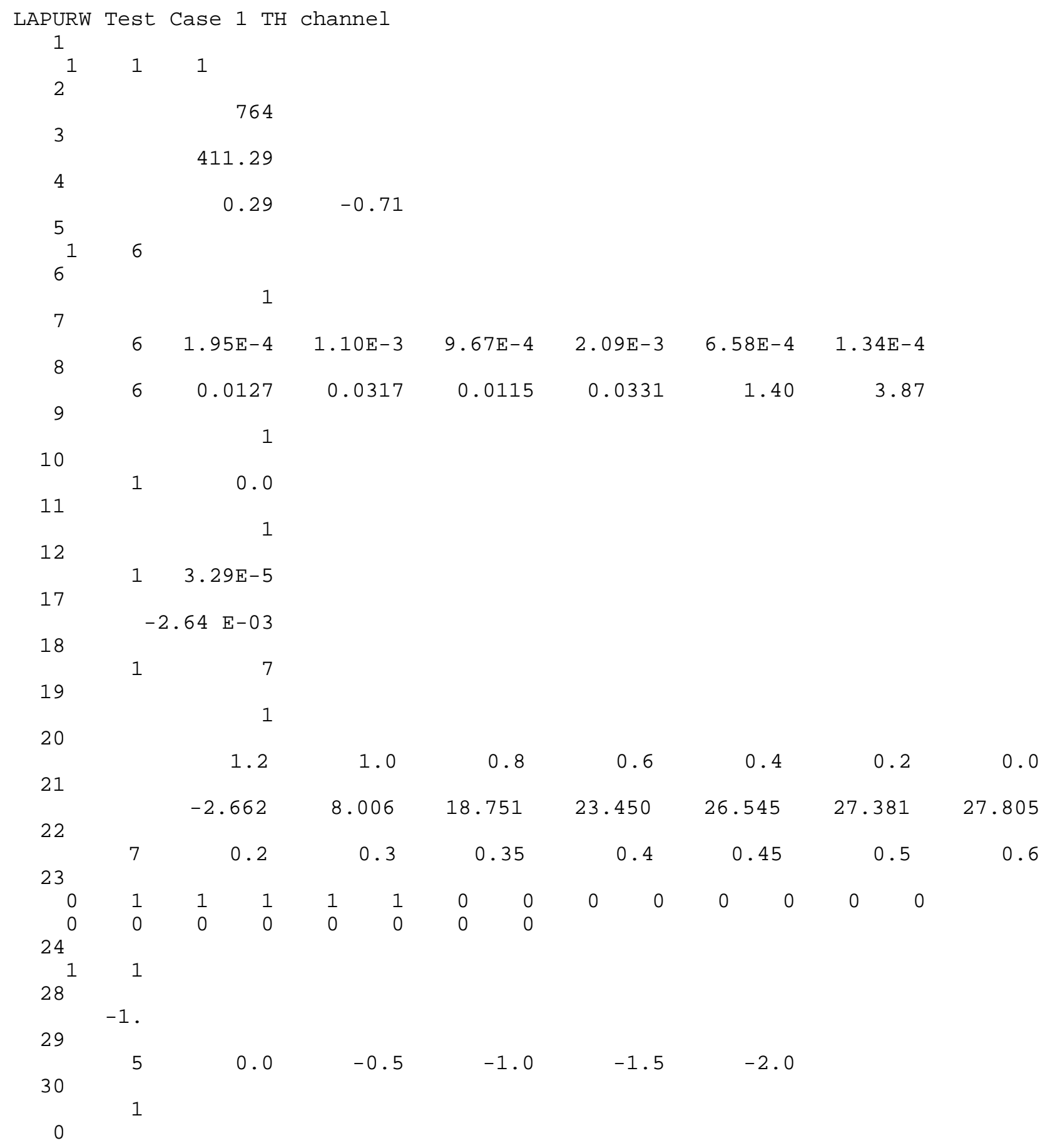




\section{APPENDIX B - SAMPLE CSV OUTPUT FILES FOR A SINGLE-CHANNEL CALCULATION}

\section{Output File LAPURX.CSV:}

LAPURX Test Case 1 TH channel

Ch,NCH,Fuel,Power,Flow,delta-P,Exit,Zb

, ,Type,(\%),(\%),(bar),Quality,(m)

$1,764,1, \quad 100.0000, \quad 100.0000, \quad .3213, \quad .1951, \quad .8438$,

\section{Output File LAPURW.CSV:}

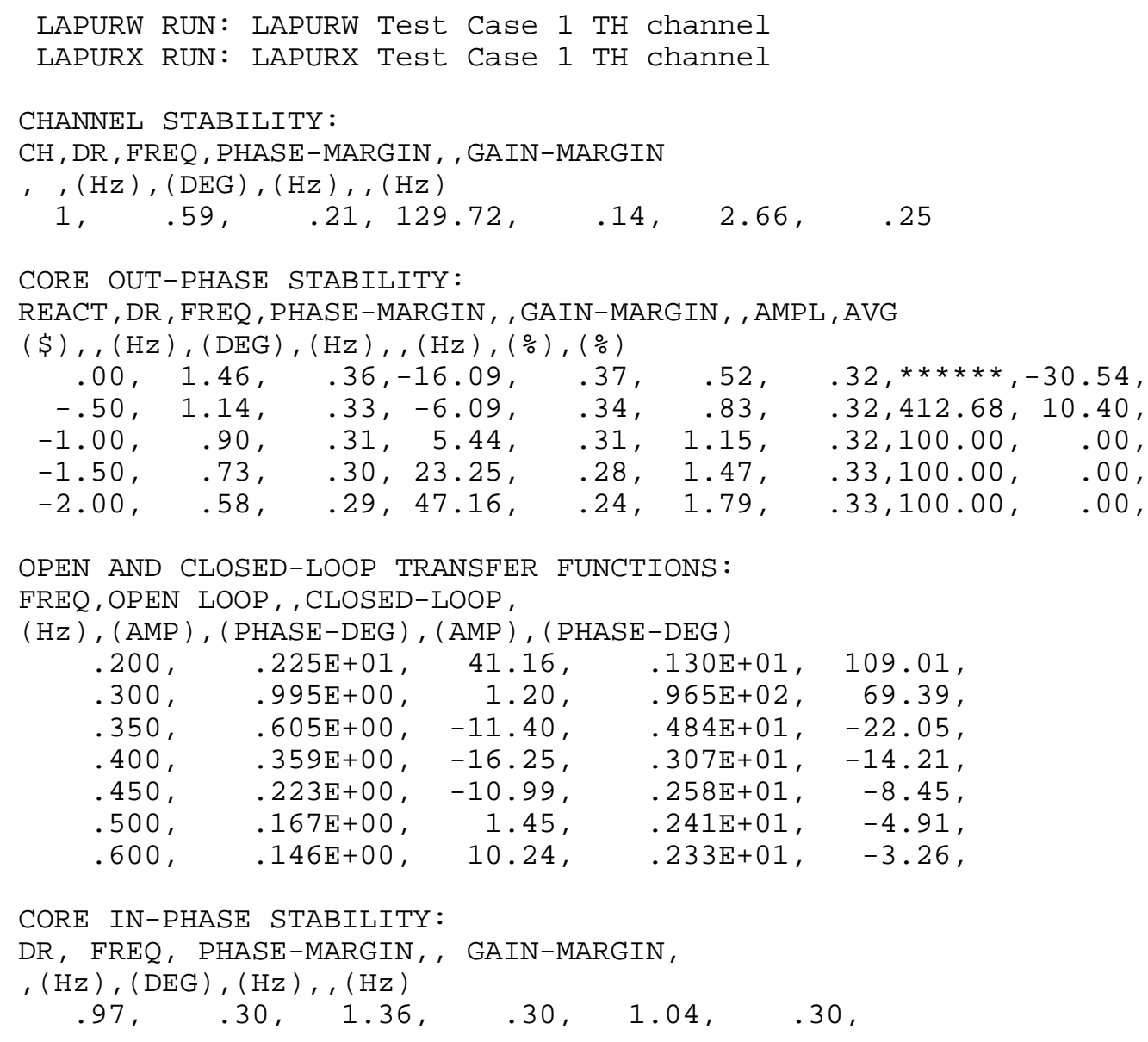

CORE IN-PHASE STABILITY:

DR, FREQ, PHASE-MARGIN, , GAIN-MARGIN, , $(\mathrm{Hz}),(\mathrm{DEG}),(\mathrm{Hz}),,(\mathrm{Hz})$
.97 ,
.30,
1. 36 ,
.30
1.04,
.30 , 


\section{APPENDIX C - SAMPLE LAPURX AND LAPURW INPUTS FOR A 200- CHANNEL CALCULATION}

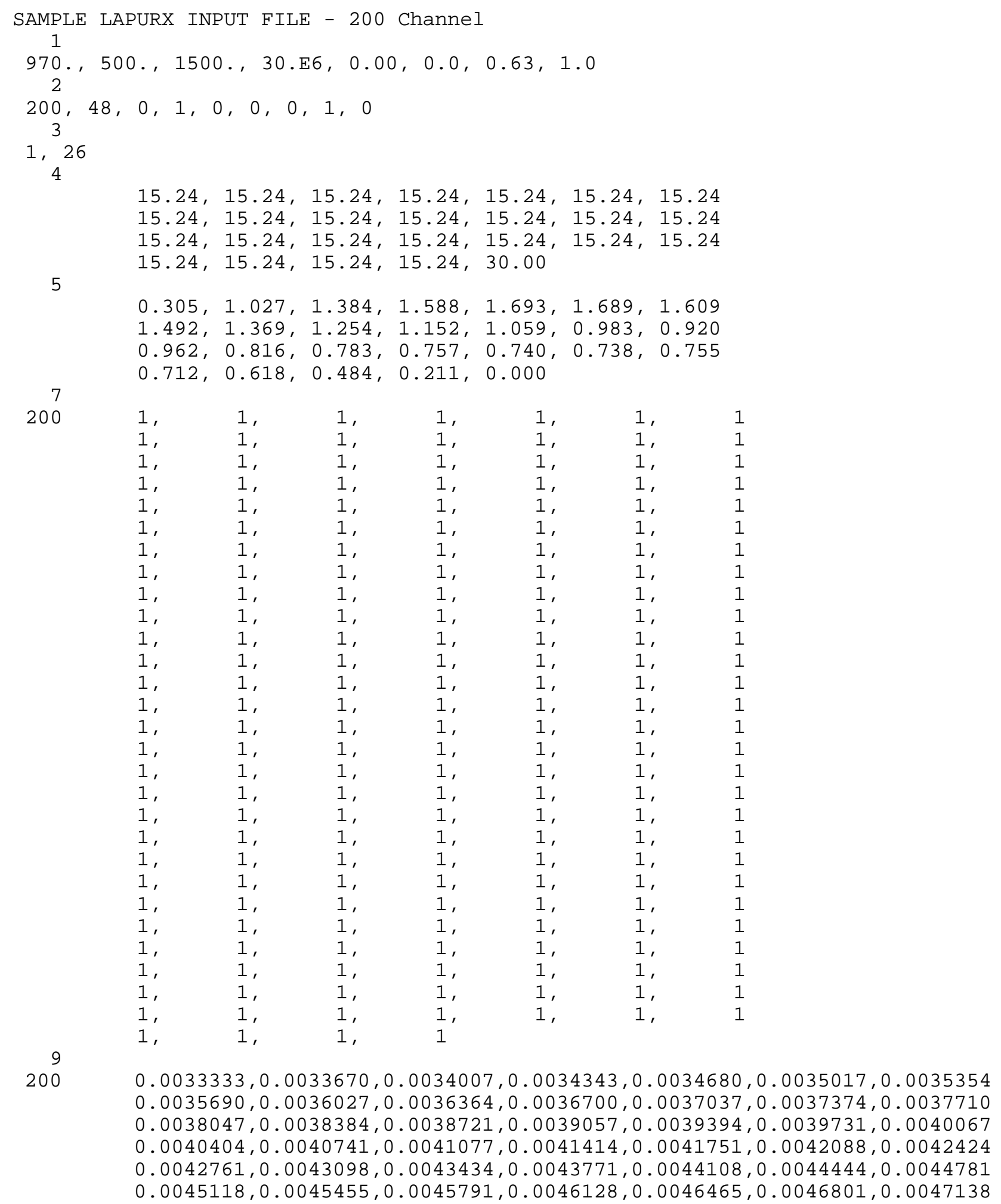


$0.0047475,0.0047811,0.0048148,0.0048485,0.0048822,0.0049158,0.0049495$ $0.0049832,0.0050168,0.0050505,0.0050842,0.0051178,0.0051515,0.0051852$ $0.0052189,0.0052525,0.0052862,0.0053199,0.0053535,0.0053872,0.0054209$ $0.0054545,0.0054882,0.0055219,0.0055556,0.0055892,0.0056229,0.0056566$ $0.0056902,0.0057239,0.0057576,0.0057912,0.0058249,0.0058586,0.0058923$ $0.0059259,0.0059596,0.0059933,0.0060269,0.0060606,0.0060943,0.0061279$ $0.0061616,0.0061953,0.0062290,0.0062626,0.0062963,0.0063300,0.0063636$ $0.0063973,0.0064310,0.0064646,0.0064983,0.0065320,0.0065657,0.0065993$ $0.0066330,0.0066667,0.0066667,0.0066330,0.0065993,0.0065657,0.0065320$ $0.0064983,0.0064646,0.0064310,0.0063973,0.0063636,0.0063300,0.0062963$ $0.0062626,0.0062290,0.0061953,0.0061616,0.0061279,0.0060943,0.0060606$ $0.0060269,0.0059933,0.0059596,0.0059259,0.0058923,0.0058586,0.0058249$ $0.0057912,0.0057576,0.0057239,0.0056902,0.0056566,0.0056229,0.0055892$ $0.0055556,0.0055219,0.0054882,0.0054545,0.0054209,0.0053872,0.0053535$ $0.0053199,0.0052862,0.0052525,0.0052189,0.0051852,0.0051515,0.0051178$ $0.0050842,0.0050505,0.0050168,0.0049832,0.0049495,0.0049158,0.0048822$ $0.0048485,0.0048148,0.0047811,0.0047475,0.0047138,0.0046801,0.0046465$ $0.0046128,0.0045791,0.0045455,0.0045118,0.0044781,0.0044444,0.0044108$ $0.0043771,0.0043434,0.0043098,0.0042761,0.0042424,0.0042088,0.0041751$ $0.0041414,0.0041077,0.0040741,0.0040404,0.0040067,0.0039731,0.0039394$ $0.0039057,0.0038721,0.0038384,0.0038047,0.0037710,0.0037374,0.0037037$ $0.0036700,0.0036364,0.0036027,0.0035690,0.0035354,0.0035017,0.0034680$ $0.0034343,0.0034007,0.0033670,0.0033333$

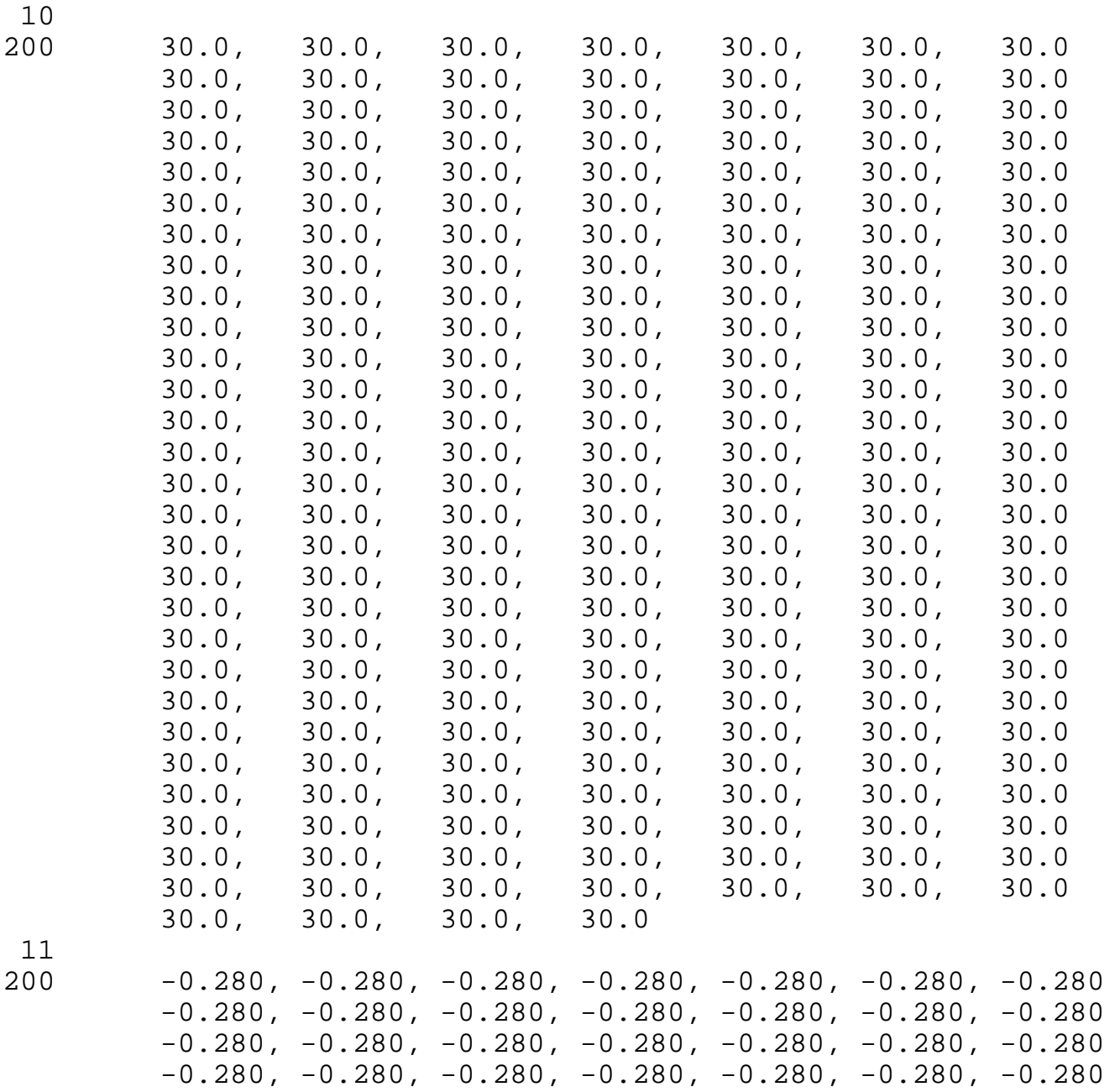




\begin{tabular}{|c|c|c|c|c|c|c|}
\hline $\begin{array}{l}0 . \\
0 . \\
0 . \\
0 .\end{array}$ & $\begin{array}{l}-0.2 \\
-0.2 \\
-0.2 \\
-0.2 \\
-0.2 \\
-0.2 \\
-0.2 \\
-0.2 \\
-0.2 \\
-0.2 \\
-0.2 \\
-0.2 \\
-0.2 \\
-0.2\end{array}$ & $\begin{array}{l}-0.2 \\
-0.2 \\
-0.2 \\
-0.2 \\
-0.2 \\
-0.2 \\
-0.2 \\
-0.2 \\
-0.2 \\
-0.2 \\
-0.2 \\
-0.2 \\
-0.2 \\
-0.2 \\
-0.2 \\
-0.2\end{array}$ & $\begin{array}{l}-0.2 \\
-0.2 \\
-0.2 \\
-0.2 \\
-0.2 \\
-0.2 \\
-0.2 \\
-0.2 \\
-0.2 \\
-0.2 \\
-0.2 \\
-0.2 \\
-0.2\end{array}$ & $\begin{array}{l}-0.2 \\
-0.2 \\
-0.2 \\
-0.2 \\
-0.2 \\
-0.2 \\
-0.2 \\
-0.2 \\
-0.2 \\
-0.2 \\
-0.2 \\
-0.2 \\
-0.2 \\
-0.2 \\
-0.2 \\
-0.2 \\
-0.2 \\
-0.2\end{array}$ & $\begin{array}{l}0, \\
0, \\
0, \\
0, \\
0, \\
0, \\
0, \\
0, \\
0, \\
0, \\
0, \\
0, \\
0, \\
0, \\
0, \\
0, \\
0, \\
0, \\
0, \\
0, \\
0\end{array}$ & $\begin{array}{l}- \\
- \\
- \\
-\end{array}-$ \\
\hline
\end{tabular}

\begin{tabular}{|c|c|c|c|c|c|}
\hline $0 .$, & $0 .$, & $0 .$, & $0 .$, & $0 .$, & $0 .$, \\
\hline $0 .$, & $0 .$, & $0 .$, & $0 .$, & $0 .$, & $0 .$, \\
\hline $0 .$, & $0 .$, & $0 .$, & $0 .$, & $0 .$, & $0 .$, \\
\hline $0 .$, & $0 .$, & $0 .$, & $0 .$, & $0 .$, & $0 .$, \\
\hline $0 .$, & $0 .$, & $0 .$, & $0 .$, & $0 .$, & $0 .$, \\
\hline $0 .$, & $0 .$, & $0 .$, & $0 .$, & $0 .$, & $0 .$, \\
\hline $0 .$, & $0 .$, & $0 .$, & $0 .$, & $0 .$, & $0 .$, \\
\hline $0 .$, & $0 .$, & $0 .$, & $0 .$, & $0 .$, & $0 .$, \\
\hline $0 .$, & $0 .$, & $0 .$, & $0 .$, & $0 .$, & $0 .$, \\
\hline $0 .$, & $0 .$, & $0 .$, & $0 .$, & $0 .$, & $0 .$, \\
\hline $0 .$, & $0 .$, & $0 .$, & $0 .$, & $0 .$, & $0 .$, \\
\hline $0 .$, & $0 .$, & $0 .$, & $0 .$, & $0 .$, & $0 .$, \\
\hline $0 .$, & $0 .$, & $0 .$, & $0 .$, & $0 .$, & $0 .$, \\
\hline $0 .$, & $0 .$, & $0 .$, & $0 .$, & $0 .$, & $0 .$, \\
\hline $0 .$, & $0 .$, & $0 .$, & $0 .$, & $0 .$, & $0 .$, \\
\hline $0 .$, & $0 .$, & $0 .$, & $0 .$, & $0 .$, & $0 .$, \\
\hline $0 .$, & $0 .$, & $0 .$, & $0 .$, & $0 .$, & $0 .$, \\
\hline $0 .$, & $0 .$, & $0 .$, & $0 .$, & $0 .$, & 0. \\
\hline $0 .$, & $0 .$, & $0 .$, & $0 .$, & $0 .$, & $0 .$, \\
\hline $0 .$, & $0 .$, & $0 .$, & $0 .$, & $0 .$, & $0 .$, \\
\hline $0 .$, & $0 .$, & $0 .$, & $0 .$, & $0 .$, & $0 .$, \\
\hline $0 .$, & $0 .$, & $0 .$, & $0 .$, & $0 .$, & $0 .$, \\
\hline $0 .$, & $0 .$, & $0 .$, & $0 .$, & $0 .$, & $0 .$, \\
\hline $0 .$, & $0 .$, & $0 .$, & $0 .$, & $0 .$, & $0 .$, \\
\hline $0 .$, & $0 .$, & $0 .$, & $0 .$, & $0 .$, & $0 .$, \\
\hline $0 .$, & $0 .$, & $0 .$, & $0 .$, & $0 .$, & $0 .$, \\
\hline $0 .$, & $0 .$, & $0 .$, & $0 .$, & $0 .$, & $0 .$, \\
\hline $0 .$, & $0 .$, & $0 .$, & $0 .$, & $0 .$, & $0 .$, \\
\hline $0 .$, & $0 .$, & $0 .$, & 0 . & & \\
\hline
\end{tabular}

200

$\begin{array}{lllllll}4, & 4, & 4, & 4, & 4, & 4, & 4 \\ 4, & 4, & 4, & 4, & 4, & 4, & 4\end{array}$




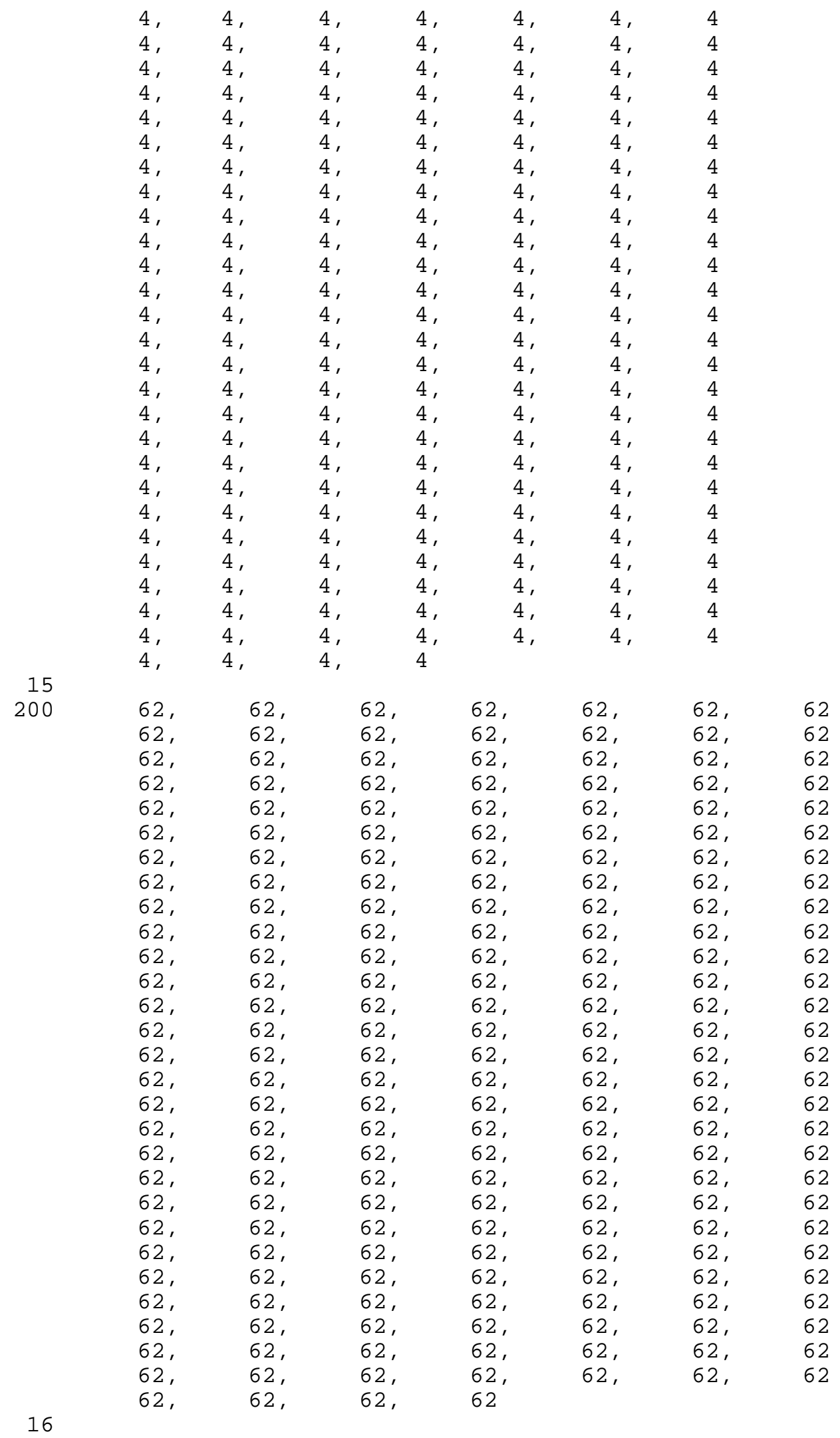




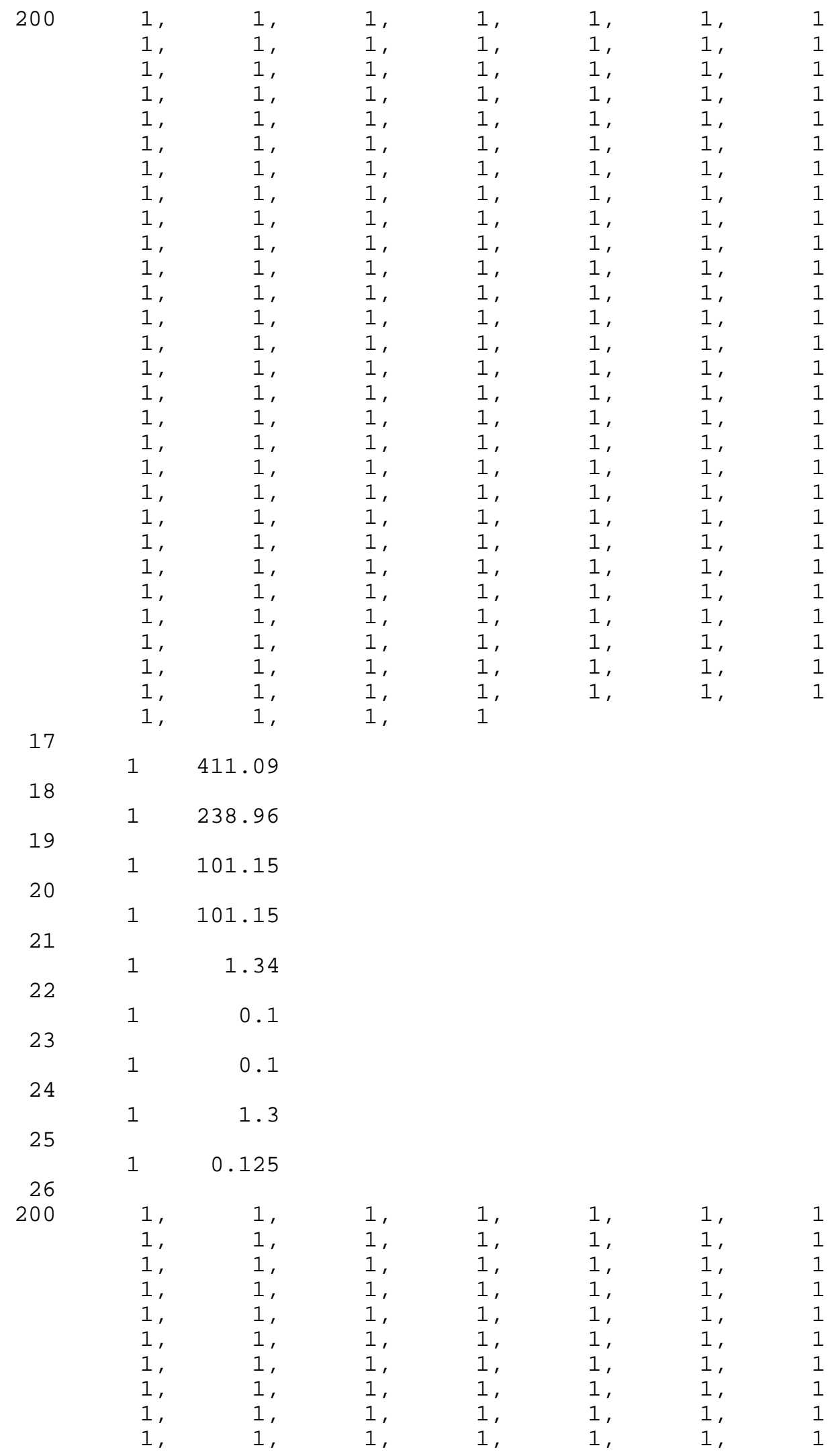




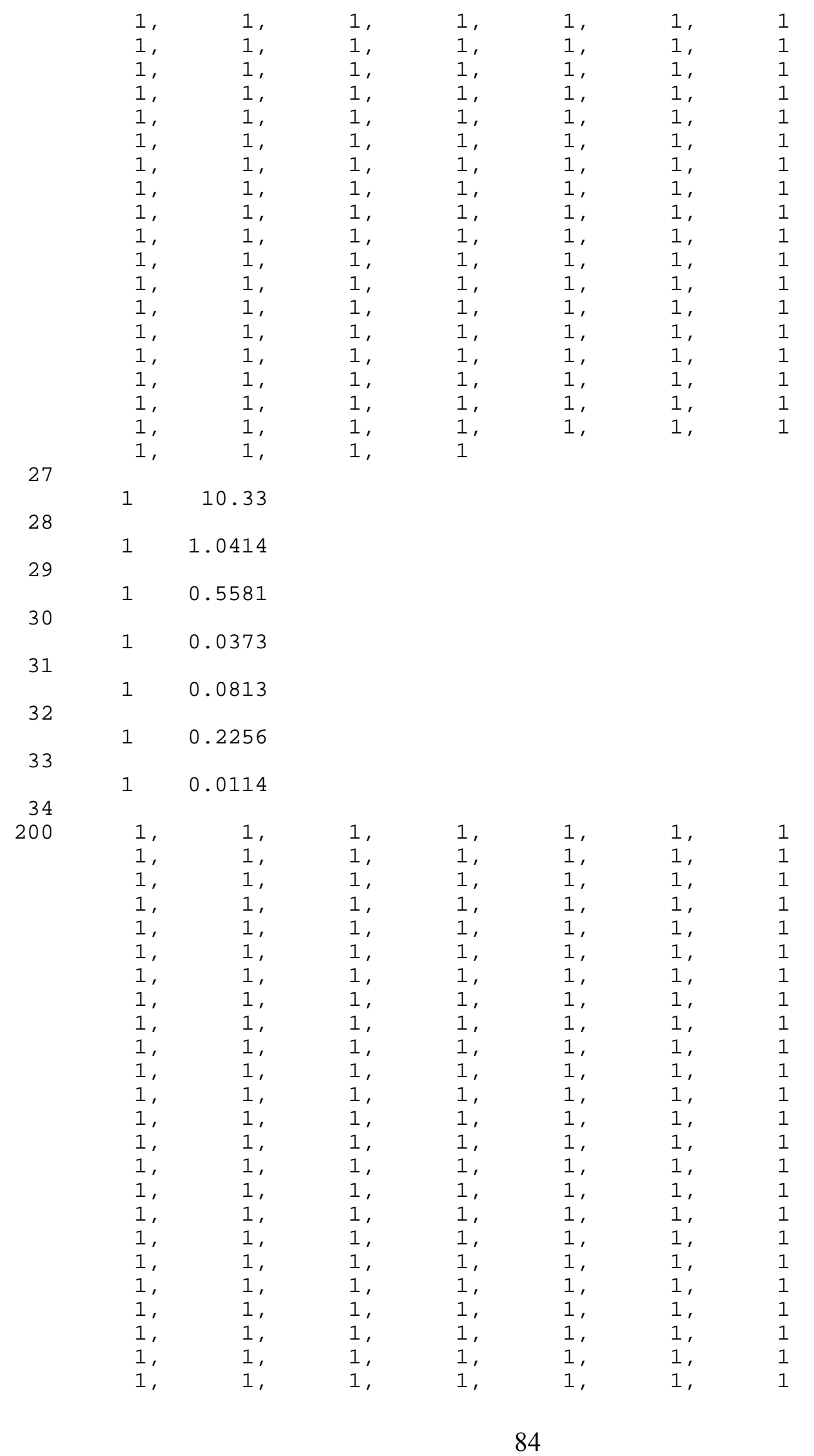




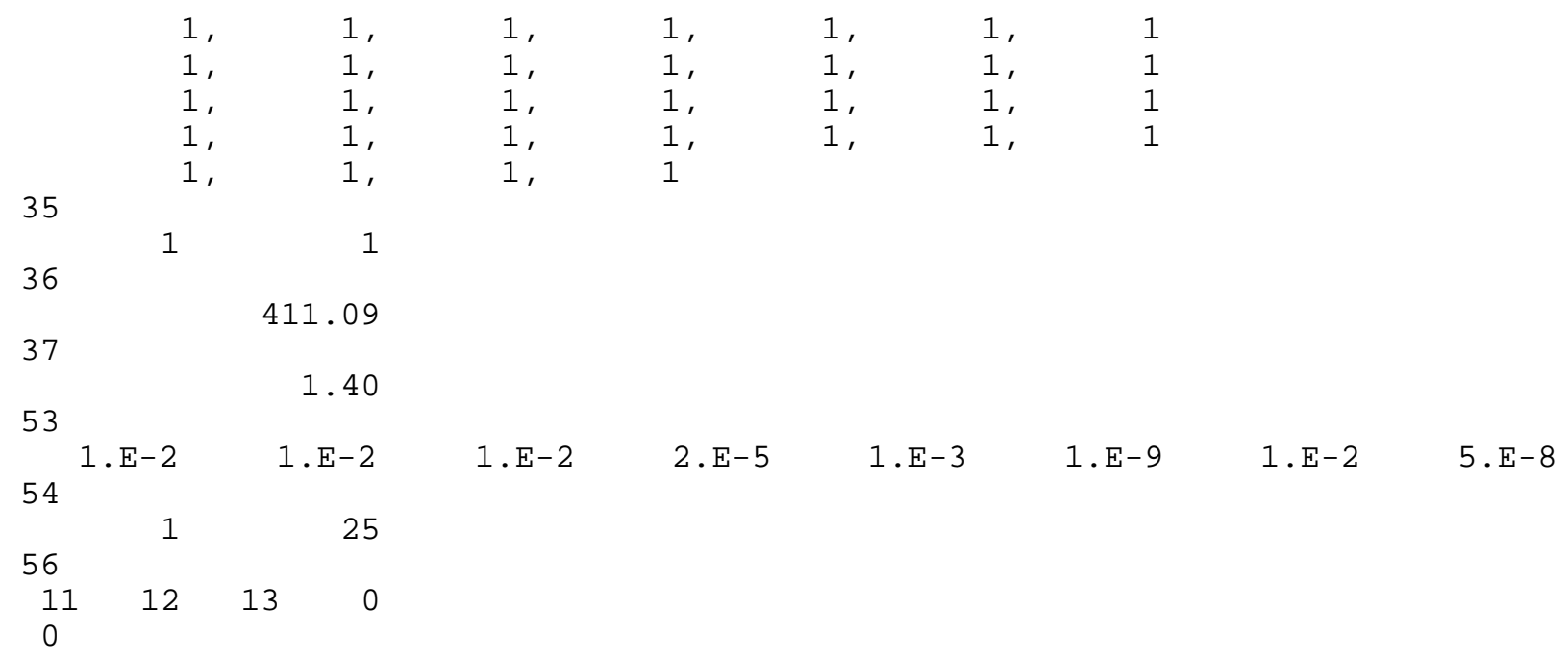




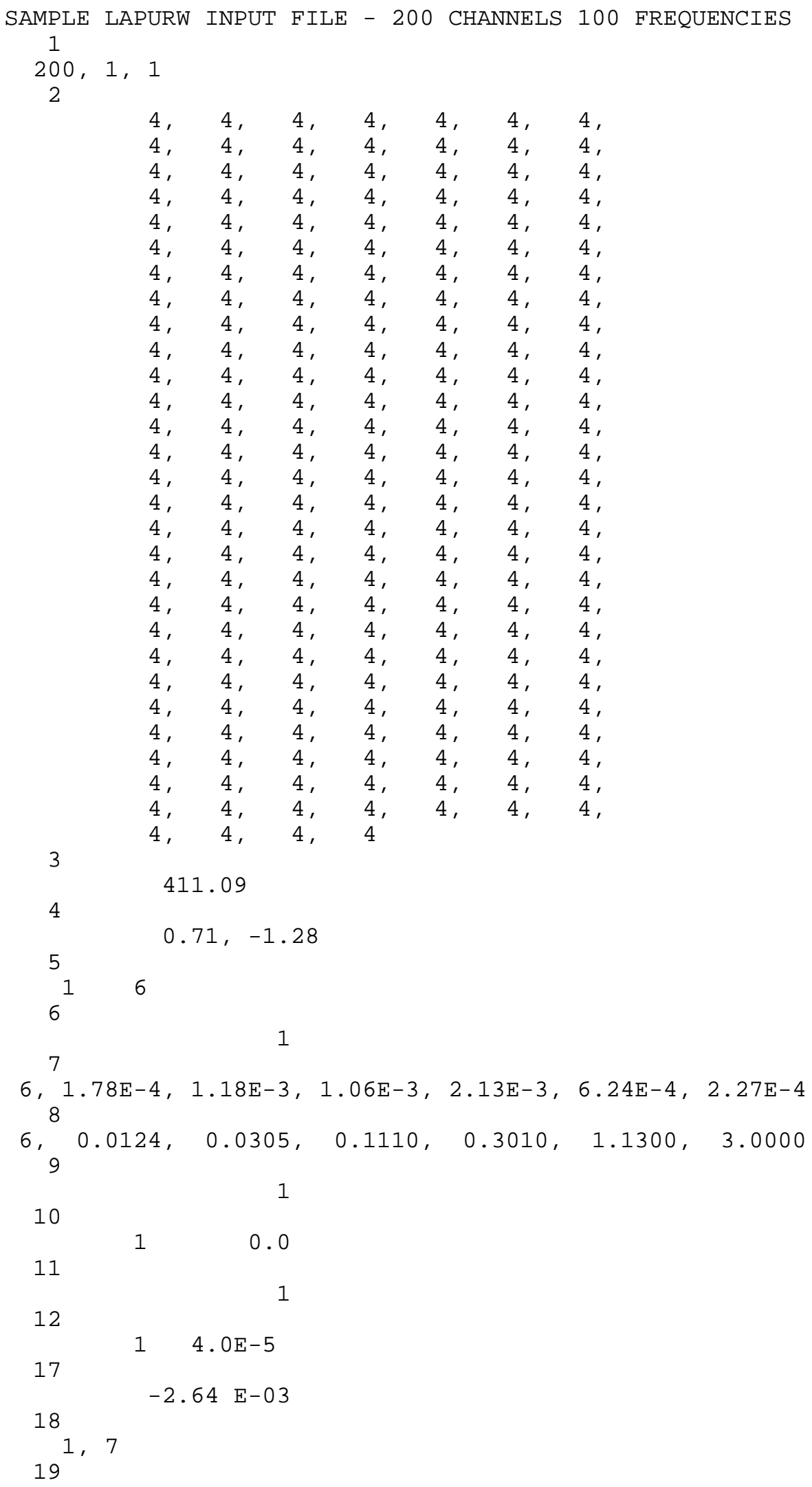




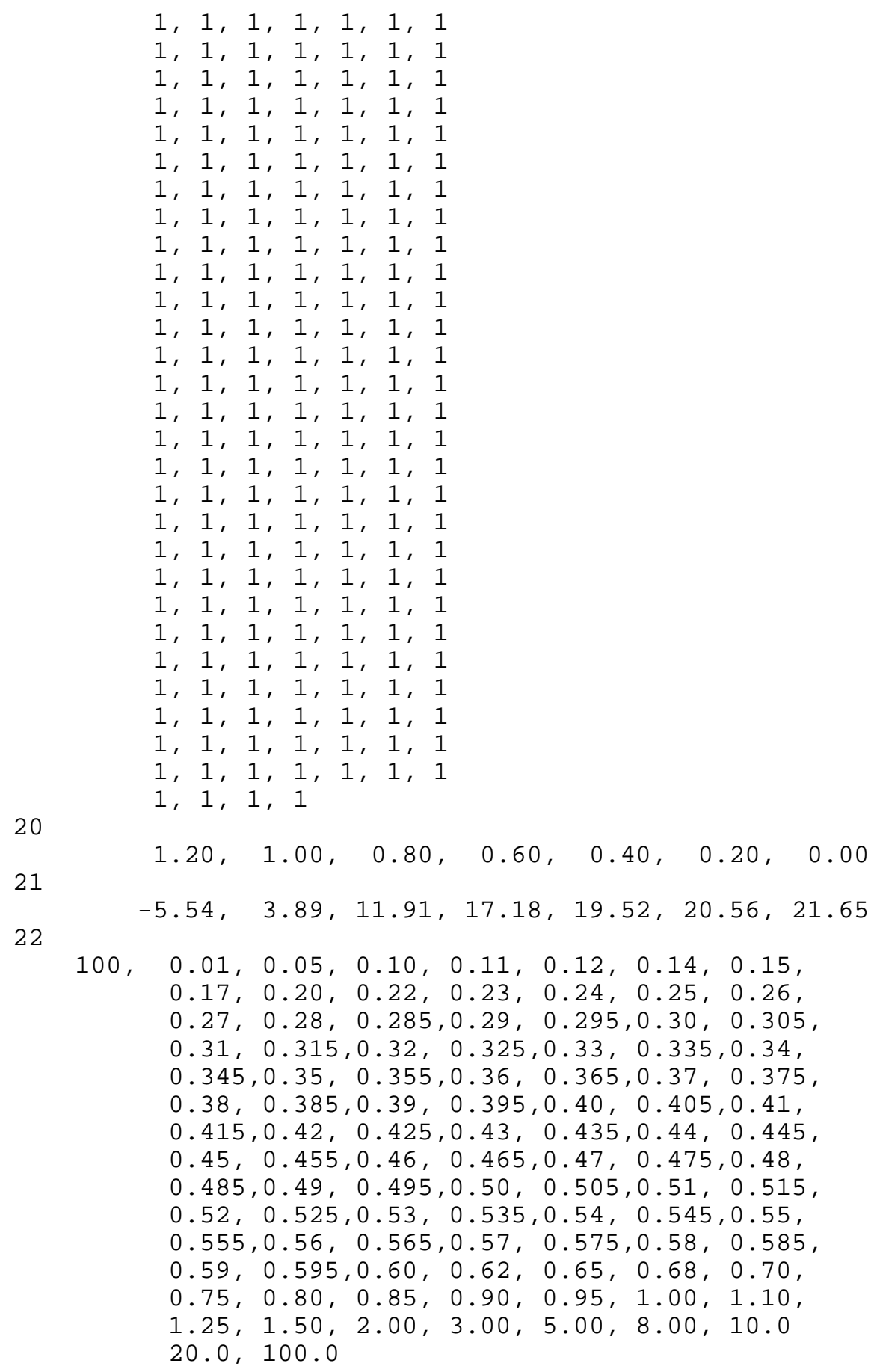

\begin{tabular}{|c|c|c|c|c|c|c|c|c|c|c|c|c|}
\hline \multicolumn{13}{|l|}{23} \\
\hline 0 & 1 & 1 & 1 & 1 & 1 & 0 & 0 & 0 & 0 & 0 & 0 & 0 \\
\hline 0 & 0 & 0 & 0 & 0 & 0 & 0 & 0 & & & & & \\
\hline \multicolumn{13}{|l|}{24} \\
\hline 1 & 1 & 1 & 1 & 1 & 1 & 1 & 1 & 1 & 1 & 1 & 1 & 1 \\
\hline 1 & 1 & 1 & 1 & 1 & 1 & 1 & 1 & 1 & 1 & 1 & 1 & 1 \\
\hline 1 & 1 & 1 & 1 & 1 & 1 & 1 & 1 & 1 & 1 & 1 & 1 & 1 \\
\hline 1 & 1 & 1 & 1 & 1 & 1 & 1 & 1 & 1 & 1 & 1 & 1 & 1 \\
\hline 1 & 1 & 1 & 1 & 1 & 1 & 1 & 1 & 1 & 1 & 1 & 1 & 1 \\
\hline
\end{tabular}




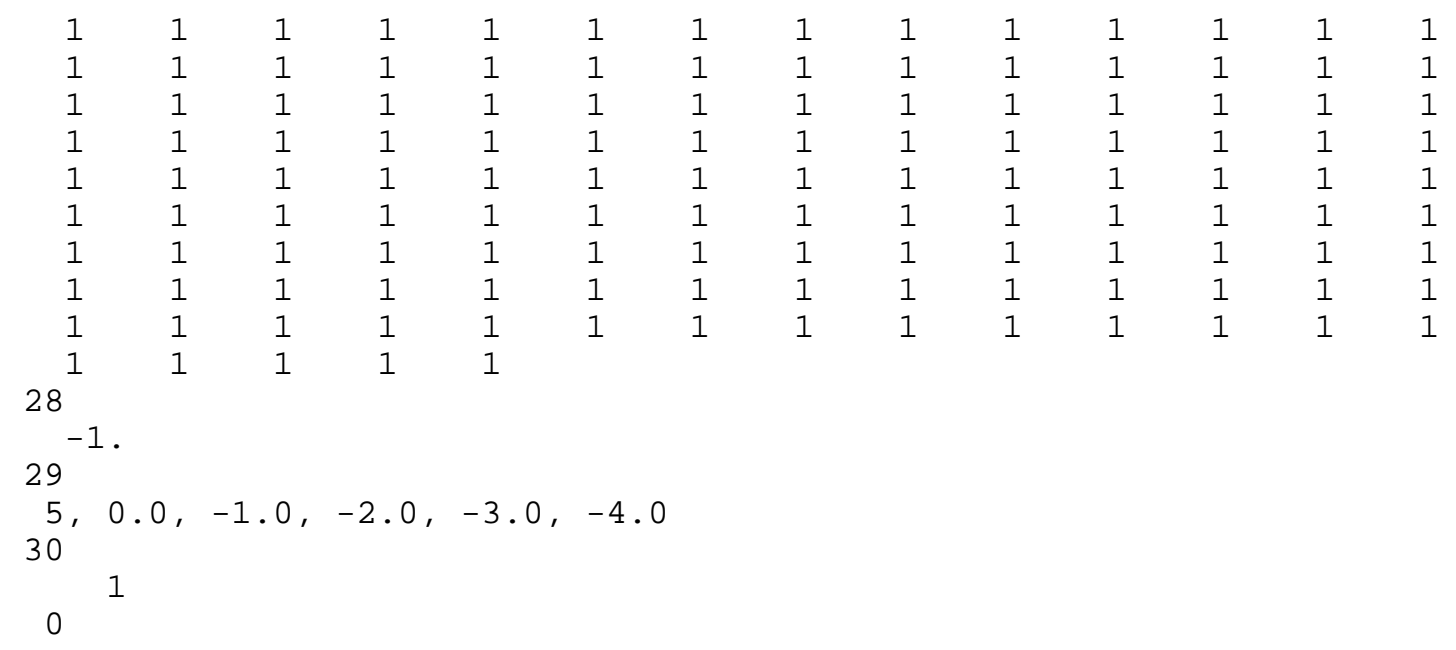




\section{APPENDIX D - SAMPLE CSV OUTPUT FILES FOR A 200-CHANNEL CALCULATION}

\section{Output File LAPURX.CSV:}

SAMPLE LAPURX INPUT FILE - 200 Channel

\begin{tabular}{|c|c|c|c|c|c|c|c|}
\hline 1 & 4 & 1, & 66.6660 & 102.8445 & .3144 , & .1114 & .9932 , \\
\hline 2, & 4, & 1, & 67.3400, & 102.8447 & .3143, & .1131 & .9850, \\
\hline 3, & 4, & 1, & 68.0140 , & 102.8843 & .3143 , & .1148 & .9774 , \\
\hline 4, & 4, & 1, & 68.6860, & 102.9362 , & .3143, & .1164 & .9702 , \\
\hline 5, & 4, & 1, & 69.3600, & 102.9575 & .3142 , & .1180 & .9629 , \\
\hline 6, & 4, & 1, & 70.0340 , & 103.0049 , & .3143 , & .1197 & .9560 , \\
\hline 7, & 4, & 1, & 70.7080 , & 103.0378 , & .3143, & .1213 & .9490, \\
\hline 8, & 4, & 1, & 71.3800, & 103.0292 , & .3142 , & .1230 & .9420 , \\
\hline 9 , & 4, & 1, & 72.0540 , & 103.0613 & .3143 , & .1247 , & .9353 , \\
\hline 10, & 4, & 1, & 72.7280 , & 103.0505, & .3142 , & .1264 , & .9284 , \\
\hline 11, & 4, & 1, & 73.4000 , & 103.0871 , & .3143 , & .1280 & .9220 , \\
\hline 12, & 4, & 1, & 74.0740 , & 103.0844 & .3143 , & .1297 , & .9155 , \\
\hline 13, & 4, & 1, & 74.7480 , & 103.0747 , & .3143 , & .1314 & .9090 , \\
\hline 14, & 4, & 1, & 75.4200 , & 103.0523 & .3142 , & .1332 & .9025 , \\
\hline 15, & 4, & 1, & 76.0940, & 103.0667 , & .3143 , & .1349 , & .8964 , \\
\hline 16, & 4, & 1, & 76.7680 , & 103.0301 , & .3143 , & .1366 & .8902 , \\
\hline 17, & 4, & 1, & 77.4420 , & 103.0271 , & .3143 , & .1383 , & .8844 , \\
\hline 18, & 4, & 1, & 78.1140 , & 103.0048, & .3143 , & .1401 , & .8785 , \\
\hline 19, & 4, & 1, & 78.7880, & 102.9630 & .3143 , & .1419, & .8726 , \\
\hline 20 & 4, & 1, & 79.4620 , & 102.9302 , & .3142 , & .1436 & .8669, \\
\hline 21, & 4, & 1, & 80.1340 , & 102.9143 & .3143 , & .1454 , & .8613 , \\
\hline 22, & 4, & 1, & 80.8080 , & 102.8742 , & .3143, & .1472 , & .8557 , \\
\hline 23 & 4, & 1, & 81.4820, & 102.8230 & .3142 , & .1490 & .8502 , \\
\hline 24, & 4, & 1, & 82.1540 , & 102.7934 & .3143 , & .1507 , & .8448 , \\
\hline 25, & 4, & 1, & 82.8280 , & 102.7414 & .3143 , & .1525 , & .8394, \\
\hline 26, & 4, & 1, & 83.5020 , & 102.6767 & .3142 , & .1544 , & .8340 , \\
\hline 27, & 4, & 1, & 84.1760 , & 102.6463 & .3143 , & .1561 , & .8290 , \\
\hline 28, & 4, & 1, & 84.8480, & 102.5942 , & .3143 , & .1580 & .8238 , \\
\hline 29, & 4, & 1, & 85.5220 , & 102.5212 , & .3142 , & .1598, & .8186 , \\
\hline 30, & 4, & 1, & 86.1960, & 102.4536, & .3142 , & .1617 , & .8136 , \\
\hline 31, & 4, & 1, & 86.8680, & 102.4128 & .3143 , & .1635 , & .8088 , \\
\hline 32, & 4, & 1, & 87.5420 , & 102.3453 & .3143 , & .1653 & .8039 , \\
\hline 33, & 4, & 1, & 88.2160 , & 102.2717 & .3143 , & .1672 , & .7991 , \\
\hline 34, & 4, & 1, & 88.8880, & 102.2035 & .3143 , & .1691 , & .7943 , \\
\hline 35, & 4, & 1, & 89.5620 & 102.1091 & .3143, & .1710 & .7895 \\
\hline 36, & 4, & 1, & 90.2360 & 102.0426 & .3143 , & .1729 , & .7849 , \\
\hline 37, & 4, & 1, & 90.9100, & 101.9658 & .3143 , & .1748 , & .7804 , \\
\hline 38, & 4, & 1, & 91.5820, & 101.8851 & .3143 , & .1767 , & .7759 , \\
\hline 39, & 4, & 1, & 92.2560 , & 101.7965 & .3143 , & .1786 , & .7714 , \\
\hline 40, & 4, & 1, & 92.9300, & 101.7035 & .3143 , & .1805 , & .7669 , \\
\hline 41, & 4, & 1, & 93.6020 , & 101.6272 & .3143 , & .1824 , & .7626 , \\
\hline 42, & 4, & 1, & 94.2760 , & 101.5408 & .3143 , & .1844 , & .7583 , \\
\hline 43, & 4, & 1, & 94.9500, & 101.4439 & .3143 , & .1863 & .7540 , \\
\hline 44, & 4, & 1, & 95.6220 , & 101.3498 & .3143 , & .1883 & .7498, \\
\hline 45, & 4, & 1, & 96.2960, & 101.2510 & .3143 , & .1903 & .7456 , \\
\hline 46, & 4, & 1, & 96.9700, & 101.1596 & .3143 , & .1922 , & .7416 , \\
\hline 47, & 4, & 1, & 97.6440 , & 101.0573 & .3143 , & .1942 , & .7375 , \\
\hline 48, & 4, & 1, & 98.3160, & 100.9593 & .3143 , & .1962, & .7335, \\
\hline
\end{tabular}




\begin{tabular}{|c|c|c|c|}
\hline 49, & 4, & 1, & 98.9900 \\
\hline 50, & 4, & 1, & 99.6640 \\
\hline 51, & 4, & 1, & 100.3360 \\
\hline 52, & 4, & 1, & 101.0100, \\
\hline 53, & 4, & 1, & 101.6840, \\
\hline 54, & 4, & 1, & 102.3560 \\
\hline 55, & 4, & 1, & 103.0300, \\
\hline 56, & 4, & 1, & 103.7040 \\
\hline 57, & 4, & 1, & 104.3780, \\
\hline 58, & 4, & 1, & 105.0500 \\
\hline 59, & 4, & 1, & 105.7240 \\
\hline 60, & 4, & 1, & 106.3980 \\
\hline 61, & 4, & 1, & 107.0700 \\
\hline 62, & 4, & 1, & 107.7440 \\
\hline 63, & 4, & 1, & 108.4180 \\
\hline 64, & 4, & 1, & 109.0900 \\
\hline 65, & 4, & 1, & 109.7640 \\
\hline 66, & 4, & 1, & 110.4380 \\
\hline 67, & 4, & 1, & 111.1120 \\
\hline 68, & 4, & 1, & 111.7840 \\
\hline 69, & 4, & 1, & 112.4580 \\
\hline 70 , & 4, & 1, & 113.1320 \\
\hline 71, & 4, & 1, & 113.8040 \\
\hline 72 , & 4, & 1, & 114.4780 \\
\hline 73, & 4, & 1, & 115.1520 \\
\hline 74, & 4, & 1, & 115.8240 \\
\hline 75, & 4, & 1, & 116.4980 \\
\hline 76, & 4, & 1, & 117.1720 \\
\hline 77 & 4, & 1, & 117.8460 \\
\hline 78, & 4, & 1, & 118.5180 \\
\hline 79, & 4, & 1, & 119.1920 \\
\hline 80, & 4, & 1, & 119.8660 \\
\hline 81, & 4, & 1, & 120.5380 \\
\hline 82, & 4, & 1, & 121.2120 \\
\hline 83, & 4, & 1, & 121.8860 \\
\hline 84, & 4, & 1, & 122.5580 \\
\hline 85, & 4, & 1, & 123.2320 \\
\hline 86, & 4, & 1, & 123.9060 \\
\hline 87, & 4, & 1, & 124.5800 \\
\hline 88, & 4, & 1, & 125.2520 \\
\hline 89, & 4, & 1, & 125.9260 \\
\hline 90 , & 4, & 1, & 126.6000 \\
\hline 91, & 4, & 1, & 127.2720 \\
\hline 92, & 4, & 1, & 127.9460 \\
\hline 93, & 4, & 1, & 128.6200 \\
\hline 94, & 4, & 1, & 129.2920 \\
\hline 95, & 4, & 1, & 129.9660 \\
\hline 96, & 4, & 1, & 130.6400 \\
\hline 97, & 4, & 1, & 131.3140 \\
\hline 98, & 4, & 1, & 131.9860 \\
\hline 99, & 4, & 1, & 132.6600 \\
\hline 100, & 4, & 1, & 133.3340 \\
\hline $101^{\circ}$ & 4, & 1, & 133.3340 \\
\hline 102 & 4, & 1, & 132.6600 \\
\hline 103 & 4, & 1, & 131.9860 \\
\hline & & 1, & 131.314 \\
\hline & & 1, & 130.64 \\
\hline & & 1, & 129.966 \\
\hline
\end{tabular}

$\begin{array}{ll}100.8563, & .3143, \\ 100.7513, & .3143, \\ 100.6462, & .3143, \\ 100.5413, & .3143, \\ 100.4307, & .3143, \\ 100.3196, & .3143, \\ 100.2133, & .3143, \\ 100.0988, & .3143, \\ 99.9847, & .3143, \\ 99.8699, & .3143, \\ 99.7509, & .3143, \\ 99.6318, & .3142, \\ 99.5232, & .3142, \\ 99.3974, & .3142, \\ 99.2744, & .3142, \\ 99.1501, & .3142, \\ 99.0283, & .3142, \\ 98.8994, & .3142, \\ 98.7926, & .3143, \\ 98.6671, & .3143, \\ 98.5325, & .3142, \\ 98.3954, & .3142, \\ 98.2667, & .3142, \\ 98.1534, & .3142, \\ 98.0136, & .3142, \\ 97.9026, & .3143, \\ 97.7540, & .3142, \\ 97.6200, & .3142, \\ 97.4818, & .3142, \\ 97.3425, & .3142, \\ 97.2113, & .3142, \\ 97.0798, & .3142, \\ 96.9420, & .3142, \\ 96.7974, & .3142, \\ 96.7004, & .3143, \\ 96.5296, & .3142, \\ 96.3868, & .3142, \\ 96.2526, & .3142, \\ 96.1086, & .3142, \\ 95.9647, & .3142, \\ 95.8270, & .3142, \\ 95.6876, & .3142, \\ 95.5460, & .3142, \\ 95.3977, & .3142, \\ 95.3015, & .3143, \\ 95.1600, & .3143, \\ 94.9736, & .3142, \\ 94.8324, & .3142, \\ 94.6880, & .3142, \\ 94.5348, & .3142, \\ 94.3995, & .3142, \\ 94.2544, & .3142, \\ 94.2544, & .3142, \\ 94.3995, & .3142, \\ 94.5348, & .3142, \\ 94.6880, & .3142, \\ 94.8324, & .3142, \\ 94.9736, & .3142, \\ 9 & \end{array}$

\begin{tabular}{|c|c|}
\hline 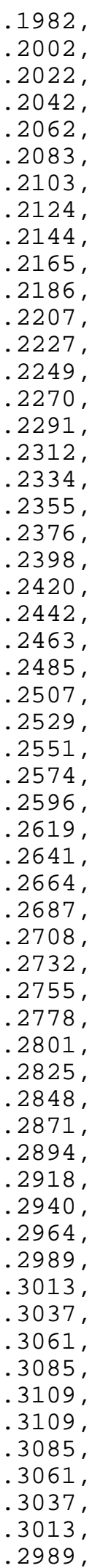 & $\begin{array}{l}.7295 \\
.7255 \\
.7217 \\
.7178 \\
.7140 \\
.7102 \\
.7065 \\
.7029 \\
.6992 \\
.6956 \\
.6921 \\
.6885 \\
.6851 \\
.6817 \\
.6782 \\
.6749 \\
.6715 \\
.6682 \\
.6651 \\
.6618 \\
.6586 \\
.6554 \\
.6523 \\
.6493 \\
.6462 \\
.6432 \\
.6401 \\
.6370 \\
.6340 \\
.6311 \\
.6281 \\
.6253 \\
.6224 \\
.6195 \\
.6169 \\
.6140 \\
.6112 \\
.6085 \\
.6058 \\
.6031 \\
.6004 \\
.5978 \\
.5952 \\
.5927 \\
.5903 \\
.5878 \\
.5851 \\
.5827 \\
.5802 \\
.5778 \\
.5754 \\
.5730 \\
.5730 \\
.5754 \\
.5778 \\
.5802 \\
.5827\end{array}$ \\
\hline
\end{tabular}




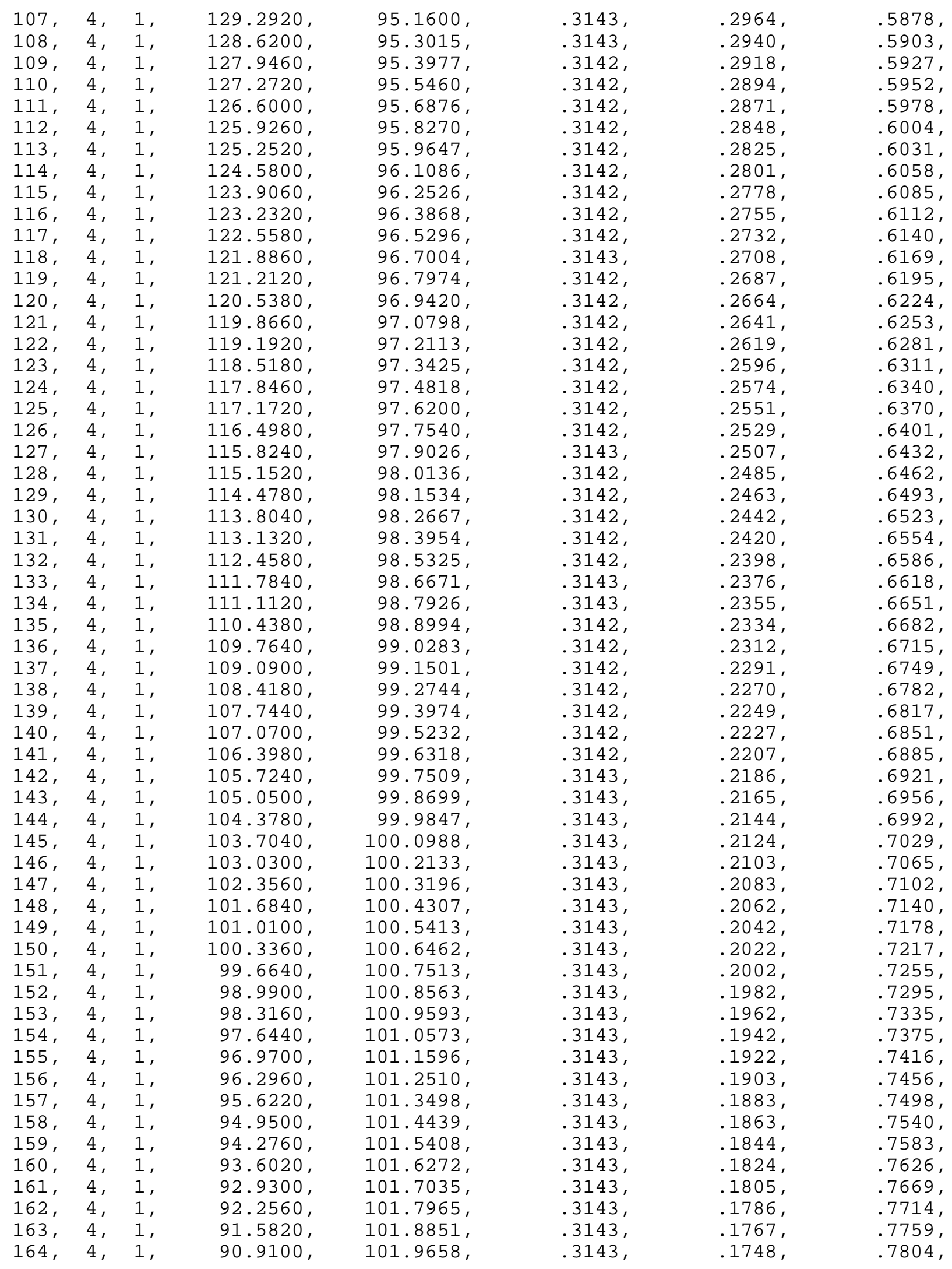




\begin{tabular}{|c|c|c|c|c|c|c|c|}
\hline 165 , & 4, & 1, & 90.2360 , & 102.0426 & .3143 , & .1729 , & .7849 , \\
\hline 166, & 4, & 1, & 89.5620 & 102.1091 & .3143 , & .1710 , & .7895, \\
\hline 167 , & 4, & 1, & 88.8880, & 102.2035 & .3143 , & .1691 , & .7943, \\
\hline 168, & 4, & 1, & 88.2160 & 102.2717 & .3143 & .1672 , & .7991, \\
\hline 169, & 4, & 1, & 87.5420 , & 102.3453 & .3143 & .1653 , & .8039 , \\
\hline 170, & 4, & 1, & 86.8680 & 102.4128 & .3143 & .1635 & .8088 \\
\hline 171, & 4, & 1, & 86.1960 & 102.4536 , & .3142 , & .1617 , & .8136 \\
\hline 172 , & 4, & 1, & 85.5220 , & 102.5212 & .3142 , & .1598, & .8186 \\
\hline 173, & 4, & 1, & 84.8480 & 102.5942 , & .3143 & .1580, & .8238 \\
\hline 174, & 4, & 1, & 84.1760 , & 102.6463 & .3143 & .1561 , & .8290 \\
\hline 175, & 4, & 1, & 83.5020 , & 102.6767 & .3142 , & .1544 , & .8340 , \\
\hline 176, & 4, & 1, & 82.8280 & 102.7414 & .3143 & .1525 , & .8394 \\
\hline 177, & 4, & 1, & 82.1540 & 102.7934 & .3143 & .1507 , & .8448 , \\
\hline 178, & 4, & 1, & 81.4820 & 102.8230 & .3142 , & .1490 & .8502 , \\
\hline 179, & 4, & 1, & 80.8080 & 102.8742 , & .3143 & .1472 , & .8557 , \\
\hline 180, & 4, & 1, & 80.1340 & 102.9143 & .3143 & .1454 , & .8613 \\
\hline 181, & 4, & 1, & 79.4620 & 102.9302 & .3142 , & .1436 , & .8669 , \\
\hline 182 , & 4, & 1, & 78.7880 & 102.9630 & .3143 & .1419 , & .8726 , \\
\hline 183, & 4, & 1, & 78.1140 & 103.0048 & .3143 & .1401 , & .8785 , \\
\hline 184, & 4, & 1, & 77.4420 & 103.0271 , & .3143 & .1383 & .8844 \\
\hline 185, & 4, & 1, & 76.7680 & 103.0301, & .3143 & .1366 , & .8902 , \\
\hline 186, & 4, & 1, & 76.0940 & 103.0667 & .3143 & .1349 , & .8964 \\
\hline 187, & 4, & 1, & 75.4200 & 103.0523 & .3142 , & .1332 , & .9025 , \\
\hline 188, & 4, & 1, & 74.7480 & 103.0747 , & .3143 , & .1314 , & .9090 , \\
\hline 189, & 4, & 1, & 74.0740 & 103.0844 & .3143 & .1297 & .9155 , \\
\hline 190, & 4, & 1, & 73.4000 & 103.0871 & .3143 & .1280 , & .9220 \\
\hline 191, & 4, & 1, & 72.7280 & 103.0505 & .3142 , & .1264 , & .9284 \\
\hline 192, & 4, & 1, & 72.0540 & 103.0613 & .3143 & .1247 , & .9353 \\
\hline 193, & 4, & 1, & 71.3800 & 103.0292 , & .3142 , & .1230 , & .9420 , \\
\hline 194, & 4, & 1, & 70.7080 & 103.0378 & .3143 , & .1213 , & .9490 , \\
\hline 195, & 4, & 1, & 70.0340 & 103.0049 , & .3143 , & .1197 , & .9560 , \\
\hline 196, & 4, & 1, & 69.3600 & 102.9575 & .3142 , & .1180, & .9629 , \\
\hline 197, & 4, & 1, & 68.6860 & 102.9362 , & .3143 , & .1164 , & .9702 , \\
\hline 198, & 4, & 1, & 68.0140 , & 102.8843 & .3143 , & .1148 , & .9774 , \\
\hline 199, & 4, & 1, & 67.3400 & 102.8447 & .3143 , & .1131 , & .9850 \\
\hline 200, & 4, & 1, & 66.6660 & 102.8445 & .3144 , & .1114 , & .9932 , \\
\hline
\end{tabular}

\section{Output File LAPURW.CSV}

\section{LAPURW RUN: SAMPLE LAPURW INPUT FILE - 200 CHANNELS 100 FREQUENCIES} LAPURX RUN: SAMPLE LAPURX INPUT FILE - 200 Channel

CHANNEL STABILITY:

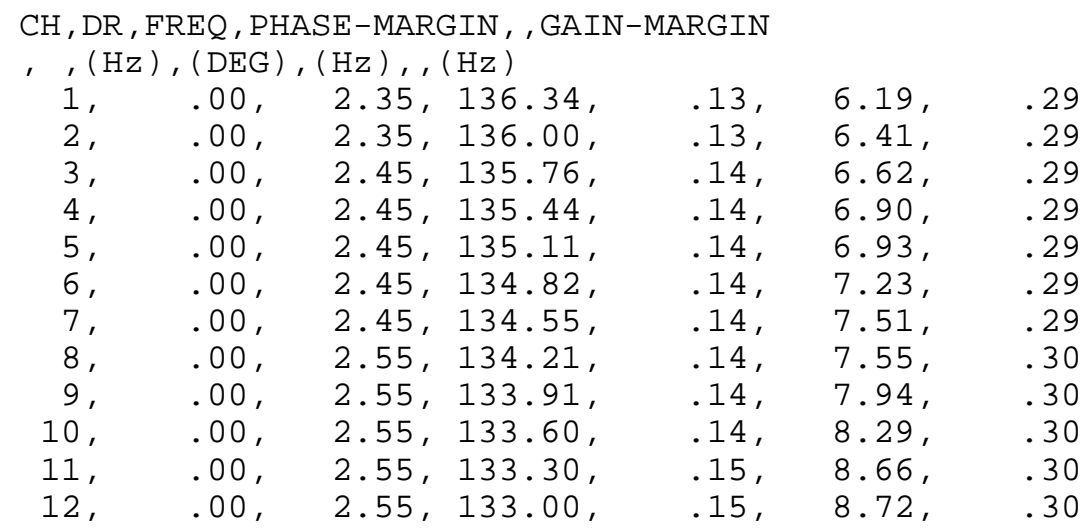




\begin{tabular}{|c|c|c|c|c|c|c|}
\hline 13, & .00 , & 2.66, & 132.61, & .15, & 9.25 , & .30 \\
\hline 14 , & .00 , & 2.66, & 132.22 , & .15, & 9.75, & .30 \\
\hline 15, & .00, & 2.66, & 131.92, & .15, & 9.79 & .31 \\
\hline 16, & .00, & 2.66 & 131.56, & .15 , & 10.44 , & .31 \\
\hline 17, & .01, & .22 & 131.23 , & .15, & 11.08 , & .3 \\
\hline 18, & .01, & .22 , & 130.88, & .15 , & 11.68 & .3 \\
\hline 19, & .01, & .22 , & 130.51 , & .16, & 11.95 & .3 \\
\hline 20 & .01, & .22 , & 130.11 , & .16, & 12.88 & .3 \\
\hline 21, & .01, & .22 , & 129.77 , & .16 , & 13.70 & .3 \\
\hline 22, & .01, & .23, & 129.38 & .16, & 13.88 & .32 \\
\hline 23, & .01, & .23, & 128.97, & .16, & 15.26 & .32 \\
\hline 24, & .01, & .23, & 128.59, & .16, & 16.64 & .32 \\
\hline 25, & .01, & .23 & 128.16 & .16, & 17.94 & .3 \\
\hline 26, & .02, & .23 & 127.73 & .16, & 18.59 , & .32 \\
\hline 27 , & .02, & .24 , & 127.32 , & .17, & 21.00, & .3 \\
\hline 28, & .02, & .24 & 126.89, & .17, & 23.42 , & .3 \\
\hline 29, & .02 , & .24 , & 126.44 & .17, & 23.16 , & .3 \\
\hline 30, & .02 , & .24 , & 126.00, & .17, & 27.51, & .3 \\
\hline 31, & .02, & .24, & 125.60 & .17, & 32.82 , & .3 \\
\hline 32, & .03, & .24 , & 125.16 & .17, & 36.99 , & .3 \\
\hline 33, & .03 , & .25 & 124.70 , & .17, & 37.51, & .3 \\
\hline 34, & .03, & .25 & 124.29 , & .18, & 49.77 , & .3 \\
\hline 35, & .03, & .25 , & 123.81, & .18, & 60.66 & .3 \\
\hline 36, & .03, & .25 , & 123.38 & .18, & 59.71, & .33 \\
\hline 37, & .04, & .25 , & 122.89 & .18, & 89.79 , & .3 \\
\hline 38, & .04, & .26, & 122.40 & .18, & 68.80 & .3 \\
\hline 39, & .04, & .26 & 121.96, & .18, & 56.47 , & .34 \\
\hline 40, & .04, & .26, & 121.47, & .18, & 51.63, & .3 \\
\hline 41, & .05, & .26, & 121.01, & .18, & 47.75 , & .34 \\
\hline 42, & .05, & .26 , & 120.51 , & .19, & 35.65 & .34 \\
\hline 43, & .05, & .26 , & 119.98, & .19, & 30.16 , & .34 \\
\hline 44, & .06, & .27 , & 119.48, & .19, & 27.06 , & .32 \\
\hline 45, & .06, & .27 , & 118.98, & .19, & 25.27 & .3 \\
\hline 46, & .06, & .27 , & 118.51, & .19, & 22.01 , & .35 \\
\hline 47, & .07, & .27, & 117.96, & .19, & 19.51 , & .3 \\
\hline 48, & .07 , & .27 , & 117.42 , & .20, & 17.87 & .3 \\
\hline 49, & .07 , & .28 , & 116.86, & .20, & 16.61, & .35 \\
\hline 50, & .08, & .28, & 116.37 , & .20, & 15.41, & .3 \\
\hline 51, & .08, & .28, & 115.84, & .20, & 14.19 , & .3 \\
\hline 52 , & .09 , & .28 , & 115.29 , & .20, & 13.22 , & .3 \\
\hline 53, & .09 , & .28, & 114.76, & .20, & 12.48 & .3 \\
\hline 54, & .10, & .29 , & 114.20 , & .20, & 11.80 & .3 \\
\hline 55, & .10, & .29 , & 113.65, & .21 , & 11.01 , & .3 \\
\hline 56, & .11, & .29 , & 113.14, & .21, & 10.45 & .3 \\
\hline 57, & .11, & .29 , & 112.58, & .21 , & 9.92 & .3 \\
\hline 58, & .12, & .29 , & 112.03, & .21 , & 9.49, & .3 \\
\hline 59, & .13, & .30 , & 111.45, & .21 , & 9.05 , & .36 \\
\hline 60, & .13, & .30 , & 110.88 , & .21, & 8.59, & .3 \\
\hline 61, & .14, & .30 , & 110.34, & .21, & 8.22, & .36 \\
\hline 62, & .15, & .30 , & 109.75 , & .22 , & 7.87, & .36 \\
\hline 63, & .15, & .30 , & 109.18, & .22, & 7.59, & .3 \\
\hline 64, & .16, & .31 , & 108.59 , & .22, & 7.30, & .37 \\
\hline 65, & .17, & .31 , & 108.01 , & .22 , & 7.00 , & .37 \\
\hline 66, & .17, & .31 , & 107.42 , & .22, & 6.74, & .37 \\
\hline 67, & .18, & .31 , & 106.86, & .22, & 6.52 , & .37 \\
\hline 68, & .19, & .31 , & 106.26 , & .23, & 6.30, & .37 \\
\hline 69, & .20, & .31 , & 105.68 , & .23, & 6.12 , & .3 \\
\hline 70, & .21, & .32 , & 105.02 , & .23, & 5.88, & .3 \\
\hline
\end{tabular}




\begin{tabular}{|c|c|c|c|c|c|c|}
\hline 71, & .21 , & .32 , & 104.43 , & .23, & 5.69 & .37 \\
\hline 72, & .22 , & .32, & 103.83 , & .23, & 5.52 & .37 \\
\hline 73, & .23 & .32, & 103.23 & .23 & 5.37 & .37 \\
\hline 74, & .24 & .32 , & 102.66 , & .23, & 5.23 & .37 \\
\hline 75, & .24 , & .33, & 102.02 , & .24, & 5.08 & .38 \\
\hline 76, & .25 , & .33, & 101.35, & .24, & 4.92 & .38 \\
\hline 77 , & .26 & .33, & 100.74 , & .24, & 4.79 , & .38 \\
\hline 78, & .27 , & .33, & 100.09 , & .24, & 4.66 & .38 \\
\hline 79, & .28, & .33, & 99.47 & .24, & 4.55 & .38 \\
\hline 80, & .28 & .34, & 98.87 & .24, & 4.44 , & .38 \\
\hline 81, & .29 , & .34, & 98.21 , & .24, & 4.33 & .38 \\
\hline 82, & .30 , & .34, & 97.54 , & .25, & 4.22 , & .38 \\
\hline 83, & .31 , & .34, & 96.96 & .25, & 4.12 , & .38 \\
\hline 84, & .31 , & .34, & 96.29 & .25, & 4.03 & .38 \\
\hline 85, & .32 , & .34, & 95.63 & .25, & 3.94 & .38 \\
\hline 86, & .33 , & .35, & 94.97 & .25, & 3.85 , & .38 \\
\hline 87, & .34 , & .35, & 94.26 & .25, & 3.76 , & .39 \\
\hline 88, & .34 , & .35, & 93.58 & .26, & 3.67 , & .39 \\
\hline 89 , & .35 & .35, & 92.93 & .26, & 3.59 , & .39 \\
\hline 90 , & .35 , & .35 , & 92.27 & .26, & 3.52 , & .39 \\
\hline 91, & .36 , & .35, & 91.62 , & .26, & 3.45 , & .39 \\
\hline 92, & .37 & .36, & 90.90 & .26, & 3.38, & .39 \\
\hline 93, & .37 , & .36, & 90.27 , & .26, & 3.32 , & .39 \\
\hline 94, & .38, & .36, & 89.62 , & .26, & 3.26 , & .39 \\
\hline 95, & .39 , & .36, & 88.86, & .27, & 3.19 , & .39 \\
\hline 96, & .39 & .36, & 88.14 & .27, & 3.12 , & .39 \\
\hline 97, & .40 & .36, & 87.48 & .27, & 3.07 , & .39 \\
\hline 98, & .40 , & .36, & 86.76, & .27, & 3.01 , & .39 \\
\hline 99, & .41 , & .37, & 86.06, & .27, & 2.96 & .39 \\
\hline 100, & .42 , & .37 , & 85.35 & .27, & 2.90 & .39 \\
\hline 101, & .42 , & .37, & 85.35 , & .27, & 2.90 & .39 \\
\hline 102, & .41 , & .37, & 86.06, & .27, & 2.96 & .39 \\
\hline 103, & .40 & .36, & 86.76 & .27, & 3.01 , & .39 \\
\hline 104, & .40, & .36, & 87.48 & .27, & 3.07 , & .39 \\
\hline 105, & .39 & .36, & 88.14, & .27, & 3.12 , & .39 \\
\hline 106, & .39 , & .36, & 88.86, & .27, & 3.19 , & .39 \\
\hline 107, & .38 , & .36, & 89.62 , & .26, & 3.26 , & .39 \\
\hline 108, & .37 , & .36, & 90.27 , & .26, & 3.32 , & .39 \\
\hline 109, & .37 & .36, & 90.90 & .26, & 3.38 & .39 \\
\hline 110, & .36 & .35 , & 91.62 , & .26, & 3.45 & .39 \\
\hline 111, & .35 , & .35, & 92.27 , & .26, & 3.52 , & .39 \\
\hline 112, & .35 & .35, & 92.93 & .26, & 3.59 , & .39 \\
\hline 113, & .34 , & .35 , & 93.58 , & .26, & 3.67 , & .39 \\
\hline 114, & .34 , & .35, & 94.26 & .25, & 3.76 , & .39 \\
\hline 115, & .33 , & .35, & 94.97 & .25, & 3.85 , & .38 \\
\hline 116, & .32 , & .34, & 95.63 & .25, & 3.94 & .38 \\
\hline 117, & .31, & .34, & 96.29 , & .25, & 4.03 & .38 \\
\hline 118, & .31 , & .34 , & 96.96 & .25, & 4.12 , & .38 \\
\hline 119, & .30, & .34, & 97.54, & .25, & 4.22 , & .38 \\
\hline 120, & .29, & .34, & 98.21, & .24, & 4.33 & .38 \\
\hline 121, & .28 , & .34, & 98.87 , & .24, & 4.44 , & .38 \\
\hline 122, & .28, & .33, & 99.47 & .24, & 4.55 & .38 \\
\hline 123, & .27 , & .33, & 100.09 , & .24, & 4.66 & .38 \\
\hline 124, & .26 , & .33, & 100.74, & .24, & 4.79 , & .38 \\
\hline 125, & .25 , & .33, & 101.35 , & .24, & 4.92 & .38 \\
\hline 126, & .24 , & .33, & 102.02 , & .24, & 5.08 & .38 \\
\hline 127, & .24, & .32, & 102.66 , & .23, & 5.23 & .37 \\
\hline 128, & .23 , & .32 , & 103.23 & .23 & 5.37 & .37 \\
\hline
\end{tabular}




\begin{tabular}{|c|c|c|c|c|c|c|}
\hline 129, & .22 , & .32 , & 103.83, & .23, & 5.52 & .37 \\
\hline 130, & .21 , & .32 , & 104.43, & .23, & 5.69, & .37 \\
\hline 131, & .21 , & .32 , & 105.02 , & .23, & 5.88 & .37 \\
\hline 132 , & .20 & .31 , & 105.68 , & .23, & 6.12 & .37 \\
\hline 133, & .19 , & .31 , & 106.26 , & .23, & 6.30 & .37 \\
\hline 134, & .18 , & .31 , & 106.86, & .22, & 6.52 , & .37 \\
\hline 135 , & .17 , & .31 , & 107.42 , & .22 , & 6.74 & .37 \\
\hline 136, & .17 , & .31 , & 108.01 , & .22, & 7.00 & .37 \\
\hline 137, & .16 & .31 , & 108.59 , & .22, & 7.30 & .37 \\
\hline 138, & .15 & .30, & 109.18 & .22 , & 7.59, & .36 \\
\hline 139, & .15 , & .30 , & 109.75 , & .22, & 7.87 & .36 \\
\hline 140, & .14 & .30, & 110.34 , & .21 , & 8.22 , & .36 \\
\hline 141, & .13 & .30, & 110.88, & .21, & 8.59 , & .36 \\
\hline 142 , & .13 & .30 , & 111.45, & .21, & 9.05 , & .36 \\
\hline 143 , & .12 , & .29 , & 112.03 & .21, & 9.49, & .36 \\
\hline 144 , & .11 , & .29, & 112.58 & .21, & 9.92 & .36 \\
\hline 145 , & .11 , & .29 & 113.14 & .21 , & 10.45 & .36 \\
\hline 146 , & .10 , & .29 & 113.65 , & .21, & 11.01 , & .36 \\
\hline 147 , & .10 , & .29, & 114.20 , & .20, & 11.80 & .36 \\
\hline 148, & .09, & .28, & 114.76, & .20, & 12.48 & .35 \\
\hline 149 , & .09 , & .28, & 115.29 , & .20, & 13.22 , & .35 \\
\hline 150, & .08 & .28, & 115.84, & .20, & 14.19 , & .35 \\
\hline 151, & .08 & .28, & 116.37 , & .20, & 15.41 & .35 \\
\hline 152 , & .07 , & .28, & 116.86 & .20, & 16.61, & .35 \\
\hline 153 & .07 & .27, & 117.42 , & .20, & 17.87 , & .35 \\
\hline 154 & .07 & .27, & 117.96, & .19, & 19.51 , & .35 \\
\hline 155 & .06, & .27, & 118.51, & .19, & 22.01, & .35 \\
\hline 156, & .06 , & .27 & 118.98, & .19, & 25.27 , & .35 \\
\hline 157, & .06, & .27, & 119.48, & .19, & 27.06, & .34 \\
\hline 158, & .05 & .26 , & 119.98, & .19, & 30.16 , & .34 \\
\hline 159, & .05 , & .26, & 120.51 , & .19, & 35.65 & .34 \\
\hline 160 & .05 , & .26, & 121.01 , & .18, & 47.75 , & .34 \\
\hline 161, & .04 & .26 , & 121.47, & .18, & 51.63 & .34 \\
\hline 162 , & .04, & .26, & 121.96 & .18, & 56.47 , & .34 \\
\hline 163, & .04, & .26, & 122.40 & .18, & 68.80, & .34 \\
\hline 164 , & .04 , & .25 , & 122.89 & .18, & 89.79 , & .34 \\
\hline 165 , & .03, & .25, & 123.38 & .18, & 59.71, & .33 \\
\hline 166, & .03 & .25 , & 123.81, & .18, & 60.66, & .33 \\
\hline 167 , & .03 & .25, & 124.29 , & .18, & 49.77 & .33 \\
\hline 168, & .03, & .25, & 124.70 & .17, & 37.51 , & .33 \\
\hline 169, & .03, & .24, & 125.16 & .17 , & 36.99, & .33 \\
\hline 170, & .02 , & .24, & 125.60 & .17, & 32.82 , & .33 \\
\hline 171, & .02 , & .24, & 126.00, & .17, & 27.51 , & .33 \\
\hline 172 , & .02 , & .24, & 126.44 , & .17 , & 23.16, & .33 \\
\hline 173, & .02 , & .24, & 126.89 , & .17, & 23.42 , & .32 \\
\hline 174 , & .02 , & .24, & 127.32 , & .17, & 21.00 & .32 \\
\hline 175 , & .02 , & .23, & 127.73 , & .16, & 18.59 , & .32 \\
\hline 176, & .01 , & .23, & 128.16 & .16, & 17.94 & .32 \\
\hline 177 , & .01 , & .23, & 128.59 , & .16, & 16.64, & .32 \\
\hline 178, & .01 , & .23, & 128.97, & .16, & 15.26 & .32 \\
\hline 179 , & .01 & .23, & 129.38 & .16 , & 13.88 & .32 \\
\hline 180, & .01 , & .22, & 129.77 , & .16, & 13.70 , & .31 \\
\hline 181 , & .01 , & .22, & 130.11 , & .16 , & 12.88 & .31 \\
\hline 182 , & .01 , & .22 , & 130.51 , & .16, & 11.95, & .31 \\
\hline 183, & .01 , & .22, & 130.88 & .15, & 11.68 & .31 \\
\hline 184, & .01 , & .22 , & 131.23, & .15 , & 11.08 & .31 \\
\hline 185 , & .00, & 2.66, & 131.56, & .15 , & 10.44 , & .31 \\
\hline 186, & .00, & 2.66, & 131.92 , & .15 , & 9.79 & .31 \\
\hline
\end{tabular}




$\begin{array}{llllll}187, & .00, & 2.66,132.22, & .15, & 9.75, & .30 \\ 188, & .00, & 2.66,132.61, & .15, & 9.25, & .30 \\ 189, & .00, & 2.55,133.00, & .15, & 8.72, & .30 \\ 190, & .00, & 2.55,133.30, & .15, & 8.66, & .30 \\ 191, & .00, & 2.55,133.60, & .14, & 8.29, & .30 \\ 192, & .00, & 2.55,133.91, & .14, & 7.94, & .30 \\ 193, & .00, & 2.55,134.21, & .14, & 7.55, & .30 \\ 194, & .00, & 2.45,134.55, & .14, & 7.51, & .29 \\ 195, & .00, & 2.45,134.82, & .14, & 7.23, & .29 \\ 196, & .00, & 2.45,135.11, & .14, & 6.93, & .29 \\ 197, & .00, & 2.45,135.44, & .14, & 6.90, & .29 \\ 198, & .00, & 2.45,135.76, & .14, & 6.62, & .29 \\ 199, & .00, & 2.35,136.00, & .13, & 6.41, & .29 \\ 200, & .00, & 2.35,136.34, & .13, & 6.19, & .29\end{array}$

CORE OUT-PHASE STABILITY:

REACT, DR, FREQ, PHASE-MARGIN, , GAIN-MARGIN, , AMPL, AVG

$(\$),,(\mathrm{Hz}),(\mathrm{DEG}),(\mathrm{Hz}),,(\mathrm{Hz}),\left(\frac{\circ}{0}\right),\left(\frac{\circ}{0}\right)$

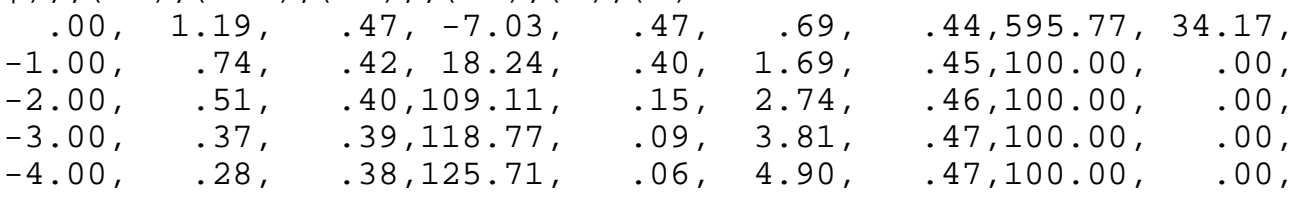

OPEN AND CLOSED-LOOP TRANSFER FUNCTIONS:

FREQ, OPEN LOOP, , CLOSED-LOOP,

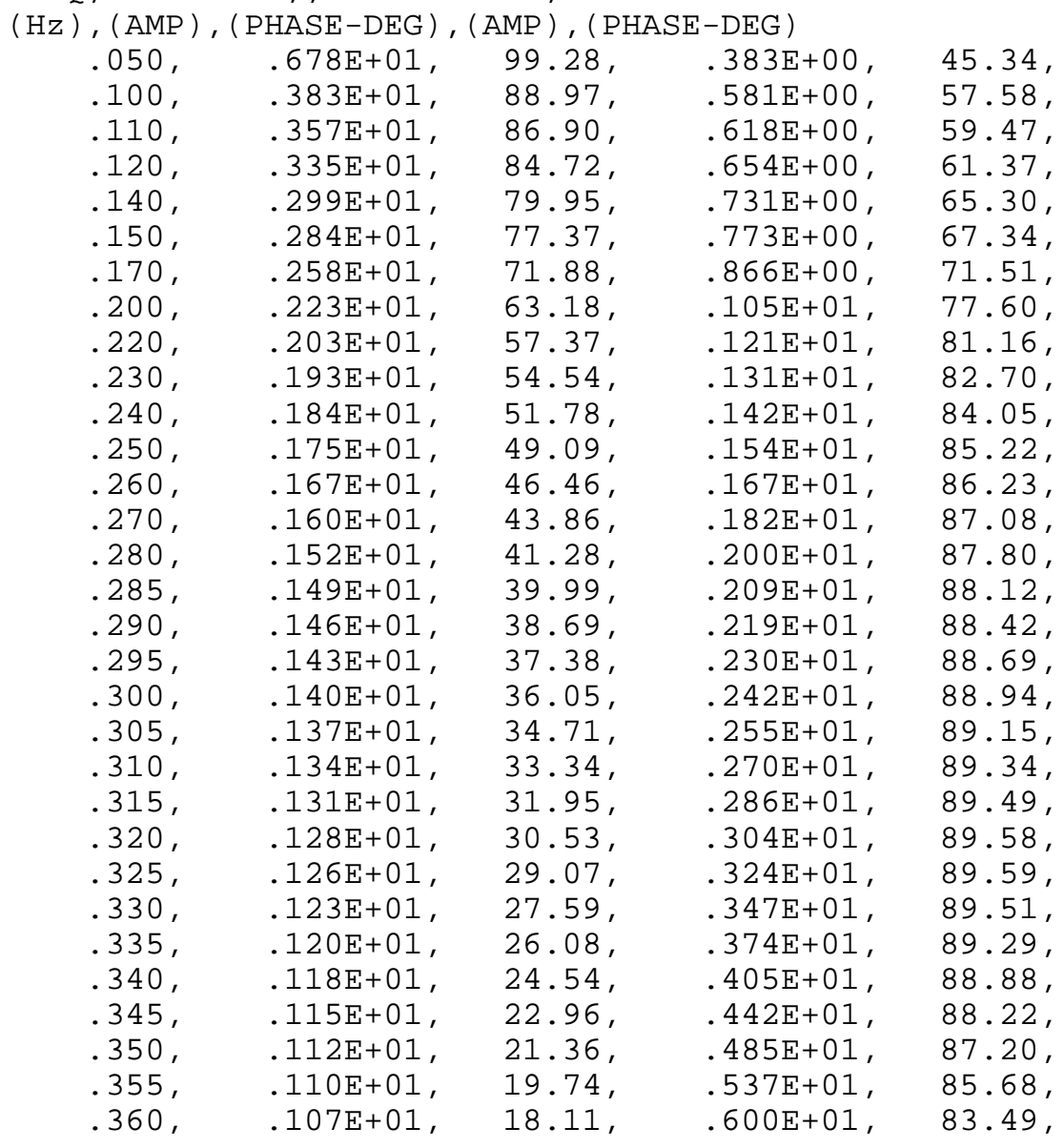




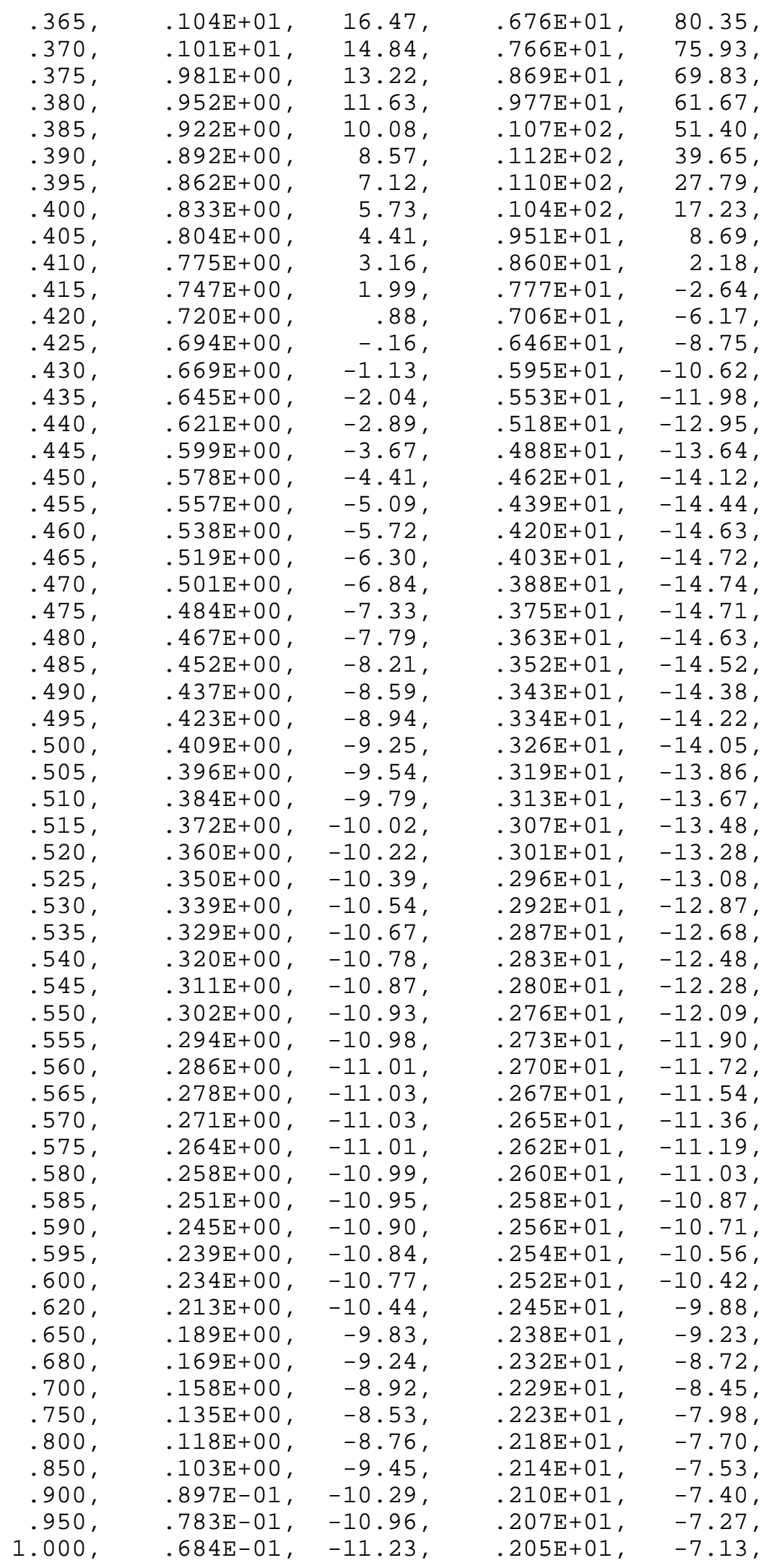




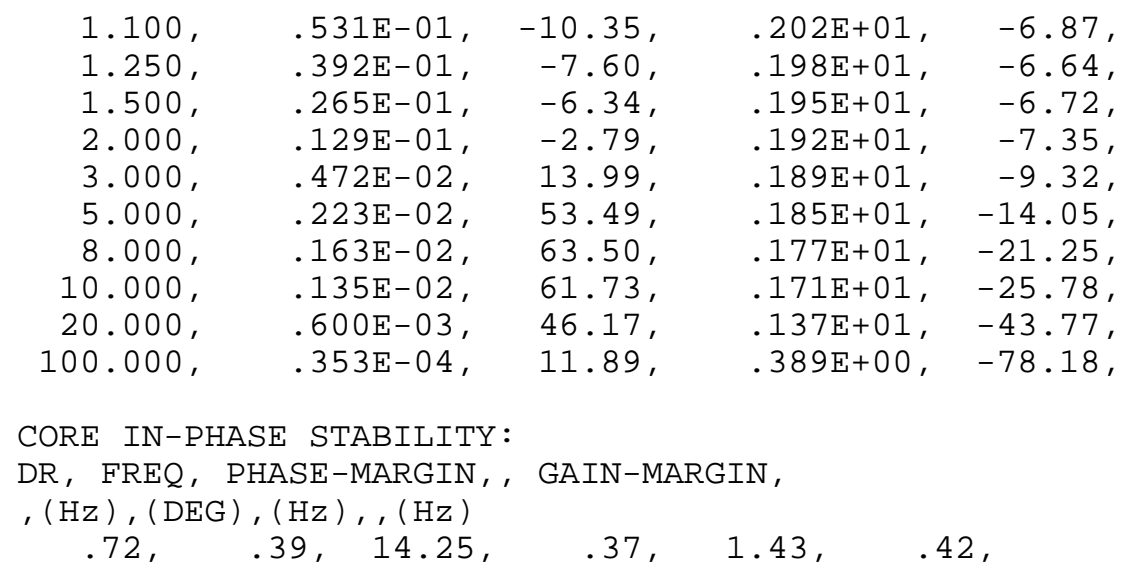




\section{APPENDIX E - MISCELLANEOUS ERRORS FOUND IN VERSION 5.1}

\section{Subroutine $X \_F L O W . F O R$}

Wrong order of dimensions for variables QG, QP, QX. The second dimension should be the maximum number of channes

\section{Old Logic:}

DIMENSION QG(7,20),QP(7,20),QX(7,20)

\section{Corrected Logic:}

DIMENSION QG(20,NCHMAX),QP(20,NCHMAX),QX(20,NCHMAX)

\section{Subroutine $X \_F L O W . F O R$}

Division by zero in the case of many channels. New lines.

\section{Old Logic:}

$\mathrm{QDG}(\mathrm{IX})=$ EPS_W*QG(M1,IX)/5.

$\mathrm{QDEG}(\mathrm{IX})=$ EPS $\_\mathrm{W}^{*} \mathrm{QG}(\mathrm{M} 1, \mathrm{IX}) / 5$.

Corrected Logic:

IF(ABS(QDG(IX)) .LT. EPS_W*QG(M1,IX)/10.)

$>\quad \mathrm{QDG}(\mathrm{IX})=$ EPS_W $* \mathrm{QG}(\mathrm{M} 1, \mathrm{IX}) / 5$.

IF(ABS(QDEG(IX)) .LT. EPS_W*QG(M1,IX)/10.)

$>\quad \mathrm{QDEG}(\mathrm{IX})=\mathrm{EPS} \_\mathrm{W}^{*} \mathrm{QG}(\mathrm{M} 1, \mathrm{IX}) / 5$.

\section{Subroutine W_FREQ.for}

Wrong dimension of variables CDPR, CDBR, CDYR, CDBRA, CDYRA

The first dimension should be the maximum number of pipes in series in the exit channel.

\section{Old Logic:}

$2 \operatorname{CDPR}(2,21), \operatorname{CDBR}(2,21), \operatorname{CDYR}(2,21)$,

3 CDBRA(1,21),CDYRA(1,21)

\section{Corrected Logic:}

$>$,CDPR(NCENMAX1,21),CDBR(NCENMAX1,21)

$>$,CDYR(NCENMAX1,21)

$>$,CDBRA(NCENMAX,21),CDYRA(NCENMAX,21)

\section{Subroutine W_ONECOR.for}

Wrong CBD and CCD calculation 
Old Logic:

$\mathrm{CBD}=\mathrm{CAD}+\mathrm{NCH}(\mathrm{IX}) *(\mathrm{CDYX}(\mathrm{IX}) * \mathrm{CMX}(\mathrm{IX})+\mathrm{CDQX}(\mathrm{IX})) * \mathrm{Q} 1$

$\mathrm{CCD}=\mathrm{CAD}+\mathrm{NCH}(\mathrm{IX}) *(\mathrm{CDYX}(\mathrm{IX}) * \mathrm{CNX}(\mathrm{IX})+\mathrm{CDTX}(\mathrm{IX}))^{*} \mathrm{Q} 1$

Corrected Logic:

$\mathrm{CBD}=\mathrm{CBD}+\mathrm{NCH}(\mathrm{IX}) *(\mathrm{CDYX}(\mathrm{IX}) * \mathrm{CMX}(\mathrm{IX})+\mathrm{CDQX}(\mathrm{IX})) * \mathrm{Q} 1$

$\mathrm{CCD}=\mathrm{CCD}+\mathrm{NCH}(\mathrm{IX}) *(\mathrm{CDYX}(\mathrm{IX}) * \mathrm{CNX}(\mathrm{IX})+\mathrm{CDTX}(\mathrm{IX})) * \mathrm{Q} 1$ 


\section{NUREG/CR- \\ ORNL/TM-2000/340}

\section{INTERNAL DISTRIBUTION}
1-20. J. A. March-Leuba
21. D. W. McDonalds
22. P. J. Otaduy
23. C. E. Pugh
24. J. D. White

\author{
25. M. C. Wright \\ 26. Central Research Library, \\ Document Reference Section \\ 27. ORNL Laboratory Records - RC \\ 28-30. ORNL Laboratory Records
}

\section{EXTERNAL DISTRIBUTION}

31. R. Caruso, U.S. Nuclear Regulatory Commission, NRR/DSSA/SRXB, MS O10 B3, Washington DC 20555

32-42. A. Escriva, Polytechnic University of Valencia, ETSII, Camino de Vera s/n, 46022 Valencia, Spain

43-49. T. L. Huang, U.S. Nuclear Regulatory Commission, NRR/DSSA/SRXB, MS O10 B3, Washington DC 20555

50. A. P. Ulses, U.S. Nuclear Regulatory Commission, NRR/DSSA/SRXB, MS O10 B3, Washington DC 20555 